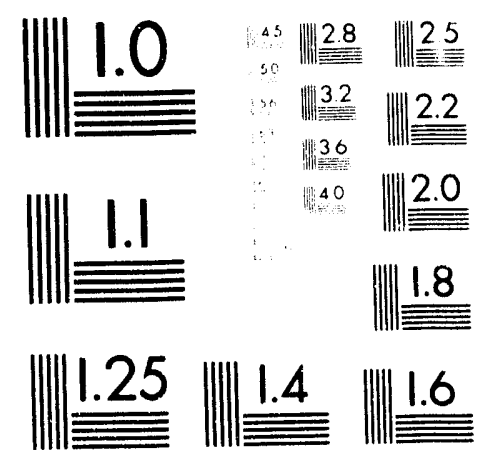



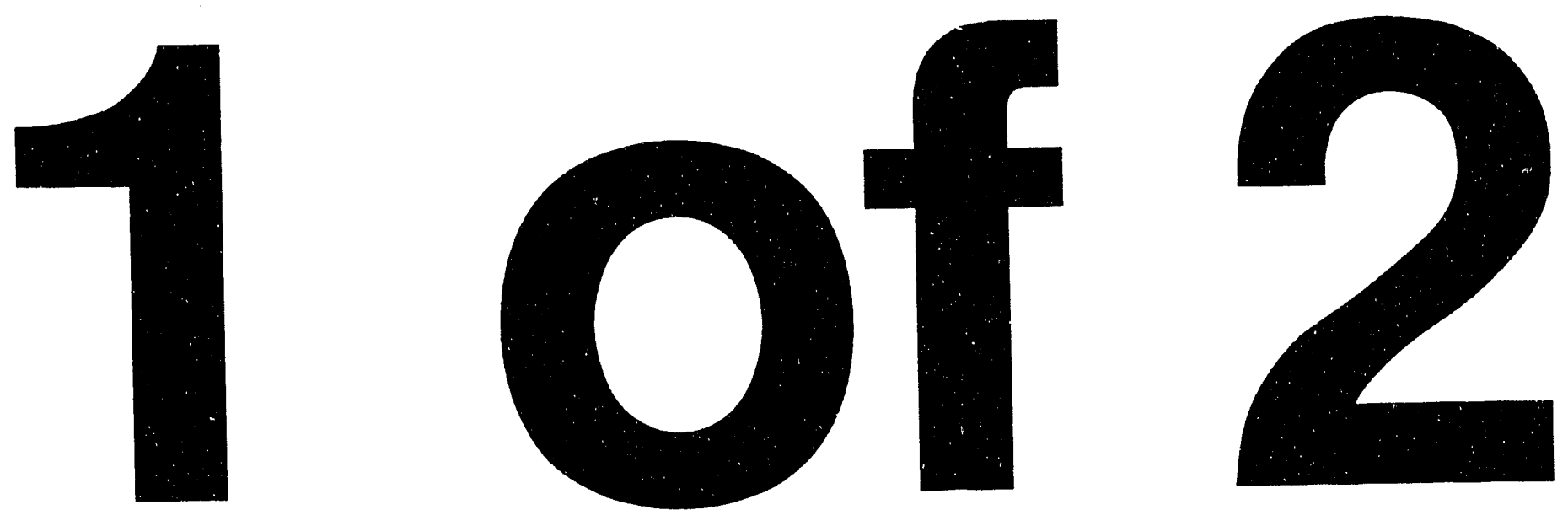
DOE/RL-93-70

Revision 0

UC-630,721

\section{Waste Analysis Plan for Confirmation or Completion of Tank Farms Backlog Waste Designation}

Date Published
August 1993

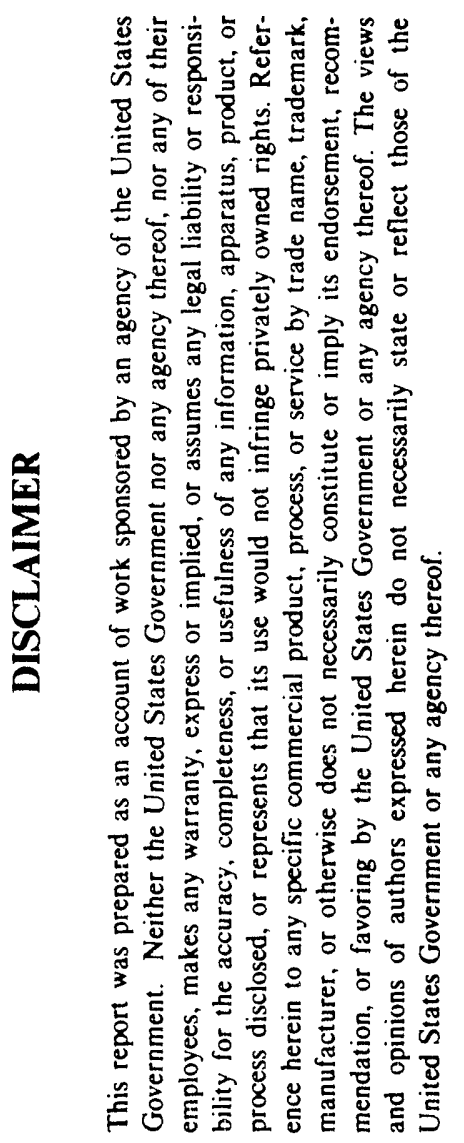

United States

Department of Energy

P.O. Box 550

Richland, Washington 99352 
TRADEMARK DISCLAIMER

Reference herein to any specific commercial product, process, or service by trade name, trademark, manufacturer, or otherwise, does not necessarily constitute or imply its endorsement, recommendation, or favoring by the United States Government or any agency thereof or its contractors or subcontractors.

This report has been reproduced from the best available copy. Available in paper copy and microfiche.

Available to the U.S. Department of Energy

and its contractors from

Office of Scientific and Technical Information

P.O. Box 62

Oak Ridge, TN 37831

(615) 576.8401

Available to the public from the U.S. Department of Commerce National Technical Information Service

5285 Port Royal Road

Springfield, VA 22161

(703) 487.4650

Printed in the United Stales of America

DISCLM-5.CHP $(8.91)$ 


\section{CONTENTS}

LLSSARY

.0 INTRODUCTION . . . . . . . . . . . . . . . . . . . . . . . . 1-1

1.1 PURPOSE . . . . . . . . . . . . . . . . . . . . . . . 1-1

1.2 DATA QUALITY OBJECTIVES .................. . . . . . 1 .

.0 WASTE MANAGEMENT ORGANIZATIONAL RESPONSIBILITIES . . . . . . . . . . 2-1

2.1 TANK FARMS . . . . . . . . . . . . . . . . . . . . . 2-1

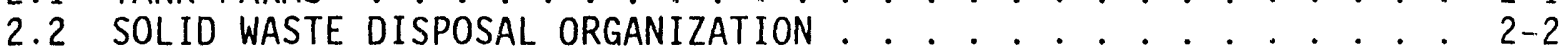

2.3 HANFORD ANALYTICAL SERVICES MANAGEMENT ORGANIZATION . . . . . . 2-2

2.4 SAMPLE AND MOBILE LABORATORY . . . . . . . . . . . . . . . . . 2-2

2.5 REPACKAGING ORGANIZATION RESPONSIBILITIES . . . . . . . . . . . 2-3

2.6 TRANSPORTATION AND PACKAGING ORGANIZATION . . . . . . . . . 2-3

.0 WASTE MANAGEMENT CRITERIA AND TRAINING . . . . . . . . . . . . . 3-1

3.1 WASTE MANAGEMENT CRITERIA . . . . . . . . . . . . . . . . . . 3-1

3.2 WASTE MANAGEMENT TRAINING . . . . . . . . . . . . . . . . 3-2

4.0 CONFIRMATION OR COMPLETION OF DESIGNATION PROCESS . . . . . . . . . $4-1$

4.1 WASTE SORTING/CATEGORIZATION .................. . . . . $4-1$

4.2 DOCUMENTATION ASSESSMENT . . . . . . . . . . . . . . . . . . 4-2

4.2.1 Process Knowledge Criteria . . . . . . . . . . . . . . 4-2

4.2.1.1 Interviews................ . 4-3

4.2.1.2 Logbooks .. . . . . . . . . . . . . . . . . 4-3

4.2.1.3 Procurement Records . . . . . . . . . . 4-3

4.2.1.4 Analytical Results . . . . . . . . . . . 4-3

4.2.1.5 Qualified Analytical Data . . . . . . . . 4-3

4.2.1.6 Radiation Work Packages . . . . . . . . . 4-3

4.2.1.7 Procedures and/or Methods . . . . . . . . . 4-3

4.2.1.8 Process Flow Charts . . . . . . . . . . . . . 4-4

4.2.1.9 Inventory Sheets .............. . 4-4

4.2.1.10 Vendor Information . . . . . . . . . . . 4-4

4.2.2 Onsite Generating Unit Performance History Criteria . . 4-4

4.2.2.1 Onsite Generating Unit Shipping Status . . . . 4-4

4.2.2.2 Administrative Procedures and Training . . . . 4-5

4.2.2.3 Container Management . . . . . . . . . . . 4-5

4.2.2.4 Physical Controls During Waste Generating . . 4-5

4.2.3 Summary of Documentation Assessment . . . . . . . . . . 4-5

4.3 CONFIRMATION OF DESIGNATION . . . . . . . . . . . . . . . 4-5

4.4 DETERMINATION OF CONFIDENCE/CONFIRMATION LEVEL . . . . . . . . . . 4-6

4.5 WASTE CONFIRMATION OF DESIGNATION PROTOCOL . . . . . . . . . . 4-6

4.6 WASTE DESIGNATION CONFIRMATION METHODS . . . . . . . . . . . . 4-6

4.6.1 Physical Confirmation .. . . . . . . . . . . . 4-7

4.6.2 Chemical Confirmation .. . . . . . . . . . . . 4-7

4.7 WASTE CONFIRMATION OF DESIGNATION PROCESS . . . . . . . . . . . 4-8

4.7.1 Physical Confirmation Criteria. . . . . . . . . . . . 4-8

4.7.1.1 Inconsistencies in Physical

Characteristics . . . . . . . . . 4-8 


\section{CONTENTS (cont)}

\subsubsection{Nondestructive Examination} Inconsistencies ...... 4-. 4-8

4.7.1.3 Visual Inspection Inconsistencies . . . . 4.-9

4.7.2 Chemical Confirmation Criteria . . . . . . . . . . . 4.9

4.7.3 Confirmation of Designation Failure . . . . . . . . 4-10

4.7.4 Confirmation of Designation Corrective Action . . . . 4-10

4.8 COMPLETION OF DESIGNATION PROCESS . . . . . . . . . . . . 4-10

5.0 SAMPLING AND ANALYTICAL METHODS . . . . . . . . . . . . . . . . 5-1

5.1 HAZARDOUS CONSTITUENT SAMPLING . . . . . . . . . . . . . . . . 5-1

5.2 CRITERIA FOR WASTE TYPE SAMPLING . . . . . . . . . . . . . . . . 5-1

5.3 WASTE SAMPLING TECHNIQUES . . . . . . . . . . . . . . . . 5-1

5.3.1 Sample Handling . . . . . . . . . . . . . . . . . 5-2

5.3.1.1 Chain of Custody ............ 5-2

5.3.1.2 Sample Containers . . . . . . . . . 5-5

5.3.1.3 Reagents............. . 5-5

5.3.1.4 Equipment . . . . . . . . . . . . . 5-5

5.3.1.5 Composite Sampling . . . . . . . . . . 5-6

5.3.2 Sample Collection .. . . . . . . . . . . . . . 5-6

5.3.3 Container Sampling Procedures . . . . . . . . . . . . . 5-6

5.4 QUALITY ASSURANCE AND QUALITY CONTROL PROTOCOL . . . . . . . . . $5-7$

5.4.1 Blank Samples ............... 5-8

5.4.2 Equipment Blanks.............. . 5-8

5.4.3 Trip Blanks . . . . . . . . . . . . . . . . . . 5-8

5.4 .4 Duplicate Samples . . . . . . . . . . . . . . . 5-8

5.5 ANALYTICAL TECHNIQUE REQUIREMENTS . . . . . . . . . . . . . . . . 5 . 5

5.5.1 Liquid Matrix Analytical Methods . . . . . . . . . . . . 5-9

5.5.2 Solid Waste Matrix Analytical Methods . . . . . . . . . 5-9

5.5.3 Deviations from SW-846 Protocol . . . . . . . . . . . 5-9

5.5.3.1 Inorganic Analysis . . . . . . . . . . . . . 5-9

5.5.3.2 Volatile and Semivolatile Organics.... . 5-10

5.5.3.3 Toxicity Characteristics Leaching

Procedure .............. . 5-10

6.0 RECORDKEEPING . . . . . . . . . . . . . . . . . . . . 6-1

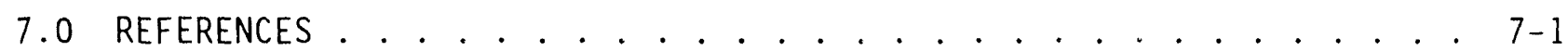




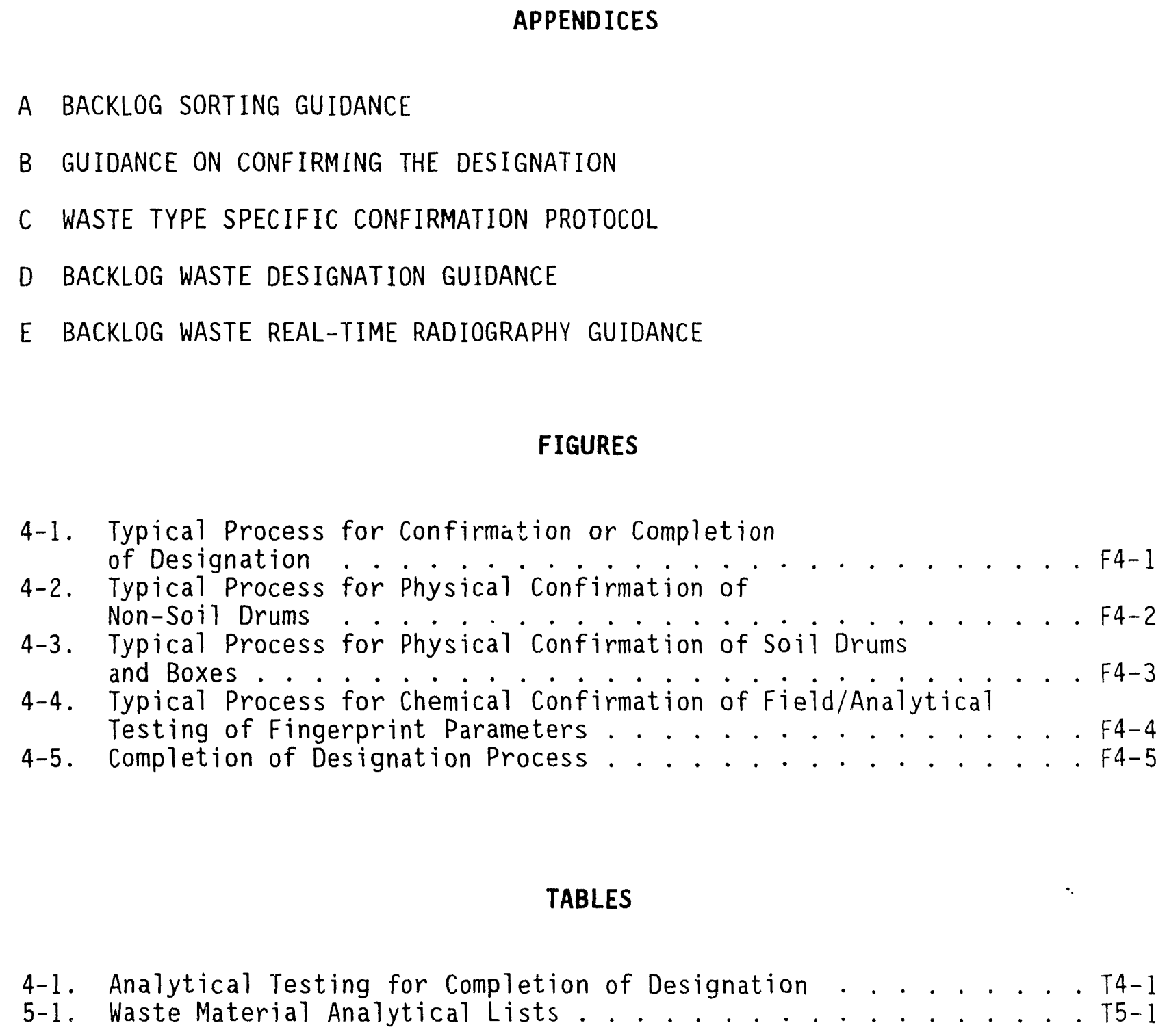

4-1. Analytical Testing for Completion of Designation . . . . . . . T4-1

5-1. Waste Material Analytical Lists............... . . T5-1 
DOE/RL-93-70, Rev. 0

$08 / 31 / 93$

This page intentionally left blank. 


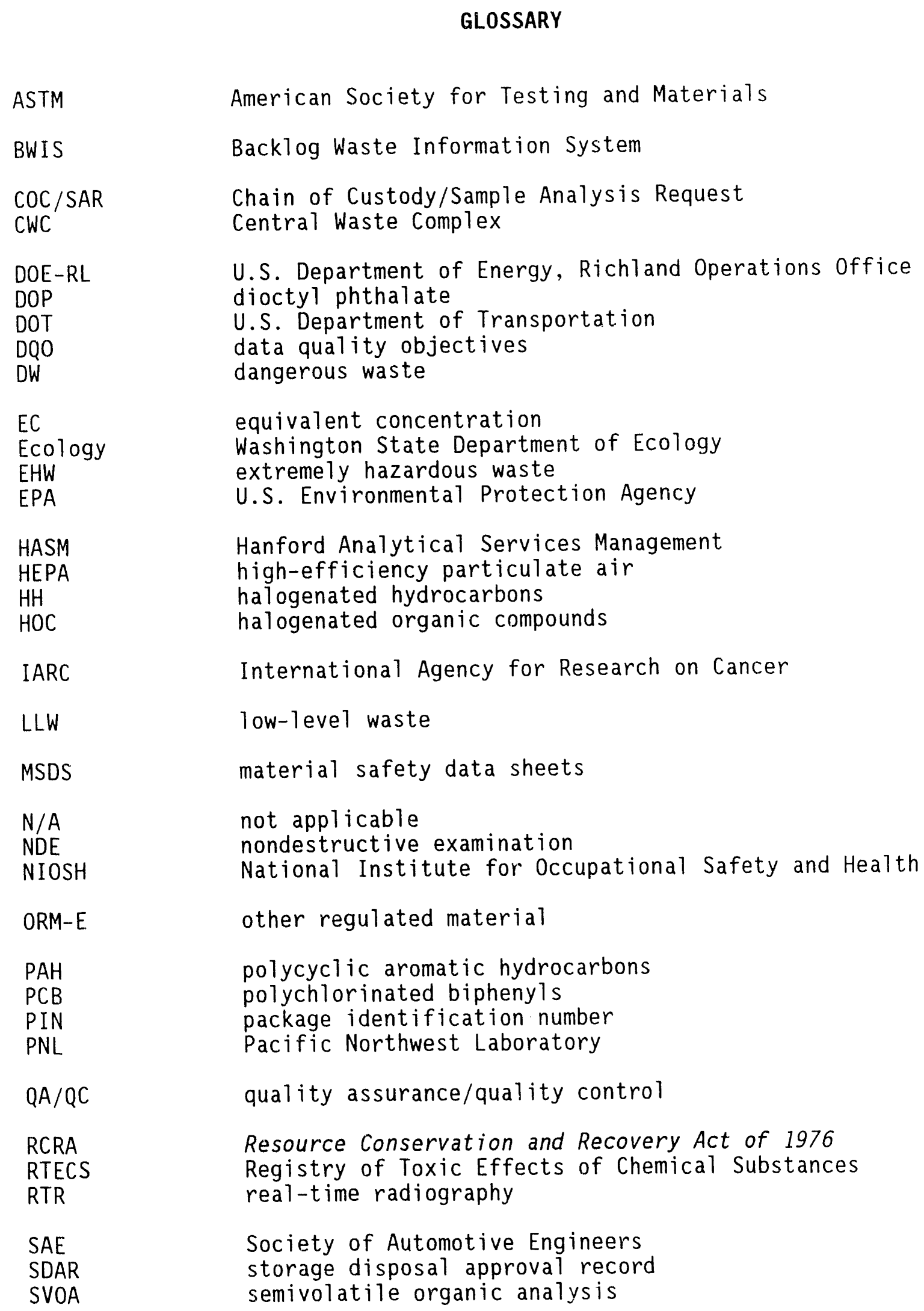


4 SWAS

5 S\&ML

6 SWD

7 SWITS

8

9 TC

10 TCLP

11 TOX

12 TSCA

13 TSD

14

15 U0

16

17

18

$19 W A C$

$20 W H C$

21

$22<$

$23>$

$24 \%$

$25 w t \%$

$26 \mathrm{ppm}$

$27 \mathrm{pH}$

28

\section{GLOSSARY (cont)}

Solid Waste Acceptance Services

sample and mobile laboratory

solid waste disposal

Solid Waste Information Tracking System

toxicity characteristic

toxicity characteristics leaching procedure

total organic halogen

Toxic Substances Control Act of 1976

treatment, storage, and/or disposal

unusual occurrence

volatile organic analysis

Washington Administrative Code

Westinghouse Hanford Company

less than

greater than

percent

weight percent

parts per million

negative concentration logarithm of the hydrogen-ion concentration 


\section{DISTRIBUTION}

Number of Copies

\section{OFFSITE}

4 Washington State Department of Ecology

M. Lerchen - 01ympia

Enforcement Officer - 01ympia

T. Tebb - Kennewick

L. Russe11 - Kennewick

2 U.S. Environmental Protection Agency

D. Duncan - Seattle

D. R. Sherwood - Richland

\section{ONSITE}

15 U.S. Department of Energy,

Richland Operations office

C. E. Clark

D. W. Claussen (4)

A5-15

R. E. Gerton

R3 -80

R. R. Guercia

J. M. Hennig

P. J. Krupin (2)

R. P. Saget

E. J. Senat

S. H. Wisness

Reading Room (2)

R3 -72

R3 -80

R3-80

A5- 15

A5-52

R3 -72

A5- 15

H2-53

1 Pacific Northwest Laboratory

Hanford Technical Library

51 Westinghouse Hanford Company

D. L. Allen

B. M. Barnes

H6-24

J. C. Biagini

S6-30

D. C. Board

S1-57

R. C. Bowman

$\mathrm{H} 6-24$

G. A. Brannon

S6-30

P. L. Crane

T3-28

S. J. Dechter

R2 -54

L. K. Dickinson 
C. K. Disibio

B3-15

B. G. Erlandson

H6-20

G. W. Faulk

T3-28

K. A. Gano

$\times 0-21$

C. J. Geier

R2-50

C. K. Girres (2)

N3-13

E. M. Greager

$\mathrm{H} 6-30$

R. D. Gustafson

$\mathrm{R} 1-51$

R. D. Haggard

H6-30

W. H. Hamilton, Jr.

N3-10

D. G. Hamrick

R. L. Hand

P. L. Hapke

H. D. Harmon

R1-51

H4-16

T4-05

R2-52

S6-30

A. Harrow

C. M. Hartman

J. R. Kasper

G. H. Landeen

T4-10

R2-50

$\mathrm{H} 6-23$

$\mathrm{H} 6-30$

M. J. La Barge

B3-63

R. E. Lerch

B3 -15

P. J. Mackey

R. L. Martin

T3-03

H. E. McGuire

B3-63

D. E. McKenney

T3-28

R. A. Meznarich

S3-90

T. L. Moore

R. D. Pierce

R. K. P'Pool

S. M. Price

D. J. Swaim

R2-93

N3-13

$\mathrm{N} 1-3 \mathrm{O}$

$\mathrm{H} 6-23$

B3-51

J. H. Tillman

G. C. Triner (2)

$\mathrm{H} 4-23$

N3-13

G. A. Whitney

$\mathrm{H} 5-33$

L. D. Zuck

EPIC (2)

ER

$\mathrm{H} 4-23$

H6-08

H6-07

Information Release Administration

(3)

$\mathrm{H} 4-17$ 
DOE /RL-93-70, Rev. 0

$08 / 31 / 93$

\subsection{INTRODUCTION}

On January 23, 1992, waste management problems in the Tank Farms were acknowledged through an Unusual Occurrence (UO) Report \# RL-WHC-TANKFARM-19920007 (DOE-RL 1992).

On March 10, 1993, the Washington State Department of Ecology (Ecology) issued a Notice of Penalty 93NM-201 (Order) to the U.S. Department of Energy, Richland Operations (DOE-RL) and the Westinghouse Hanford Company (WHC) asserting that "DOE-RL and WHC have failed to designate approximately 2,000 containers of solid waste in violation of WAC 173-303-170(1)(a) and the procedures of WAC 173-303-070" (Ecology 1993).

On June 30, 1993 a Settlement Agreement among Ecology, DOE-RL, and WHC was approved by the Pollution Control Hearings Board. Item 3 of the Settlement Agreement requires that DOE-RL and WHC submit a waste analysis plan for the waste subject to the Order by September 1, 1993 (PCHB 1993).

\subsection{PURPOSE}

This waste analysis plan satisfies the requirements of Item 3 of Ecology order 93NM-201 as amended per the Settlement Agreement. Item 3 states: "Within forty (40) calendar days of receipt of this Order, DOE-RL and WHC shall provide Ecology with a plan for review and approval detailing the established criteria and procedures for waste inspection, segregation, sampling, designation, and repackaging of all containers reported in item \#1. The report shali include sampling plan criteria for different contaminated media, i.e., soils, compactable waste, high-efficiency particular air (HEPA) filters, etc., and a schedule for completing the work within the time allowed under this order."

Item 3 was amended per the Settlement Agreement as follows: "In addition to the waste inspection plans for the "unknowns" previously provided and currently being supplemented, DOE-RL and WHC shall provide a draft waste analysis plan for the containers reported in Item 1 of the Order to Ecology by July 12, 1993. A final, DOE-RL approved waste analysis plan shall be submitted to Ecology by September 1, 1993, for Ecology's written approval by September 15, 199.3."

Containers covered by the Order, Settlement Agreement, and this waste analysis plan consist of all those reported under Item 1 of the Order, less any
containers that have been identified in unusual occurrences reported by Tank Farms. Other containers that are identified to have newly generated waste will be reported through the occurrence reporting system. A final list of covered containers will be generated as part of the response to Item 9 of the order.

This waste analysis plan describes the procedures that will be undertaken to confirm or to complete designation of the solid waste identified in the order. 
This waste analysis plan, in combination with the Backlog Waste Information Shett. (BWIS) process is intended to fulfill the regulatory requirements of the Dangerous Waste Regulations Washington Administrative Code (WAC) 173-303

related to completion or confirmation of designation of the containers covered by the order. To fulfill the requirements of Item 3 , the following areas are addressed:

- Description of the waste types included under Ecology Order \# 93NM-201

- Minimum documentation required by the generator in order to formally accept the waste for storage at the Central Waste Complex (CWC)

- Method for sorting the wastes into waste types

- Procedures for confirming the Tank Farms designation of a waste lot/batch received at the CWC.

- Procedure for completing designation of the waste if the Tank Farms designation of the lot/batch cannot be confirmed.

\subsection{DATA QUALITY OBJECTIVES}

The data quality objectives (DQO) planning process recommended by the EPA (EPA 1987) has been used as guidance for developing this waste analysis plan.

The question established during the DQO process is: "How does one demonstrate that the waste (in the containers) has been properly designated in accordance with the Order and Settlement Agreement?"

The data obtained to answer this question is specifically intended to ensure that:

- The Tank Farms designation has been confirmed or completed

- The designated waste class of the waste is correct (i.e., dangerous waste or extremely hazardous waste)

- The waste is designated in accordance with WAC 173-303-070.

The DQ0s developed for the process are specifically addressed as criteria throughout this document. 
DOE/RL-93-70, Rev. 0

$08 / 31 / 93$

\subsection{WASTE MANAGEMENT ORGANIZATIONAL RESPONSIBILITIES}

Waste management organizational responsibilities are discussed in the following sections.

\subsection{TANK FARMS}

Tank Farms will be responsible for processing the backlog waste included in the order in accordance with this waste analys is plan.

Tank Farms, as a generating unit, will maintain responsibility for the waste included under the Order until the waste is formally accepted by the CWC.

This responsibility includes waste designation, laboratory analysis, formal acceptance certifications, compaction/void filling (if required), repackaging, appropriate documentation and labeling, and other regulatory requirements applied to onsite generating units.

Tank Farms will be responsible for ensurirg that the waste included under the order have accurate documentation required for designation. This

documentation includes, but is not limited to, sampling results; inventory sheets; documented process knowledge; and certification plans, studies, and tank characterization analyses.

Tank Farms also will be responsible for the following:

- Determining the final sorting of the containers into lots/batches for confirmation or completion of waste designation

- Requesting for storage disposal approval records (SDARs) (These requests either will be for open SDARs or for specific SDARs depending on the waste type.)

- Signing a certification statement for each waste package as outlined in Hanford Site Solid Waste Acceptance Criteria (WHC-EP-0063)

- Reporting, through the occurrence reporting system, all significant discrepancies found during confirmation or completion of the waste designation.

NOTE: Significant discrepancies are defined as discrepancies that, if uncorrected, would cause mismanagement of the container(s) at a treatment, storage and/or disposal (TSD) unit, (i.e., waste is determined to have an erroneous designation or to contain prohibited items). 
DOE/RL-93-70, Rev. 0

$08 / 31 / 93$

\subsection{SOLID WASTE DISPOSAL ORGANIZATION}

The Solid Waste Disposal (SWD) organization will provide the following:

- Technicar assistance on characterization issues

- Perform technical assistance for all field analysis for confirmation or completion of designation, as required by this waste analysis plan

- Provide SDARs for the waste

- Ensure that all containers are stored in accordance with WAC 173-303 interim status TSD requirements

- Inspect all waste containers included under the order to confirm container integrity ( $A$ list of those containers needing repackaging/overpacking will be provided to Tank Farms.)

- Retrieving the containers in a sequence requested by Tank Farms for shipping the backlog containers for processing

- Receive and store and/or dispose of containers approved in accordance with WHC-EP-0063

- Perform physical confirmation such as nondestructive examination (NDE) via $X$-ray and nondestructive assay of the containers, as necessary, as described by this waste analysis plan

- Coordinate all changes necessary for the solid waste information tracking system (SWITS) to track all containers throughout the process

- Track the waste containers through SWITS (This will include data input and report output as necessary.)

- Perform surveillances, as required, if Tank Farms are not approved to ship radioactive waste in accordance with WHC-EP-0063 (WHC 1989).

\subsection{HANFORD ANALYTICAL SERVICES MANAGEMENT ORGANIZATION}

The Hanford Analytical Services Management (HASM) organization will coordinate sampling efforts between the laboratory and the CWC or the T Plant Complex sampling unit.

\subsection{SAMPLE AND MOBILE LABORATORY}

The Sample and Mobile Laboratory (S\&ML) will provide the following:

- Collecting protocol samples in support of backlog waste confirmation or completion of designation 
- Initiating and maintaining chain of custody on collected samples

- Shipping collected samples to offsite laboratories

- Documenting sampling activities in a controlled field logbook.

\subsection{REPACKAGING ORGANIZATION RESPONSIBILITIES}

The Repackaging organization will make appropriate preparations for the following:

- Accept waste for confirmation

- Accept waste that fails confirmation

- Perform completion of designation as necessary

- Perform repackaging as necessary.

The repackaging organization will be responsible for obtaining permits (as applicable), writing procedures, and ensuring all necessary supplies are available.

\subsection{TRANSPORTATION AND PACKAGING ORGANIZATION}

Transportation and Packaging organization wi1l provide support for shipment of samples and containers. 
DOE/RL-93-70, Rev. 0

$08 / 31 / 93$

This page intentionally left blank. 


\subsection{WASTE MANAGEMENT CRITERIA AND TRAINING}

Waste management criteria and personnel training are discussed in the following sections.

\subsection{WASTE MANAGEMENT CRITERIA}

Before final acceptance by the CWC, waste will be designated in accordance with WAC 173-303-070. The CWC will not accept unidentified or uncharacterized waste not identified in the Hanford Central Waste Complex Part A Permit Application (DOE/RL-88-20). In addition, the CWC will not accept the following prohibited items:

- Etiologic agents (49 CFR 173.386)

- Chemically incompatible materials in any waste container (40 CFR 265.313)

- Explosives (10 CFR 61.56)

- Pyrophorics (10 CFR 61.56)

- Gas cylinders permanently not vented.

Containers must be in good condition with no visible cracks, holes, dents, bulges, corrosion, or other damage that effects the integrity of the container (as described in WHC-EP-0063).

The radioactive limits for the CWC cannot be exceeded without documentation from the SWD organization allowing a deviation from the limits as follows.

- The maximum surface-radiation dose rate will not exceed 100 millirems per hour at any point. If the dose rate exceeds the limit, the package will be shielded down to the acceptable limit.

- Removable contamination on the exterior surfaces of all waste packages will not exceed the following limits:

- 220 disintegration per minute per 100 square centimeters for alpha contamination

- 2,200 disintegration per minute per 100 square centimeters for betagamma contamination.

- The total fissile content of any container will not exceed 15 grams. 


\subsection{WASTE MANAGEMENT TRAINING}

Personnel involved in the operation of this plan are expected to be trained in accordance with current onsite standards. These specific training requirements are rot addressed in this waste analysis plan. Personnel responsible for waste designation will be trained in Waste Designation, responsibe No. 035012. Personnel responsible for shipping dangerous waste will be trained in the Department of Transportation Hazardous Waste Shipment

certification, Course No. 020159. Personnel responsible for the shipment of radioactive waste will be trained in Radioactive Materials Shipment Certification, Course No. 020069.

12

Although formal training is not required by this waste analys is plan, workshops will be given to present this waste analysis plan along with the methodology, and to discuss in detail the various processes embodied by this 16 plan. 


\subsection{CONFIRMATION OR COMPLETION OF DESIGNATION PROCESS}

This section describes the process that will be used for confirmation of or completion of the designation of the backlog waste (Figure 4-1).

All containers will be sorted into lots, which will be the basis for establishing the confirmation and designation process. Documentation will be reviewed to determine the accuracy of the information, the level of designation/confirmation needed for the waste type, the confirmation methods, and to determine if further designation will be required.

\subsection{WASTE SORTING/CATEGORIZATION}

Tank Farms will assess the backlog waste documentation so the waste containers can be sorted into manageable lots for confirmation or completion of waste designation. The waste sorting/categorization process is a two step process: preliminary sorting and verification of sorting. Preliminary scrting will be performed using information provided in SWITS and the backlog waste information sheets files. During the second step of the process, preliminary sorting will be verified using information contained in field files and various process knowledge documents (e.g., tank characterization analysis or process history documents).

Criteria for performing the sorting are contained in Appendix $A$. The preliminary waste types to be used are as follows:

- Aerosols

- Paints

- Acids

- Hazardous liquids

- 0ils

- Free liquids (condensate)

- Mercury

- Filters (e.g., HEPA)

- Soits

- Soft debris - paper, plastic, rubber, cloth

- Hard debris - cement, metal, wood, asphalt

- Asbestos

- Low-Level waste

- Speciar case.

Other waste types could be identified as the documentation assessment progresses. New waste types will be identified according to physical and chemical characteristics. All containers of a given waste type will be classified as a lot. Each lot could be further subdivided into batches by point of origin or waste characteristics as appropriate. (Appendix A provides the basis for establishing each lot and a list of lots currently defined.) Confirmation will be accomplished on a lot/batch basis. 
1 Each lot/batch will be identified by a 10-digit sorting number that will

clearly identify the type of waste and the confirmation level. The containers that contain more than one waste type will be evaluated and assigned the appropriate sorting number based on the sorting process described in Appendix A. After all containers have been assigned a sorting number, the sorting number will be entered into the SWITS for future reference.

\subsection{DOCUMENTATION ASSESSMENT}

Documentation assessment will review all process knowledge available on the backlogged waste staged at the CWC. The completeness and reliability of the data will be assessed for each lot to determine a confidence level associated with the designation of the waste. The confidence level will be a basis for establishing the confirmation protocol for each 1ot/batch. Appendix B provides the guidance for performing the documentation assessment.

To consistently and objectively assess all waste containers, a 'lot/batch waste documentation checklist' will be used (Appendix B). This checklist will enable the documentation to be separated into two types: process kriowledge and generating unit performance history.

\subsubsection{Process Knowledge Criteria}

Process knowledge will be used as part of the waste characterization process. Use of process or material knowledge could involve some risk of inaccurate waste designation. The need for a greater degree of waste characterization must be balanced against the risks to personnel and the environment with sampling the waste. The amount of waste characterization that must be known and the degree of accuracy with which the waste characterization must be known depends on the intended destination of the waste.

The use of process knowledge will be employed when one or more of the following conditions are met.

- The waste stream is difficult to sample because of physical form. This applies to pieces of metal (e.g., shielding) that contain hazardous constituents in their composition rather than as a residue that could be removed for testing or in a decontamination process.

- Sampling and analysis of the waste stream could result in unacceptable risks of exposure to radionuclides and dangerous substances [i.e., not consistent with the as low as reasonably achievable (ALARA) precept (DOE Order 5400.5)].

- Waste is too variable to be characterized by one set of samples (e.g., containers with contaminated clothing, rags, or absorbent).

- Process knowledge is sufficiently documented and provides a complete characterization of the waste stream. 
The following sources will be considered when assessing the use of process knowledge.

4.2.1.1 Interviews. Interviews could be used to determine if chemicals known to be present were used, if procedures were used as written or if deviations were allowed, or to verify the events in a logbook.

Without any supporting documentation, interviews are, in some cases, the least reliable source for process knowledge.

4.2.1.2 Logbooks. Logbooks could contain the activities of an individual or may be kept to document cne activities of a specific project. Logbooks could be reviewed to identify potential waste streams from which the waste could be designated.

Logbooks also could consist of operating logs such as daily inspection forms, vessel transfer sheets, instrument reading forms, etc. This documentation could be used to determine the total amount of material processed; therefore, the amount of waste generated might be estimated. While this information probably would not include those constituents addressed by WAC 173-303, the processing constituents and those constituents used for process controi might be identifiable.

4.2.1.3 Procurement Records. Procurement records could indicate the amount of chemicals purchased during a given year. Several years of procurement records could provide enough data on chemicals used at the Tank Farms; therefore, the amount of waste generated might be estimated.

4.2.1.4 Analytical Results. Analytical results could provide concentration of constituents present in samples. The usefulness of analytical results depends on the representativeness of a sample to the media it was sampled from, its correlation to a specific stream, and the constituents that were analyzed. If only one or two process control constituents were analyzed, the target analytes could be used to support other documentation. If the concentrations of the analyzed constituents match logbook or operating records, then credibility could be given to other logbook/operating record entries.

4.2.1.5 Qualified Analytical Data. Qualified analytical data that are generated, but do not have adequate documentation, might be considered process knowledge to prevent the data from being completely discarded. Incomplete data might include chain of custody or sampling plans. This would not invalidate the analytical results. Therefore, qualified analytical data results will be considered process knowledge.

4.2.1.6 Radiation Work Packages. Radiation work packages could contain information regarding waste generating activities at the Tank Farms.

4.2.1.7 Procedures and/or Methods. Procedures and/or methods could give specifics as to how an activity was or will be performed. This could allow for either a determination of the amount of waste generated or characterization of the waste. 
4.2.1.8 Process Flow Charts. Process flow charts could show chemical input and output of various streams. Process flow charts can be studied along with the reactions that occur during processing to determine constituents as well as constituent concentrations. Generally, only the constituents that would cause the waste to be designated are documented.

4.2.1.9 Inventory Sheets. Inventory sheets may be produced as a container of waste is generated listing the container contents. If these sheets are signed and dated as a certification of the contents, the probability of the data being accurate is increased. When used in conjunction with other process knowledge and the Generating Unit Performance History (Section 4.2.2), a determination of the validity of the process knowledge can be determined.

4.2.1.10 Vendor Information. Vendor information (i.e., material safety data sheets (MSDSS) could provide chemical data that could characterize dangerous waste. If the MSDS does not give enough information to make this determination, the manufacturer of the product can be contacted and might be able to provide additional information on chemical constituents and concentrations.

\subsubsection{Onsite Generating Unit Performance History Criteria}

The past performance of the onsite generating unit is a strong indication of how valid the process knowledge is. The criteria discussed in the following sections will be used to determine performance history.

\subsubsection{Onsite Generating Unit Shipping Status. An oversight and} certification program defines the shipping status of a generating unit. oversight and certification assessments are conducted at the TSD unit and are used to control shipments of waste to the CWC. The following describes the four status types that can be assigned to a generating unit:

- APPROVED - This generating unit, considered to have an acceptable waste management system, can ship waste to the CWC.

- LIMITED APPROVAL - A generating unit has some waste streams that are restricted and some waste streams that are not restricted. When a waste stream is restricted, CWC requires a surveillance of the waste packages before shipment.

- APPROVAL PENDING - This status is used when a generating unit might have waste management personnel that must be trained. Once training is accomplished, the generating unit will become approved.

- NOT APPROVED - Generating units that have been assigned this shipping status can ship waste only on a case-by-case basis as approved by CWC.

The shipping status of the generating unit is used in this context to determine the reliability of information found in all documentation, which is based on the assessment of the waste management program. 
1 4.2.2.2 Administrative Procedures and Training. The reliability of waste 2 management information is a criterion of performance history. Waste 3 management personnel will have been trained in procedures governing dangerous 4 waste activities.

4.2.2.3 Container Management. Container management, considers the generating unit's control of the issuance, tracking, and documented control of waste containers within the unit. This criterion gauges the reliability of that portion of the documentation that describes the contents of the container.

4.2.2.4 Physical Controls During Waste Generating. This criterion gauges the physical controls the generating unit will have over the coritainers of waste that are generated. The criterion will measure the probability of waste being placed in the container after the container was declared as full. These acts could lead to erroneous packaging of waste, i.e., batteries being placed in a container specifically labeled for rags.

\subsubsection{Summary of Documentation Assessment}

After the 'lot/batch waste documentation checklist' has been completed for each waste container, each lot/batch will be reevaluated. Resorting of some of the waste containers might occur at this time. If a lot number is changed for a container, the lot number must be changed in SWITS. Documentation recording the change and the reason for the change will be placed in the Tank Farms container file. Each backlog waste container will have a file established that contains all documentation required by this waste analysis plan.

\subsection{CONFIRMATION OF DESIGNATION}

Tank Farms may request Solid Waste Acceptance Services (SWAS) to issue a SDAR for any lot that is believed to have adequate documentation to designate the waste according to WAC 173-303-070.

The steps used to answer the question, Is Designation Confirmed? are as follows:

- Step 1: Tank Farms' waste characterization data will be referenced or placed in the container field file;

- Step 2: Tank Farms' field file as well as supporting documentation will be transmitted to SWAS for evaluation;

- Step 3: SWAS will answer the question by comparing the data received to WAC 173-303-070 and WHC-EP-0063 requirements. The designation criteria for making this determination are provided in Appendix $D$;

- Step 4: If the answer to the question is 'YES', SWAS will issue a notice of confirmation to Tank Farms and other organizations, as applicable, authorizing the SDAR to be used. If the answer to the 
question is 'NO', the waste designation is not confirmed and a notice of rejection will be issued.

\subsection{DETERMINATION OF CONFIDENCE/CONFIRMATION LEVEL}

If the documentation assessment has been completed for each container and the designation is not yet confirmed, a confidence level will be established for each lot/batch. The confidence level will be used to determine the level of confirmation necessary for the lot/batch. A graded approach to confirmation will be used to correlate the level of work to the completeness of the data.

The confidence level is determined using a lot/batch waste information worksheet' and guidance provided in Appendix B.

\subsection{WASTE CONFIRMATION OF DESIGNATION PROTOCOL}

Confirmation will be specified for each lot/batch. The 'lot/batch waste information worksheet' will be used to document the confirmation levels and methods for each 1ot/batch. The confirmation protocol is dictated by the waste type and the confidence level associated with the lot/batch.

Appendix C, Waste Type Specific Confirmation, provides tables specifying the confirmation of designation measures, sample size, and error tolerances that will be used for each waste type. In some cases, exact analytes cannot be specified because the 'fingerprint' 1 ' of the waste could vary (i.e., aerosols, paints, etc.). In these cases, a determination will be made in the field as to the most appropriate fingerprint based on process information, e.g., MSDS or container label.

The number of containers to be sampied will be based on a percentage of the containers or ASTM D140-70, "Cubed Root" Method [found in Waste Analysis Plans, A Guidance Manual, EPA-530-SW-84-012 (EPA 1984)].

\subsection{WASTE DESIGNATION CONFIRMATION METHODS}

Physical and chemical confirmation will be used to confirm the Tank Farms' designation of the waste. The exact methods of confirmation of designation are described in the following sections.

'Fingerprint' parameters are those parameters that will confirm process knowledge, i.e., a container is labeled 'corrosive', and states the product contains sodium hydroxide; therefore, the product will be tested for sodium

47 and $\mathrm{pH}$ to confirm that process knowledge is correct. 


\subsubsection{Physical Confirmation}

Physical confirmation methods will be as follows:

- Physical Characteristics Measurements--CWC will validate the physical characteristics such as weight and dose rate noted in the backlog waste documentation.

- Nondestructive Examination (NDE)--using real-time radiography (RTR) equipment, the waste container will be viewed and the observed contents will be compared to available documentation. The NDE operator will record :DE results on a NDE confirmation checklist (Appendix E, Backlog Waste Real-Time Radiography Guidance). The NDE also will be used to obtain information that does not impact confirmation, but is applicable to long-term management of the waste (i.e., determination of the presence of a liner, percentage of void space, etc.).

- Visual Inspection of Contents--the container will be opened for a cursory visual inspection of the waste and the contents will be compared to the documentation provided, unless prohibited by ALARA. This method will be used when NDE identifies a potential problem or when the use of NDE is not practical.

\subsubsection{Chemical Confirmation}

Chemical confirmation will be accomplished using field testing equipment, nonobtrusive testing such as x-ray fluorescence, headspace gas analysis, or laboratory chemical analysis.

A waste container chosen from a lot for confirmation might not require full sampling for characterization. In most cases, confirmation based on the predetermined fingerprint parameters of the waste type will be sufficient. For example, on inspection of the contents of a container, a red powder is observed. Based on the Tank Farms initial characterization of the waste type and its fingerprint, the red powder could be generated only from one source on the Hanford Facility. Therefore, the waste sampling for that container is complete.

Currently, HAZCAT ${ }^{1}$ kits and other EPA-approved field testing methods and equipment are used to determine the identity of waste. Field results are confirmed by performing SW-846 protocol sample testing (EPA 1986) on 10 percent of the waste samples. Analytical analysis will be performed in accordance with Section 5.0 of this waste analysis plan.

${ }^{1}$ HAZCAT is a tradename of Haztech Systems, Inc. 


\subsection{WASTE CONFIRMATION OF DESIGNATION PROCESS}

Figures 4-2, 4-3, and 4-4 outline the process of physical and chemical confirmation of a lot/batch.

The sample set, initially outlined for each lot/batch, is the basis for the first 'round' of waste designation confirmation. If one container fails confirmation of designation out of a sample set, another sampie set of the same size will be chosen from the lot for confirmation of designation. The second set is the basis for the second 'round' of confirmation. (NOTE: If the original sample size was 100 percent, it is not possible to have a second round of confirmation.)

The 'second round' is to ensure that the one failure is truly an anomaly. If one container fails confirmation, the lot/batch is not failed. The lot/baich proceeds through the process and the failed container is removed from the lot/batch and handled separately.

Once each step in the confirmation process is complete (Section 4.3), the next step can commence. Ncte that every container in the lot/batch might not be involved in physical and/or chemical confirmation. Only those containers that are chosen as part of the sample set are confirmed and will be corisidered representative of the entire lot/batch.

\subsubsection{Physical Confirmation Criteria}

Inconsistencies found during any step of physical confirmation should be evaluated and flagged if further confirmation needs to be performed in the container.

4.7.1.1 Inconsistencies in Physical Characteristics. A difference in measired weight greater than 10 percent of the documented weight will be flagged as an inconsistency. Weights can be expected to vary because measurements were obtained in the field.

A difference in measured dose rate greater than 100 percent of the measured dose rate will be flagged as an inconsistency. This high percentage is used because of the variability in the dose rate reading due to instrument variability and the ability to detect 'hot spots' on the container. For lower dose rate containers, a larger range is required to avoid unnecessary flagging.

4.7.1.2 Nondestructive Examination Inconsistencies. The islilts of RTR could result in several actions.

- Inconsistencies are identified between the RTR and the inventory sheets for the backlog container but the discrepancies do not change the waste codes on the container. The change in the inventory sheets will be identified on the solid waste storage/disposal records but no further confirmation is needed on the container. 
- Inconsistencies are identified that potentially could cause a confirmation of designation failure. Further process knowledge is gathered to substantiate the designation of the waste. Process knowledge is used to determine if the inconsistency is a failure. If process knowledge is not sufficient to make this determination, further confirmation is necessary.

- Inconsistencies are found and sufficient information exists to call the inconsistency a failure. No further confirmation is needed for the container.

- RTR couTd reveal trace amounts of liquids that appear to be condensate. The first 10 containers will be opened to confirm that the liquid is condensate. If the liquid is water, no further containers that exhibit similar characteristics will be opened for confirmation.

Action to be taken for specific cases not identified in this waste analysis plan will be decided at the time of RTR using best professional judgment.

4.7.1.3 Visual Inspection Inconsistencies. Visual inspection inconsistencies of the waste in a container will result in the following actions.

- The determination of whether the designation is confirmed may be able to be made by visual observation of the waste.

- Additional process knowledge gathered after visual inspection of the waste could result in sufficient information to determine whether the designation is confirmed.

- Visual inspection could identify waste that needs further chemical analysis before a determination can be made. The container will be flagged and the appropriate chemical analysis performed.

\subsubsection{Chemical Confirmation Criteria}

Field analysis may be used for confirming whether or not a waste is ignitable, corrosive, or reactive. Field analysis also is acceptable for determining if a waste contains organic constituents or confirming the presence of gross quantities of organic or inorganic constituents. Ten percent of all field analysis will be confirmed with analytical analysis.

The acceptable error tolerance for analytical analysis is \pm 20 percent of the regulatory threshold. If laboratory analysis falls into this area, the sample QA/QC will be assessed to determine the actual accuracy of the analytical result. A decision of regulatory status will be based on this assessment.

Inconsistencies found during field testing of fingerprint parameters should be evaluated to determine if a confirmation of designation failure occurred. Field testing could result in further analytical testing of the waste. 
A determination will be made based on the analytical results and whether the inconsistencies result in a confirmation of designation failure.

\subsubsection{Confirmation of Designation Failure}

A confirmation of designation failure is defined as any inconsistency that will not allow Tank Farms to fulfill the objectives of this plan as defined in Section 1.2. If two containers fail either the first round confirmation or a combination of the first and second rounds of confirmation, Tank Farms will determine whether the error is a sorting error or a true confirmation failure.

\subsubsection{Confirmation of Designation Corrective Action}

If the inconsistency is determined to be due to a sorting error, the determination will be documented by letter to the Tank Farms container file. On making this determination, Tank Farms will instruct the CWC to either set aside the lot for repackaging/designation or will reassign containers to other lots (as applicable).

EXAMPLE: The contents of the container might have been labeled as F-Listed "derived from" soil and was sorted accordingly. Analys is reveals higher levels of contaminants than normally had been known. After further investigation, it is determined that the soil was created from an activity in which other chemicals contaminated the soil. Therefore, these containers should be in a separate lot and will be resorted accordingly.

If the inconsistency is determined to be a Confirmation of Designation failure, the appropriate waste codes should be applied to the lot/batch an occurrence report will be issued with specific guidelines.

\subsection{COMPLETION OF DESIGNATION PROCESS}

Following the completion of the confirmation of designation process, the answer to the question "Is designation confirmed?" will be answered as outlined in Section 4.3. If the answer to the question is 'Yes', SWAS will issue a notice of confirmation to Tank Farms and other organizations, as applicable, authorizing the SDAR to be used. If the answer to the question is 'No', designation will be completed in accordance with this section.

During completion of the designation process, SWAS will compare the Tank Farms designation to WAC 173-303-070. The information will allow SWAS to fully designate the waste. This process is outlined in Figure 4-4.

After SWAS has determined which section(s)/subsection(s) of WAC 173-303-070 are required to be completed, SWAS will determine the analytical testing (Table 4-1) that must be done. Table 4-1 contains analytical methods used in 
the designation process. Actual testing requirements must be based on process knowledge, waste matrix, physical state, etc.

After analytical results are received from a laboratory, SWAS will notify Tank Farms which SDAR to use for CWC to formally accept the waste.

7 Al1 sample analysis will be performed in accordance with section 5.0. 
DOE/RL-93-70, Rev. 0

08/31/93

This page intentionally left blank. 


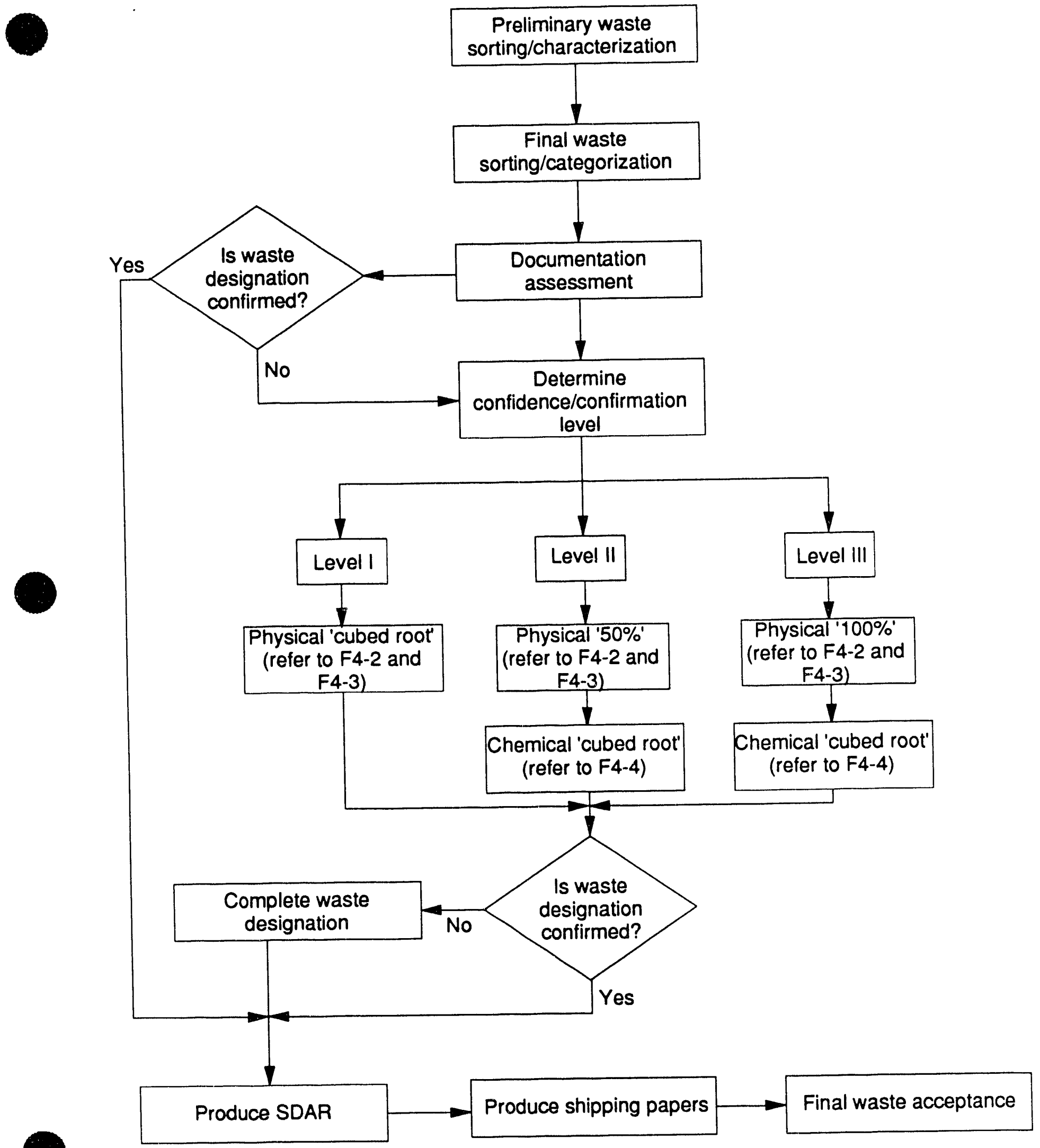

Figure 4-1. Typical Process for Confirmation or Completion of Designation. 


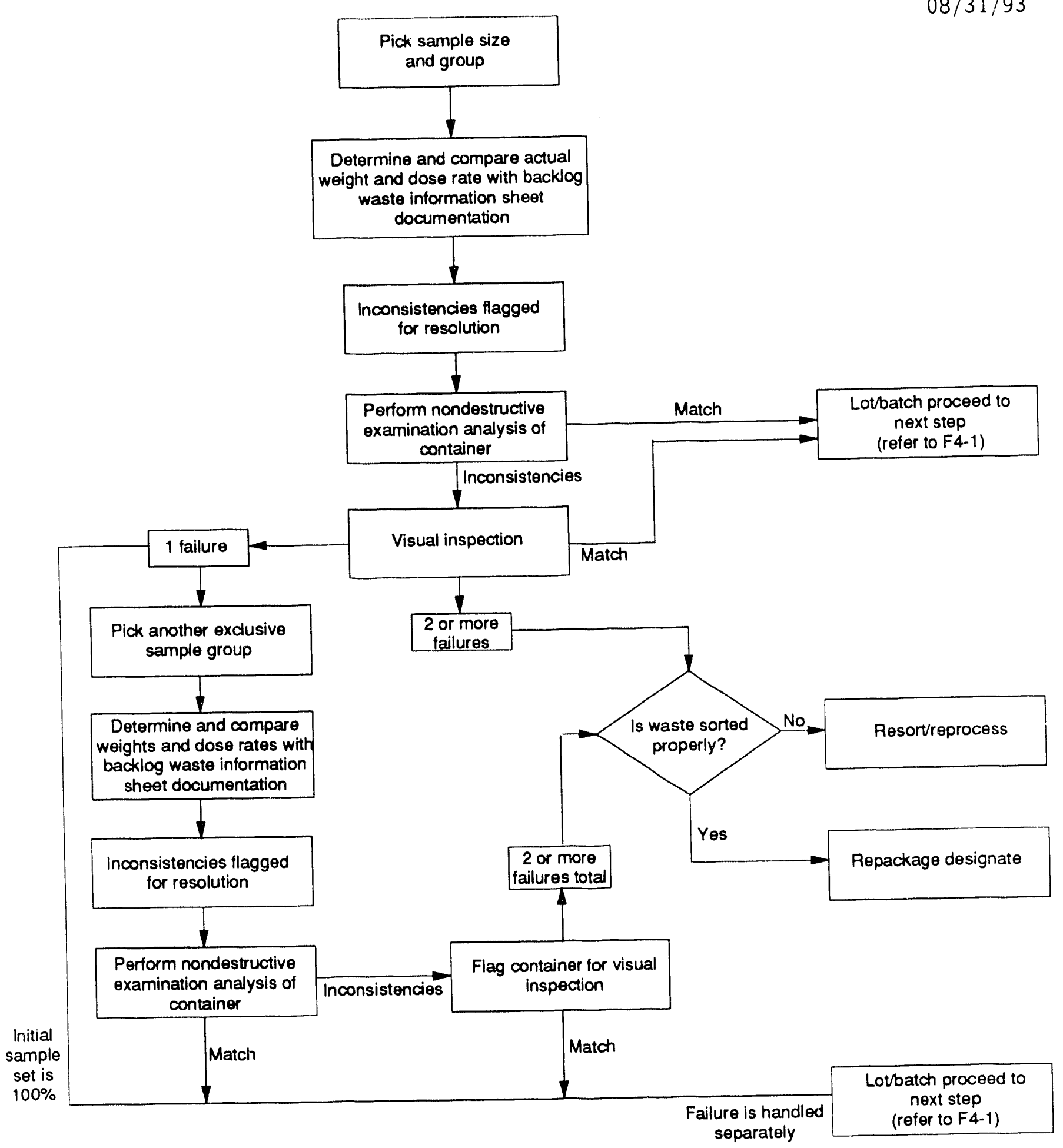

Figure 4-2. Typical Process for Physical Confirmation of Non-Soil Drums. 


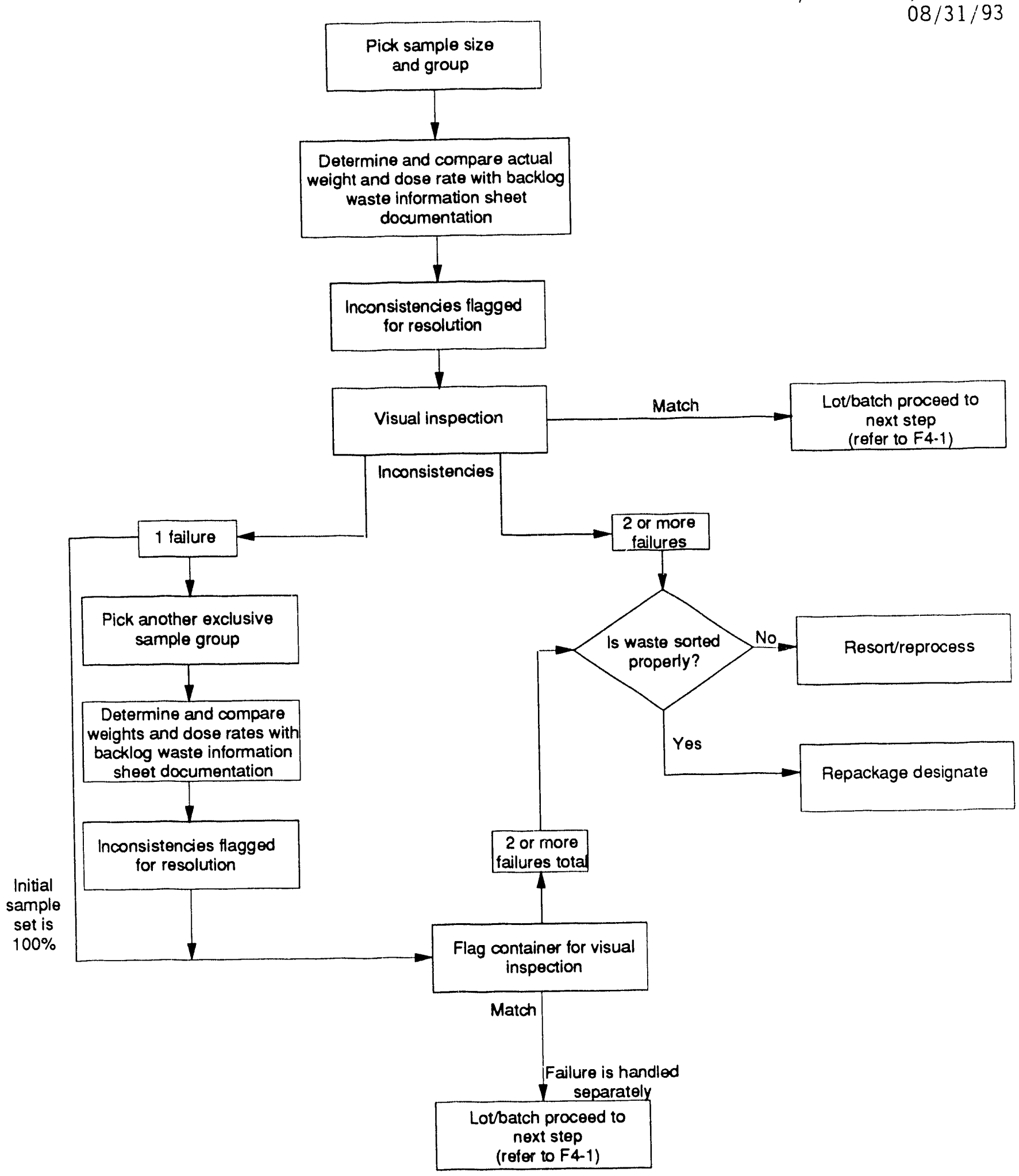

Figure 4-3. Typical Process for Physical Confirmation of Soil Drums and Boxes. 
DOE/RL-93-70, Rev. 0

$08 / 31 / 93$

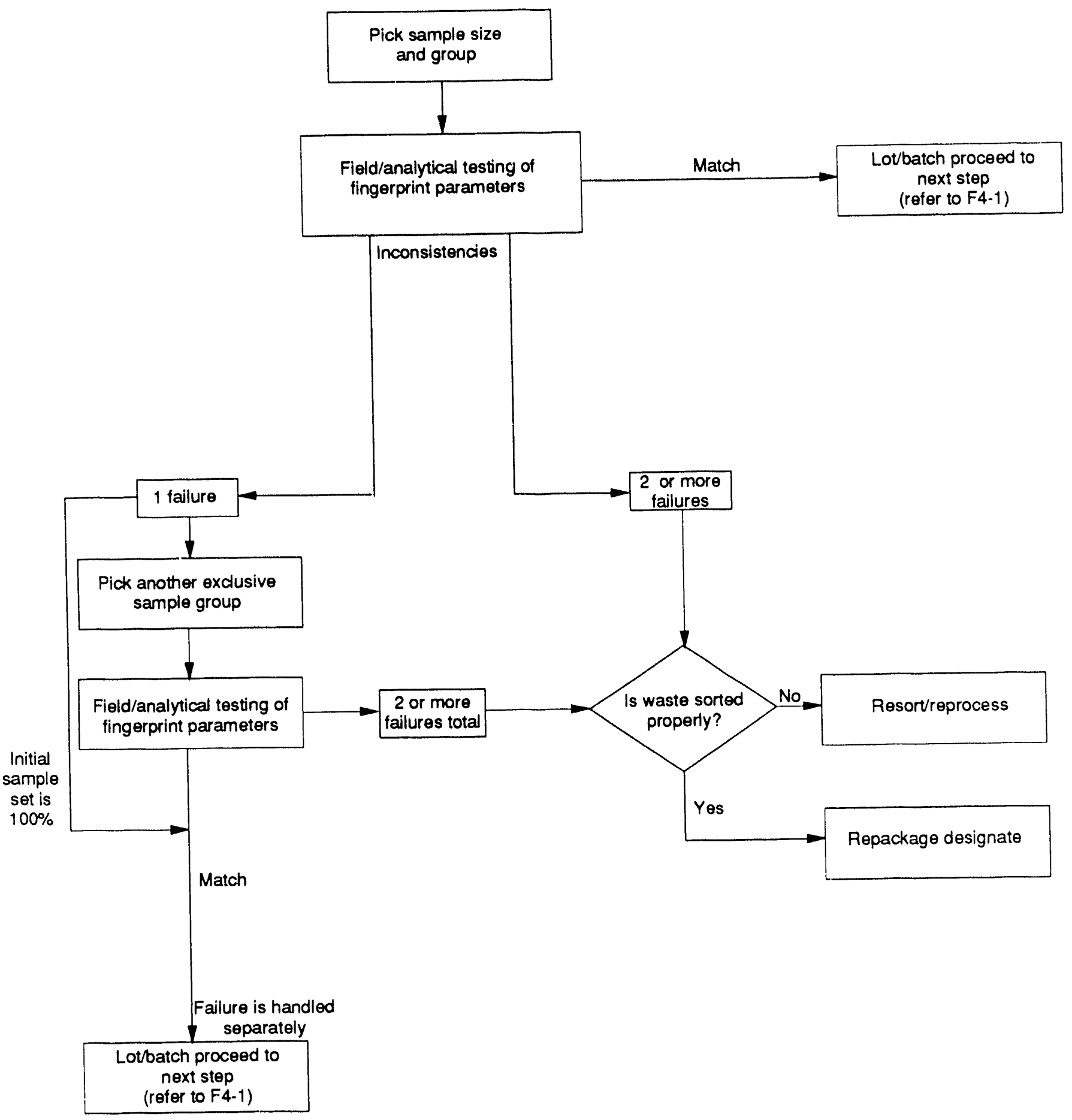

Figure 4-4. Typical Process for Chemical Confirmation of Field/Analytical Testing of Fingerprint Parameters. 


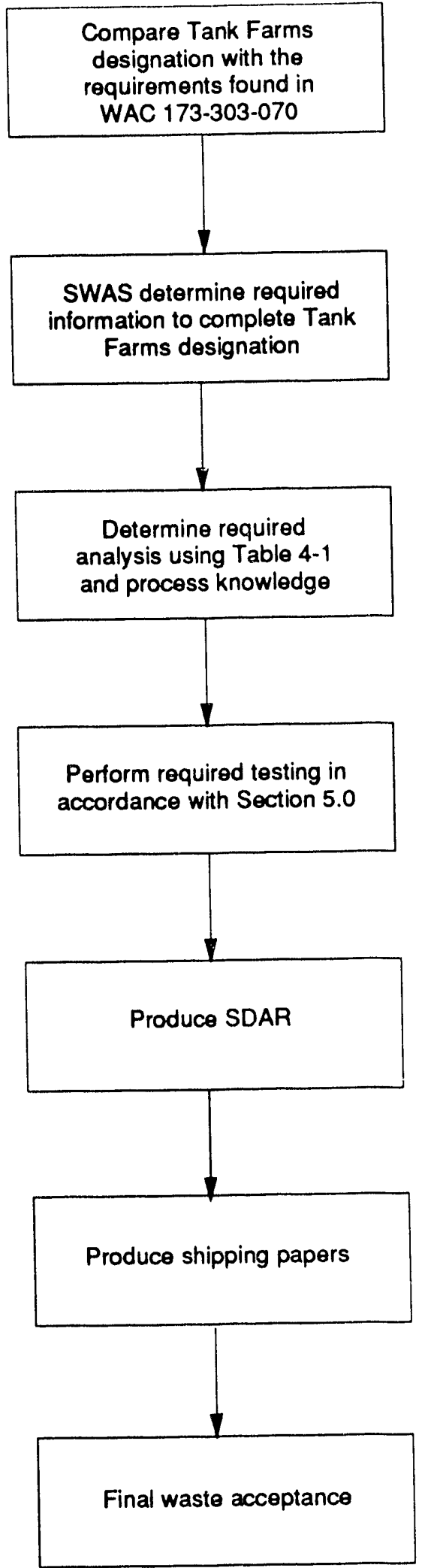

Figure 4-5. Completion of Designation Process. 
Table 4-1. Analytical Testing for Completion of Designation.

\begin{tabular}{|c|c|}
\hline Designation criteria & Analysis and information required \\
\hline Discarded chemical products & Process knowledge \\
\hline Dangerous waste sources & SVOA, VOA and process knowledge \\
\hline Toxicity & $\begin{array}{l}\text { SVOA, VOA, ICP metals, anions, } \\
\text { process knowledge }\end{array}$ \\
\hline Carcinogenic & $\begin{array}{l}\text { SVOA, VOA, ICP metals, anions, } \\
\text { process knowledge }\end{array}$ \\
\hline Persistence & TOX \\
\hline Ignitability & $\begin{array}{l}\text { Flashpoint } \\
\text { Field flammability testing } \\
\text { Field oxidizer testing }\end{array}$ \\
\hline Corrosivity & $\mathrm{pH}$ \\
\hline Reactivity & $\begin{array}{l}\text { Analytical cyanide/sulfide } \\
\text { field reactivity testing }\end{array}$ \\
\hline TCLP & ICP metals, SVOA, VOA \\
\hline PCB & PCB; process knowledge \\
\hline
\end{tabular}

NOTE: TCLP will not necessarily be used as a basis for designation. A TCLP analysis could be taken on a percentage of the samples with the primary use of the results being for future treatment and disposal of the waste [i.e., to meet the Land Disposal Restriction Requirements (40 CFR 268)].

SVOA = semivolatile organic analysis.

VOA = volatile organic analysis.

ICP = inductively coupled plasma.

TOX = total organic halogens.

$P C B=$ polychlorinated biphenyls.

TCLP = toxicity characteristics leaching procedure. 


\subsection{SAMPLING AND ANALYTICAL METHODS}

2

3

4

This section will be followed whenever analytical sampling is required as specified in this waste analysis plan.

\subsection{HAZARDOUS CONSTITUENT SAMPLING}

Sampling of lots/batches will be based on a simple random selection method as outlined in SW-846 (EPA 1986). The random selection will be based on a random number generating method.

Table 5-1 1ists the sample protocol for each type of waste material. Field analysis and process knowledge will be used to determine the specific analytes to be tested for in a waste. Note that no analytes are specified for sampling 'hards' (cement, metals, wood, asphalt). A representative sample cannot be taken from this material for chemical testing. Only in cases where there is a 'crust' on the surface of the material that can be scraped off will sampling take place.

\subsection{CRITERIA FOR WASTE TYPE SAMPLING}

Sampling might not lead to detailed laboratory analysis. Sampling could be specified after visual screening, simple field testing, or analysis for waste type fingerprint parameters as appropriate.

The following information will be used by Tank Farms as a baseline description of each waste type:

- General waste type description

- Physical and known chemical characteristics of the waste

- Available sample results.

The degree and type of sampling will depend on existing knowledge and available field screening results. For initial waste type characterization, several samples and associated sample results will be required. The sampling and confirmation of designation for a waste type will become the basis for the Tank Farms process knowledge. When a waste type requires completion of designation, a level of information similar to initial waste type designation will be needed.

\subsection{WASTE SAMPLING TECHNIQUES}

This section describes how various waste types are to be sampled, establishes standard procedures for sampling various kinds of waste covered under the order, and documents how these procedures vary from sampling procedures referenced in Ecology guidance documents, including SW-846, Volume II, Chapter 9.0, "Sampling". Standardized criteria for determining the locations and number of duplicate samples to be collected in various sampling situations 
are established. These sampling guidelines will be incorporated into work plans.

\subsubsection{Sample Handling}

Waste sample handling will be conducted by S\&ML personnel who have successfully completed training in environmental protocol sampling (Section 3.0). In general, sample handling will follow recommended practices found in SW-846. Deviations from these practices are described in this section.

5.3.1.1 Chain of Custody. All waste samples will have the following chain of custody.

5.3.1.1.1 Sample Labeling. All waste samples will be labeled before analysis. Where possible, the sample container will be labeled with the following information:

- Sample number or other unique identification

- Requested analysis

- Name or initials of the sampler

- Preservation methods

- Date and time the sample was collected

- Available information on radionuclides and radiation level if applicable

- Location where the sample was collected.

In instances where labeling the sample container is not practical, the sample packaging and/or overpack will be clearly labeled with this information.

5.3.1.1.2 Sample Evidence Tape. Sample evidence tape will be used to ensure sample integrity if practical. If sample evidence tape is required, the tape will be affixed to the sample container where possible, and will include the same information as the waste label (Section 5.3.1.1.1). In instances where sample evidence tape cannot be applied to the sample container, the tape will be applied to the sample overpack. Such instances may occur when application of a sample evidence tape to the container in the field could result in radiological doses that are not consistent with ALARA. Sample evidence tape should be affixed in a manner that will reveal tampering.

5.3.1.1.3 Sample Logbooks. The S\&ML organization will maintain a controlled field logbook. As a minimum, the following entries will be made for each sample: 
- Names of personnel involved in the field activity

- Titles and responsibilities of personnel involved in the field activity (if applicable)

- Signature of person making an entry (the printed name of the person is to occur at least once per logbook by their signature)

- Type and purpose of field activity

- Date of field activity

- Site map, sketch, or other definitive site description

- Field observations (e.g., weather conditions)

- Brief description of the job

- Samp1ing methods used

- Instrument calibration information

- Equipment identification numbers (if applicable)

- Condition of equipment

- Field decontamination of equipment and personnel

- Decontamination of equipment before arrival onsite

- Field problems, solutions, corrective actions

- Attachments (e.g., photographs)

- Audits or surveillances conducted during the sampling event

- Sample identification table with identification numbers, date, time, preservative, and analysis

- Field measurement data

- Lot numbers of the sample collection containers used

- The condition of each sampled container (e.g., leaking, bulged, corrosion, etc.)

- Status of the inside liner (e.g., horsetailed, taped, open, if a liner is present or not, etc.)

- Package identification number (PIN) of the container sampled

- Any declared waste components and concentrations. 
5.3.1.1.4 Chain-of-Custody Record/Sample Analysis Request. A COC/SAR record sheet will be completed for each sample shipment and will accompany the shipment to a laboratory. The COC/SAR will include, at a minimum, the following information for each sample:

- Sample number or other unique identifier (matching that in the sample logbook)

- Date and time of sample collection

- Jescription of sampling location

- Number of sample containers associated with each sample

- Analyses requested

- Inclusive times and dates of sample possession, and signatures for each person handling the sample shipment.

Where possible, the COC/SAR will be packaged with the samples in the shipping container (e.g., sealed in a plastic bag). In instances where it is not practical to package the COC/SAR with the sample, it will accompany the sample during transport.

The following steps will ensure the integrity of the samples.

Step 1: The S\&ML sampling technician will initiate and maintain custody.

- The S\&ML sampling technician will maintain custody of sample(s) from collection until appropriate transfer of custody.

- The S\&ML sampling technician will record the following in the field logbook:

- Sample identification numbers

- Witness name.

Step 2: To document transfer of samples, the person relinquishing custody and the next person accepting custody will sign, dace, and record the time of transfer on the $C O C$ form. The COC form initiator and the first person to sign the "Relinquished by" block on the COC form will be the same person.

Step 3: The original COC form will accompany the sample(s), and a copy of the COC form will be given to the S\&ML sampling technician for information.

Step 4: A copy of the COC/SAR, shipping documentation, and radiation documentation will be forwarded to HASM for tracking purposes by the close of business the working day following sample shipment. 
Step 5: The laboratory sample custodian will inspect transferred samples to ensure the following:

- Seals are intact

- Labels are affixed and legible

- A SAR accompanies each sample or discrete set of samples

- The physical condition of samples is acceptable

- Samples being transferred are those on the COC form.

5.3.1.2 Sample Containers. Where possible, sample containers indicated on Table 5-1 will be used for sample collection and transport. In some instances, sample containers required by $\mathrm{SW}-846$ cannot be used. In these instances, samples will be shipped to the laboratory as soon as practical, and transferred to an approved container.

Sample containers will be vendor certified, precleaned, with Teflon'-lined closures, and bar coded from the manufacturer with lot number and identification number. The number and sizes of the required containers will depend on the analysis requested and the specific laboratory requirements. The HASM will provide a list of the container volumes required by the specific analytical laboratory before sampling.

5.3.1.3 Reagents. Reagents used during sampling will include the following:

- ASTM Type II water

- Pre-certified silica sand.

5.3.1.4 Equipment. The following is a typical list of equipment that could be used in the collection of samples (additional items could be required, depending on the individual sampling task):

- Sample containers

- Sample labels, pre-printed and blank

- Sampling scoops and trowels

- Sampling bowls

- Composite liquid waste sampler (COLIWASA)

- Thief sampler (open tube sampler)

- Grain sampler

- Sampling trier

- Hand-auger

- Dip sampler

- Surgeons gloves

- Safety glasses

- Scissors

- Ice chest

- Peristaltic pump

- Evidence tape

- Bung wrench

- Absorbent pads 
3

4

- Ratchet wrench/open-end wrench

- Field notebooks.

5.3.1.5 Composite Sampling. Composite samples will be collected for containers that come from the same waste stream. Up to five containers that contain the same matrices can be composited into one sample. Sampling events will be evaluated by S\&ML on a case-by-case basis to determine how compositing will be performed and the number of containers that will be composited.

\subsubsection{Sample Collection}

Standard sampling protocol used for confirmation and characterization of waste covered under the Order is summarized in the following sections. Most of these methods are based on or are correlated to suggested sampling methods in SW-846 or ASTM Methods referenced in WAC 173--303.

\subsubsection{Container Sampling Procedures}

The container sampling procedures will be as follows:

- Verify the PIN on the container to be sampled

- Photograph the container to be sampled and date and label the photograph. (If possible, the side of the container that the PIN number is on should be photographed.)

NOTE: If any hazards are discovered that could jeopardize personnel safety, discontinue sampling of the container(s) and notify the CWC representative and/or the S\&ML cognizant scientist. Any anomalies will be noted in the field logbook.

- Inspect the outside of the container for any previously unidentified leaks, bulging, or other hazards

- Observe the environment for any possible contamination problems (dust, odors, liquid, breezes, etc.):

- Document existence of possible contamination problems

- Evaluate potential effects on the samples.

- Open the container. For a container ring, use either a bung wrench or open-end wrench, depending on the type of container

- For sample collection, use the instructions provided in Handbook for Sampling and Sample Preservation of Water and Wastewater (EPA 1982) and $\mathrm{SW}-846$. 
NOTE: In the following, the sample label must include the following information:

Identification of lead sampler and initials

Sample identification number

Date and time sample collected

Sample event location

Analys is to be performed.

- Complete the sample label and affix to the sample container

- Place evidence tape on the sample bottle in such a way that if the container is opened, the evidence tape will be broken

- Replace the lid/bung on the container

- Tighten the lid/bung

- Record sampling data and conditions

- Clean the exterior of the sample containers

- Evidence tape the bung or lid of the container. Make sure that the evidence tape includes the date and the name of the technician who performed the sampling

- If the sample comes from a radiation zone, request that a radiation survey be performed

- Bag each sample in double plastic bags and bubble wrap

- Place bagged samples in an ice chest

- Seal the ice chest closed

- Decontaminate the sampling equipment at the sampling site. If unable to decontaminate, discard the equipment as waste at the sampling site.

\subsection{QUALITY ASSURANCE AND QUALITY CONTROL PROTOCOL}

In general, $Q A$ and $Q C$ will follow recommended practices found in SW-846.

Deviations from these practices are described in this section. 


\subsubsection{Blank Samples}

Blank samples will be transported with the collected samples to a laboratory for analysis. The samples will be used to determine the following:

- Cleanliness of sampling equipment

- Contamination or cross-contamination that might occur during sample handling and transportation

- Document the precision of sampling and analytical techniques.

Depending on the sample matrix (soil or water), pre-certified silica sand or reverse osmosis/deionized ASTM Type II water will be used for equipment and trip blanks.

\subsubsection{Equipment Blanks}

Equipment blanks will be collected using the exact sampling equipment that is to be used in subsequent sample collection and will imitate the sampling event. Equipment blanks will be representative of all equipment used in sample collection. Equipment blanks will be analyzed for the same constituents as an actual sample collected during the sampling event.

\subsubsection{Trip B1anks}

Trip blanks will be collected in a controlled environment. A container from the same lot number that will be used in the sampling event will be used to contain the trip blank. Trip blank(s) will be collected only if volatile organic analysis (VOA) is to be preformed on an actual sample. As a recommendation, one trip blank will be prepared for every ice chest that contains a VOA sample and all VOA samples per shipment will be sent in one ice chest to minimize the number of trip blanks.

\subsubsection{Duplicate Samples}

A duplicate sample will be two samples that are collected from the same container or composite material. The basis of collecting a duplicate sample will be to evaluate the replicability of sampling and analysis. A duplicate sample will be analyzed for the same constituents as the sample it duplicates.

\subsection{ANALYTICAL TECHNIQUE REQUIREMENTS}

The standard methods to be used to analyze waste parameters associated with the waste covered under the Order are described in the following sections. In general, these methods are based on SW-846 and will be consistent with SW-846 requirements. These requirements include, but are not 1 imited to, (where appropriate) duplicates, matrix spikes, matrix spike duplicates, laboratory 
DOE/RL-93-70, Rev. 0

$08 / 31 / 93$

1 blanks, and surrogate spikes. However, mixed waste analysis protocol varies

2 slightly from those described in SW-846; a general summary of those areas of

3 variance are provided in Section 5.3. Online instrumentation (e.g.,

4 continuous air monitors, radiation monitors, etc.) will be discussed in the

5 work plans.

7

8

9

10

11

12

13

14

15

16

17

18

19

\subsubsection{Liquid Matrix Analytical Methods}

The methods used for liquid mixed waste samples will be based on SW-846 methods. In some instances, three different methods are provided for mixed waste samples. The actual laboratory and analytical method used for a given waste sample depend on sample characteristics and the specific laboratory where the analysis is performed.

\subsubsection{Solid Waste Matrix Analytical Methods}

Analysis of mixed waste solid samples will be based on SW-846. As described in Section 5.3.1, up to three different methods will be provided for some mixed waste constituents.

\subsubsection{Deviations from SW-846 Protocol}

This section provides a general discussion of the currently documented deviations from SW-846 protocol that will occur during the analys is of mixed waste samples. Many of the deviations from SW-846 protocol arise from the radioactive nature of the samples handled. In addition to the specific deviations mentioned, recommended sample holding times are probably going to be exceeded for the waste samples that must be handled in laboratory hot cells. Preparation of these samples is complicated by the remote nature of the hot cell operations. Additionally, redundant 1 aboratory instruments currently are not available for many hot cell operations. Maintenance and repair activities also are complicated by the remote hot cell environment. Instrument failures also have caused holding times to be exceeded.

In general, when samples cannot be sent to offsite laboratories because of radioactive content, Pacific Northwest Laboratory (PNL) and the 222-S Laboratory Complex will deviate from SW-846 protocol. Analytical methods used by PNL are described in "Analytical Chemistry Laboratory (ACL) Procedure Compendium", PNL-MA-599 (PNL 1993). Procedures used by the 222-S Laboratory Complex are: ICP metals including arsenic, lead, and selenium - LA-505-151; mercury - LA-325-104; cyanide - LA-695-102; nitrite, nitrate, fluorine, chlorine, sulfate, and phosphate - LA-533-105; and $\mathrm{pH}-$ LA-212-102 (WHC 1993).

5.5.3.1 Inorganic Analysis. Analytical procedures used to characterize inorganic species deviate from SW-846 protocols in the general areas of sample preparation, sample size, and analytical techniques. These deviations are discussed in the following sections. 
5.5.3.1.1 Sample Size and Preparation. In general, smaller sub-sample sizes $(0.25$ grams to 0.5 grams versus 1 to 2 grams) are to be used when sampling highly radioactive mixed waste samples to reduce radiation exposure to laboratory personnel. Many sample preparation steps will be performed in disposable Tefion beakers.

5.5.3.1.2 Analytical Techniques. Fluoride, nitrate, sulfate, and phosphate analyses will be performed using an ion chromatographic method. This method is based on EPA methods for waste water analyses.

5.5.3.2 Volatile and Semivolatile Organics. Because of radiological controls and exposure constraints, it will not be possible to refrigerate mixed waste samples during laboratory storage. This complicates the ability to comply with required storage temperature constraints.

5.5.3.3 Toxicity Characteristics Leaching Procedure. Onsite laboratories can perform the TCLP [Method 1311 (WAC 173-303)] on a very limited basis. As the
ability to ship and process samples is limited by radiological constraints,

18 total analyses are going to be used in place of TCLP extractions. Solid

20 samples containing a total concentration of a toxic characteristic (TC)

21 regulated compound, which is less than 20 times the regulatory limit, are not

22 considered TC wastes. 
D0E/RL-93-70, Rev. 0

$08 / 31 / 93$

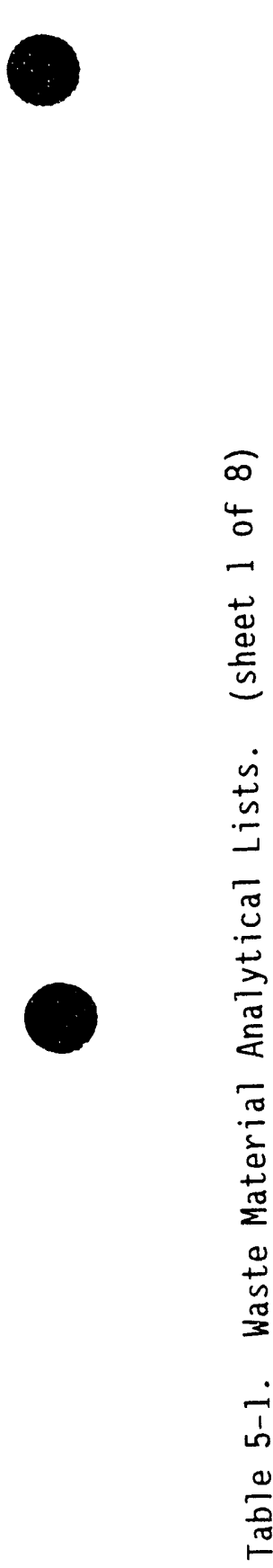

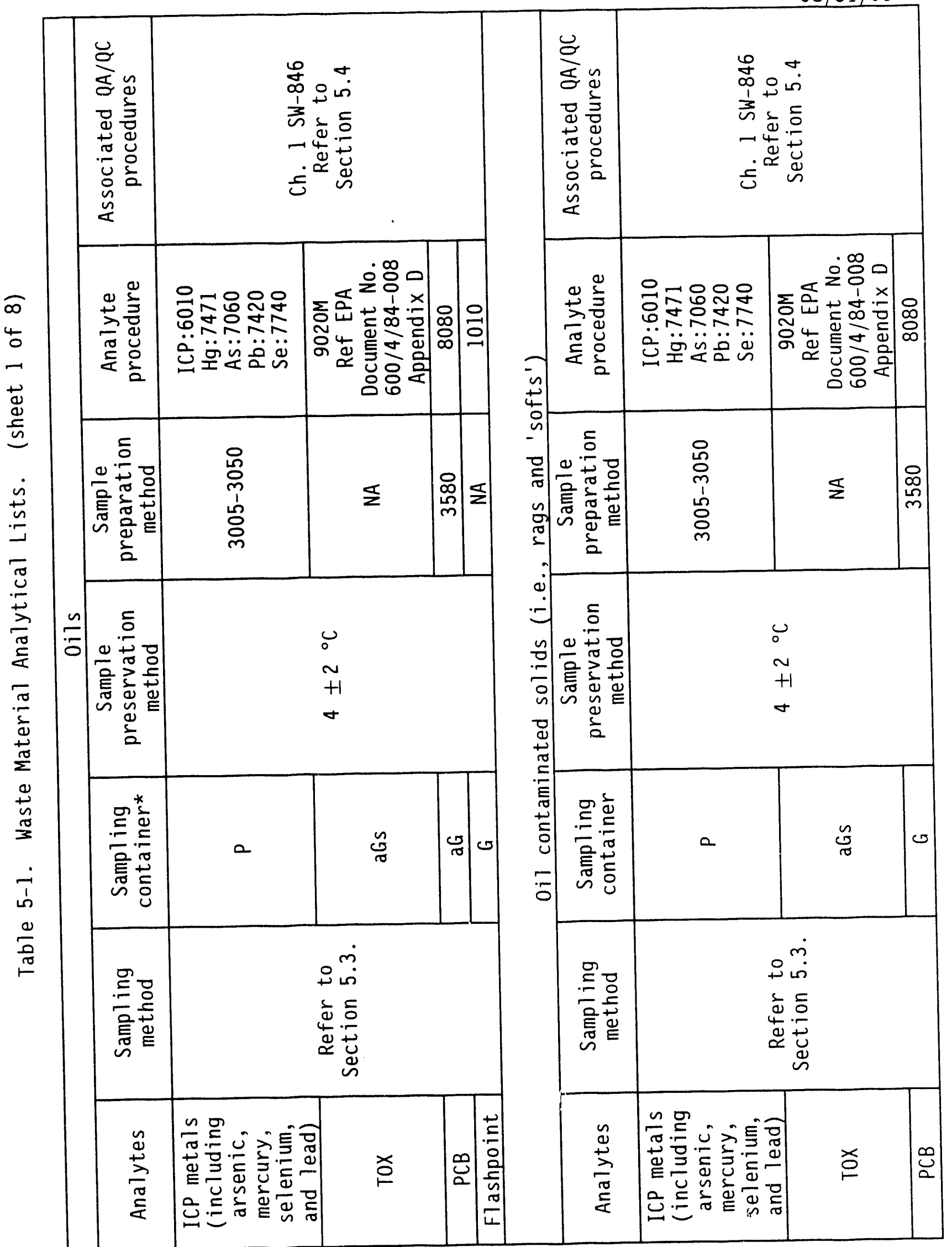


DOE/RL-93--70, Rev. 0

$08 / 31 / 93$

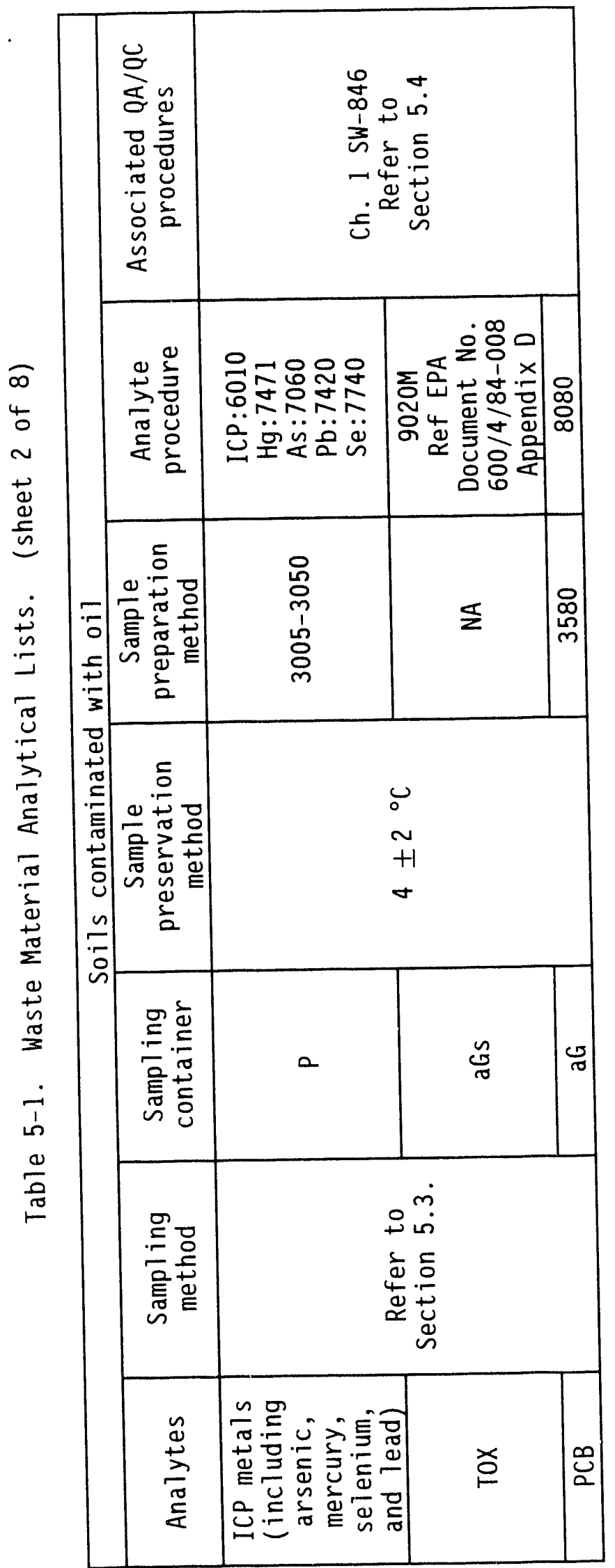


DOE/RL-93-70, Rev. 0

$08 / 31 / 93$

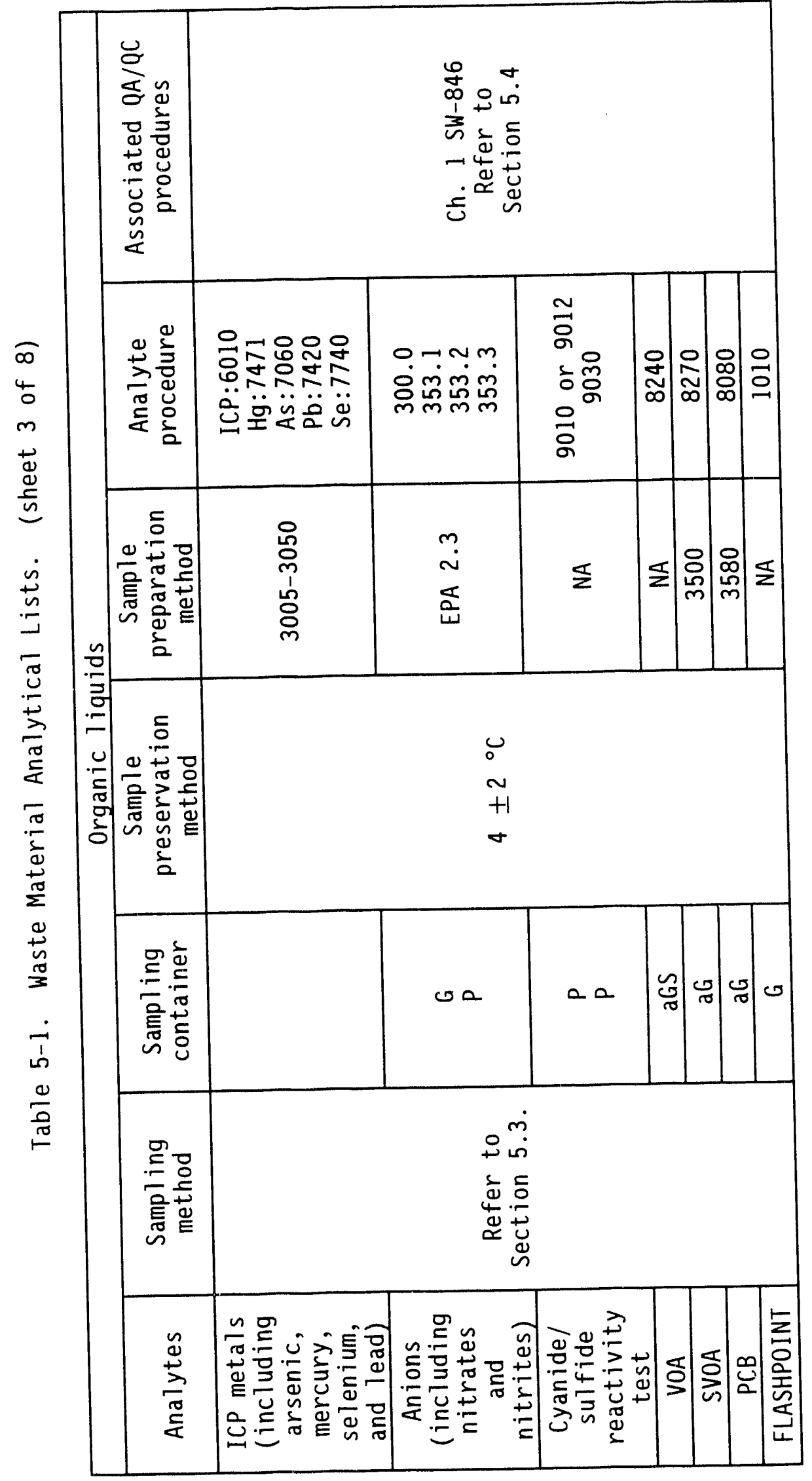


D0E/RL-93-70, Rev. 0 $08 / 31 / 93$

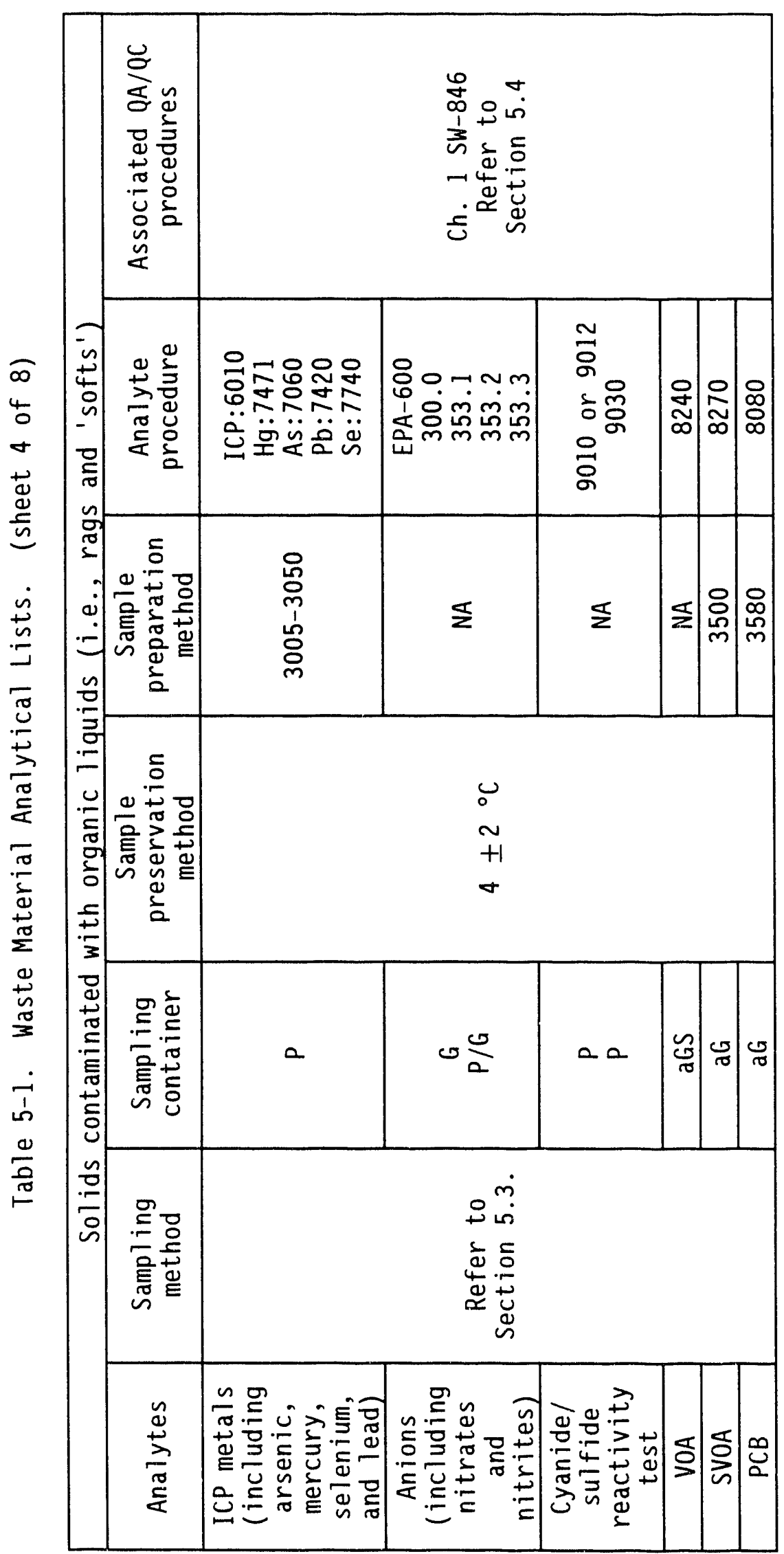


DOE/RL-93-70, Rev. 0 $08 / 31 / 93$

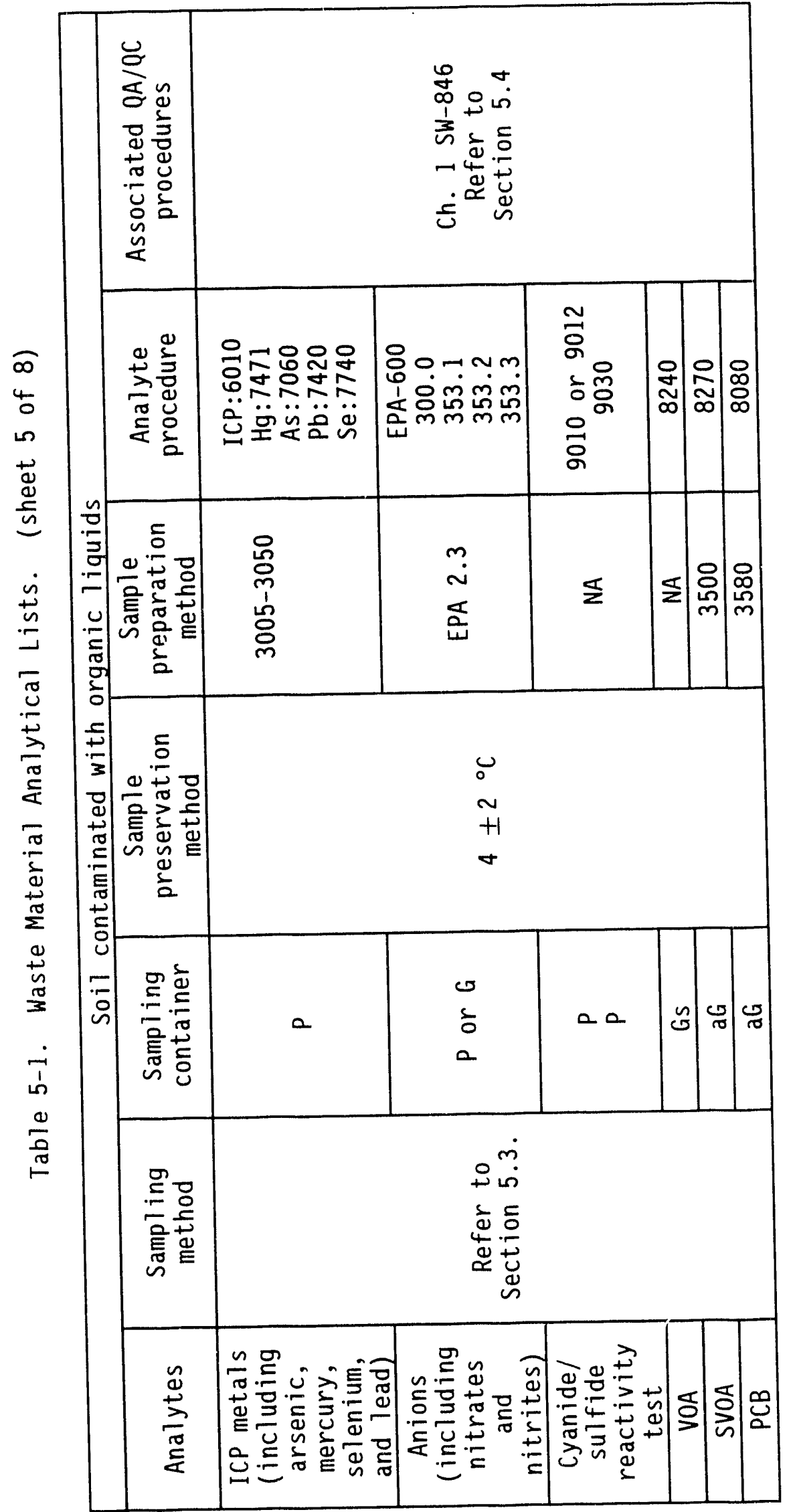


D0E/RL-93-70, Rev. 0

$08 / 31 / 93$

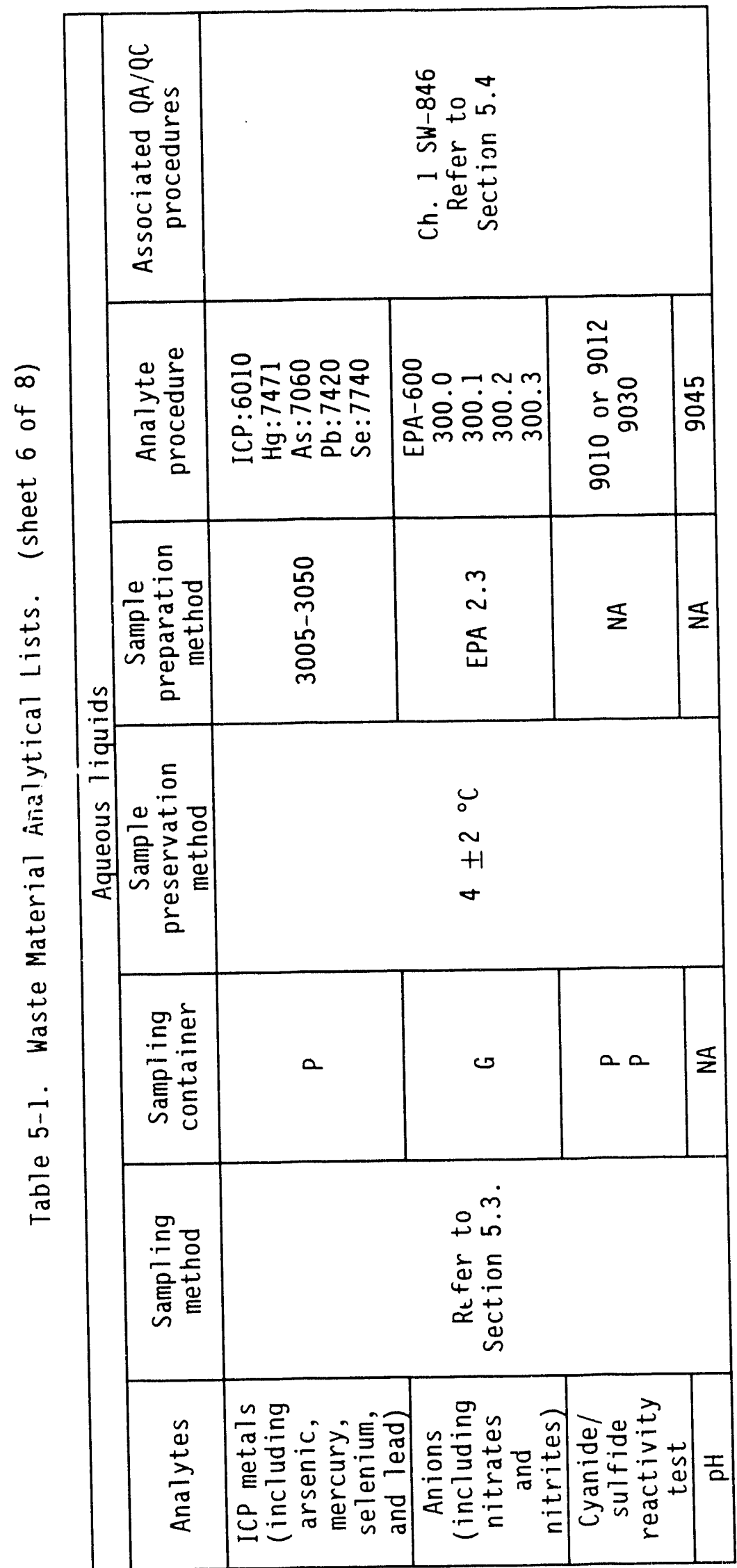


DOE/RL-93-70, Rev. 0 $08 / 31 / 93$

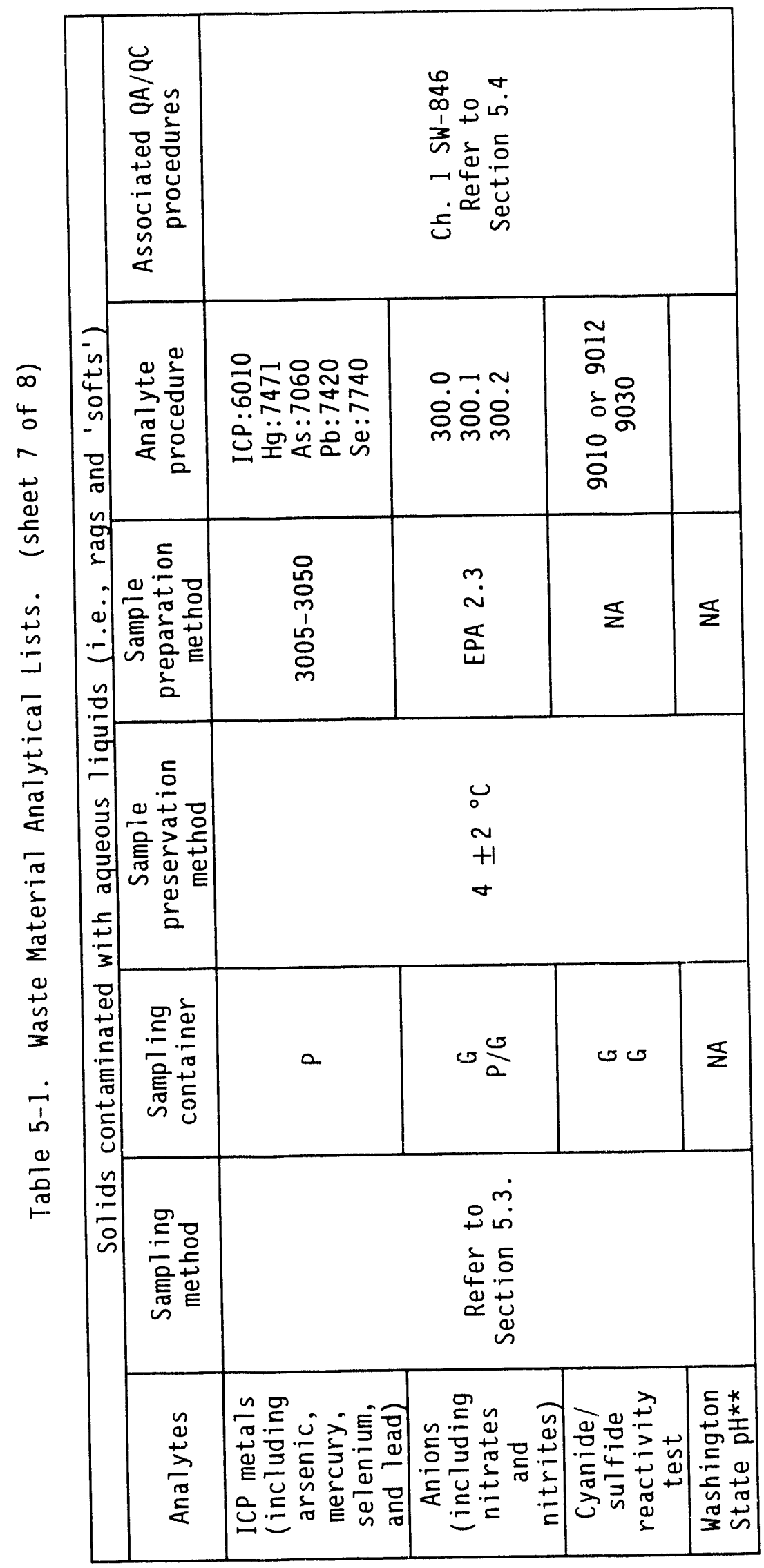


DOE/RL-93-70, Rev. 0 $08 / 31 / 93$
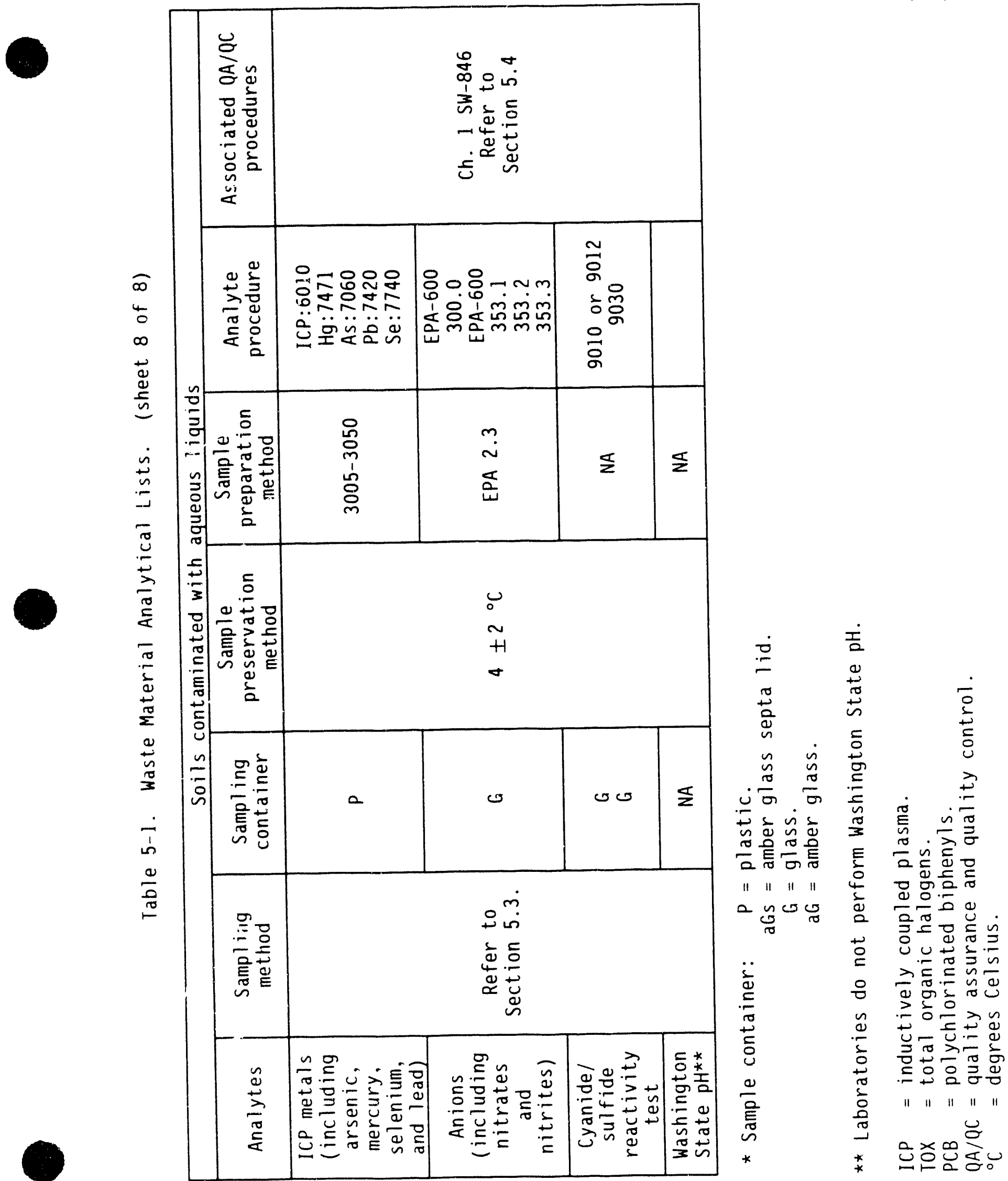
DOE/RL-93-70, Rev. 0 $08 / 31 / 93$

\subsection{RECORDKEEP ING}

2

3

4 Records generated during the implerientation of the waste analys is plan will be 5 maintained until the closure of the CWC in accordance with WAC 173-303-380. 
DOE/RL-93-70, Rev. 0

$08 / 31 / 93$

1

2

3

4
5

This page intentionally left blank. 
DOE/RL-93-70, Rev. 0

$08 / 31 / 93$

\subsection{REFERENCES}

DOE-RL, 1988, Hanford Facility Dangerous Waste Part A Permit Application, DOE/RL-88-20, revised periodically, U.S. Department of Energy, Richland Operations Office, Richland, Washington.

DOE-RL, 1992, "Unusual Occurrence Report", RL-WHC-TANKFARM-1992-0007, U.S. Department of Energy, Richland Operations Office, Richland, Washington.

Ecology, 1993, "Notice of Penalty, Order No. 93NM-201", issued to U.S. Department of Energy, Richland Operations Office and Westinghouse Hanford Company, March 10, 1993, Washington State Department of Ecology.

EPA, 1982, Sampling and Sample Preservation of Water and Waste Water, EPA/4-82-029, U.S. Environmental Protection Agency, Washington, D.C.

EPA, 1984, Waste Analysis Plans, A Guidance Manua7, EPA/530-SW-84-001, U.S. Environmertal Protection Agency, Washington, D.C.

EPA, 1986, Test Methods for Evaluating Solid Waste: Physical/Chemical Methods, SW-846, U.S. Environmental Protection Agency, Washington, D.C.

EPA, 1987, Data Quality Objectives for Remedial Response Activities, Development Processes, EPA/540-87-003, U.S. Environmental Protection Agency, Washington, D.C.

NIOSH, 1993, Registry of Toxic Effects of Chemical Substances, National Institute for Occupational Safety and Health, updated quarterly.

PCHB, 1993, Settlement Agreement and Order Thereon, PCHB 93-64, June 10, 1993, among Washington State Department of Ecology, U.S. Department of Energy, Richland Operations Office, and Westinghouse Hanford Company, Pollution Control Hearing Board, Lacey, Washington.

PNL, 1993, Analytical Chemistry Laboratory (ACL) Procedure Compendium, PNL-MA-599, 7 Vols., Pacific Northwest Lauuratory, Rich? and, Washington.

WHC, 1989, Hanford Site Solid Waste Acceptance Criteria, W'HC-EP-0063, as revised, Westinghouse Hanford Company, Richland, Washington.

WHC, 1993, 222-S Laboratory Procedures for the Confirmation or Completion of Tank Farms Backlog Waste Designation, WHC-SD-WM-PROC-011, Rev. 0, Westinghouse Hanford Company, Richland, Washington.

Resource Conservation and Recovery Act of 1976, as amended, 42 USC 6901 et seq.

Toxic Substances Control Act of 1976, 90 Stat. 2003, 15 USC 2601 et seq.

WAC 173-303, Dangerous Waste Regulations. 
110 CFR 61, Licensing Requirements for Land Disposal of Radioactive Waste.

2

40 CFR 265, Interim Status Standards for Owners and Operators of Hazardous Waste Treatment, Storage, and Disposal Facilities.

40 CFR 268, Land Disposal Restrictions.

40 CFR 302, Designation, Reportable Quantities, and Notification.

9

49 CFR 172, Hazardous Material Tables and Hazardous Materials Communications.

49 CFR 173, Shipper--General Requirements for Shipments and Packagings.

DOE Order 5400.5, Radiation Protection of the Public and the Environment. 


\section{APPENDICES}
A BACKLOG SORTING GUIDANCE
B GUIDANCE ON CONFIRMING THE DESIGNATION
C WASTE TYPE SPECIFIC CONFIRMATION PROTOCOL
D BACKLOG WASTE DESIGNATION GUIDANCE
12 E BACKLOG WASTE REAL-TIME RADIOGRAPHY GUIDANCE

11 
D0E/RL-93-70, Rev. 0

$08 / 31 / 93$

This page intentionally left blank. 
DOE/RL-93-70, Rev. 0

$08 / 31 / 93$

APPENDIX A

BACKLOG SORTING GUIDANCE 
APPENDIX A

\section{CONTENTS}

1.0 PURPOSE ..................................... APP A-1

2.0 SORTING PROCESS ...................... . . APP A-1

2.1 WASTE TYPES . . . . . . . . . . . . . . . . . . APP A-1

2.2 PRELIMINARY SORTING . . . . . . . . . . . . . APP A-2

2.3 ASSIGNING SORTING NUMBERS TO LOTS/BATCHES . . . . . . . . . . APP A-4

2.3 VERIFICATION OF SORTING . . . . . . . . . . . . APP A-5

2.4 RESORTING..................... . . APP A-5

3.0 RECORDKEEPING . . . . . . . . . . . . . . . . APP A-5

\section{FIGURE}

1. Typical Resort Justification Information ........... APP A F-1

\section{TABLE}

1. Initial Backlog Waste Sort Description . . . . . . . . . APP A T-1 
DOE/RL-93-70, Rev. 0

$08 / 31 / 93$

\subsection{PURPOSE}

This appendix provides guidance for the sorting of the Backlog Waste containers into lots. During this sorting process, lots could be further subdivided into batches for waste management purposes. The sorting allows Tank Farms to manage similar wastes in a more efficient manner.

This appendix describes the criteria by which the waste will be sorted into lots/batches. The containers that are sorted into a lot/batch must contain like contaminants. For example, containers having a like characteristic (i.e., produces condensate) will be sorted in a batch of their own so that these containers can be overpacked and absorbent added in preparation for long-term storage. This guidance contains the following elements:

- Clarification of the sorting process

- Waste type specific sorting guidance/criteria.

\subsection{SORTING PROCESS}

The sorting process will be a two-step process consisting of a preliminary sorting of containers into lots/batches and a secondary verification of sorting.

\subsection{WASTE TYPES}

The following lists the preliminary waste types in order of priority to be used in the sorting process:

- Aerosols

- Paints

- Acids

- Hazardous liquids

- 0ils

- Free 1 iquids (condensate)

- Mercury

- Filters

- Soils

- Soft debris (paper, plastic, rubber, cloth)

- Hard debris (cement, metal, wood, asphalt)

- Asbestos

- Low-Tevel waste

- Speciar case.

Other waste types could be identified in the confirmation or at the completion of designation process. New waste types will be described as to their physical and chemical characteristics. 


\subsection{PRELIMINARY SORTING}

The preliminary sorting process will be performed using information provided by SWITS and contained in BWIS files. The information includes PINs, type of container and weight, waste type, generating unit, and designation information. Some BWIS files contain inventories and contents of specific containers.

Using this information, Tank Farms personnel will sort the containers into specific categories according to the following criteria:

Aerosols--Al1 waste packages that are recorded as containing or suspected of containing aerosols will be placed in three lots: flammable, nonflammable, and not identified. Lots will be further subdivided into batches by additional waste characteristics if applicable. (Basis aerosol containers pose the greatest hazard, require special handling in accordance with WAC 173-303, and might require changes in packaging in preparation for long-term storage.)

Paints--Waste packages containing non-latex paints or non-latex paint debris and none of the previously mentioned waste types will be placed in two lots: liquid non-latex paint and non-latex contaminated debris. (Basis - non-latex liquid paints usually are flammable, could contain heavy metals, and require different handling than the typical F-Listed waste generated at Tank Farms.)

Acids--Waste packages containing acids or acid debris and none of the previously mentioned waste types will be placed in two lots: acid liquid and acid contaminated debris. (Basis - acids pose unique problems for long-term storage and require different handling than the typical FListed waste generated at Tank Farms.)

Hazardous liquids--Waste packages containing hazardous liquids other than oils and those mentioned previously will be placed in a lot. This lot will be further subdivided into batches according to waste

characteristics. (Basis - liquids pose unique problems for long-term storage and require different handling than the typical F-Listed waste generated at Tank Farms.)

oils--Waste packages containing oil and oil contaminated debris and none of the previously mentioned waste types will be placed in two lots:

liquids and oil contaminated debris. If applicable, lots will be further subdivided into PCB contaminated and non-PCB contaminated batches.

(Basis - oils pose unique problems for long-term storage and oils have a greater than normal probability of containing PCBs, which have unique handling requirements.)

Free liquids (condensate)--Waste packages containing free liquids (condensate) and none of the previously mentioned waste types will be placed in a lot. (Basis - condensate will, if not correctly packaged, 
impact long-term storage. Also, condensate requires different handling than the typical F-Listed waste generated at Tank Farms.)

Mercury--Waste packages containing mercury and mercury contaminated debris and none of the previously mentioned waste types will be placed in two lots: liquid mercury and mercury-contaminated debris. (Bas is mercury requires special packaging for long-term storage.)

HEPA filters--Waste packages containing HEPA filters, including chemical cartridges and nonspecified cartridges, and none of the previously mentioned waste types will be placed in three lots: exhauster, chemical cartridge, and nonspecified cartridge HEPA filters. HEPA-only mask cartridge filters are not regulated for dioctyl phthalate (DOP) and will be considered 'softs'. [Basis - onsite process knowledge (analytical analysis) exists for this waste.]

Soils--Waste packages containing greater than 25 percent soil and none of the previously mentioned waste types will be placed in a lot. This lot will be further subdivided into batches by farms within Tank Farms, i.e., SY/SX farms are enclosed by one fence; therefore, this would be a tank farm enclosure. Some soil containers might not fit this criterion. These containers will be placed in the waste type 'SPECIAL CASE'. (Basis - soils might require overpacking to prepare the container for long-term storage. This decision will be based on the relative corrosion observed during the confirmation process. In addition, this material may not follow the same confirmation process. Current RTR equipment has been deemed ineffective as a physical confirmation tool for soils; therefore, a cursory visual inspection will be necessary to confirm the contents of the container.)

Soft debris--Waste packages containing greater than 50 percent soft debris, less than 35 percent asbestos, and, do not meet the criteria of the previously mentioned waste types will be placed in a lot. (For purposes of determining waste category, the soils and asbestos in waste packages with less than 25 percent soils and less than 35 percent asbestos will be categorized as soft debris.) This lot will be further subdivided into batches by farms within Tank Farms, i.e., SY/SX farms are enclosed by one fence; therefore, this would be a tank farm enclosure. Some containers might not fit this criterion. These containers will be placed in the waste type 'SPECIAL CASE'. [Basis - soft debris primarily is step-off pad waste that might contain incidental contact waste (incidental contact waste is waste that might have minor or secondary contamination). No identifiable reason exists to further segregate the material because of the low probability of the waste to contain vastly different concentrations of contaminants.]

Hard debris--Waste packages containing greater than 51 percent hard debris, less than 35 percent asbestos, and does not meet the criteria of the previously mentioned waste types will be placed in a lot. This lot wi11 be further subdivided into batches by Tank Farms, i.e., SY/SX farms are enclosed by one fence; therefore, this would be a tank farm enclosure. Some containers might not fit this criterion. These 
containers will be placed in the waste type 'SPECIAL. CASE'. Process equipment that has come in direct contact with waste stored in a specific tank will be placed in the SPECIAL CASE waste type. [Basis - hard debris primarily is 'tank farm cleanup' waste (such as fencing, pallets, etc.) that might contain incidental contact waste. No identifiable reason exists to further segregate the material because of the low probability of the waste to contain vastly different concentrations of contaminants. Also, a representative sample cannot be taken from this material for chemical testing. Therefore, the designation of this material will be made solely from the process knowledge obtained during the soil and soft. debris testing.]

Asbestos--Waste packages containing greater than 35 percent asbestos and none of the criteria of the previousiy mentioned waste types will be placed into two lots: asbestos-containing soft debris and asbestoscontaining hard debris. These lots will be further subdivided into batches by Tank Farms, i.e., SY/SX farms are enclosed by one fence; therefore, this would be a tank farm enclosure. Some containers might not fit this criterion. These containers will be placed in the waste type 'SPECIAL CASE'. Process equipment that has come in direct contact with waste stored in a specific tank will be placed in the 'SPECIAL CASE' waste type. (Basis - waste packages containing large volumes of asbestos have an increased probability of containing small quantities of condensate because of the required packaging protocol for asbestos. Therefore, these containers could require additional packaging in preparation for long-term storage.

Low-level waste--Waste packages containing only low-level waste will be placed in a lot. (Basis - the material has been designated as containing no designated constituents; therefore, no reason exists to believe that this waste will require special handling other than that mentioned previously for hard debris, i.e., chemical sampling will not be performed. However, chemical sampling will be performed on that portion of the waste that is not hard debris.)

Special case--Waste packages that match the above criteria, based on knowledge provided in operational documentation, will be placed in a lot. These containers are to be batched in accordance with the information provided, i.e., process equipment from a specific tank, identified chemical spill, etc. (Basis - the material is not reflected in containers of another batch; therefore, these small miscellaneous waste streams will be processed on a case-by-case basis.)

\subsection{ASSIGNING SORTING NUMBERS TO LOTS/BATCHES}

After the preliminary sorting has been completed, each lot/batch will be issued a unique 10-digit sorting number for tracking purposes. A preliminary number will be completed for each container before the start of confirmation. The first step in assigning the sorting number is to assign each container a lot and batch, if applicable, based on the previously discussed protocol and Table Al. 
The format of the sort number is: $x x x-x x x-x x$. The first set, $x x x$, represents the Lot. The second set, $X X X$, represent the Batch (if applicable). The third set, $X X$, represents the confirmation level assigned from reviewing all the available preliminary information. Table Al lists the preliminary

lots/batches.

Additional batches might be required based on further waste characteristics. These batches will be noted by replacing the 0 in the batch portion of the number. For example, Corrosive Flammable Aerosols would be identified as ARO-FLC-XX and Corrosive Flammable Hazardous Liquids would be identified as HLO-FLC-XX.

\subsection{VERIFICATION OF SORTING}

After the preliminary sorting is complete, Tank Farms will search all field information sources to ensure that the waste containers are sorted correctly. At this time, containers could be reassigned to other lots/batches.

\subsection{RESORTING}

Some resorting of the waste might be necessary as new process information is discovered. This resorting might be done based on information found during the documentation assessment and confirmation stages. The letter $R$ (for resorting) will be assigned to the container using the numbers from Table $A 1$.

EXAMPLE: HFO-EXO-02 must be resorted, therefore the number will change to HFR-EXO-02. The $R$ will be placed in the last available space of the Lot number.

In addition to the $R$ being added to the sorting number, a resorting justification will be submitted by Tank Farms with concurrence by the CWC (Figure Al). If any sorting number is changed, the sorting number will be documented in SWITS and a letter of justification will be placed in the Tank Farms container file.

\subsection{RECORDKEEPING}

Tank Farms will create a 'living document' containing the lots/batches of all containers within a lot/batch, and containers identified on the list that is scheduled for physical and chemical confirmation.

A valid copy of the living document must, at a minimum, be available for CWC, Tank Farms, T Plant, and SWITS data entry personnel as applicable. The process for changing the living document is described in Section 2.4. A11 changes must be expeditiously routed by Tank Farms to the CWC, T Plant, and 52 SWITS data entry personnel as applicable. It will be the responsibility of 
1 each organization haviny an official copy of the living document to maintain

2 the document by adding those changes immediately on receipt of changes from

3 Tank Farms. 


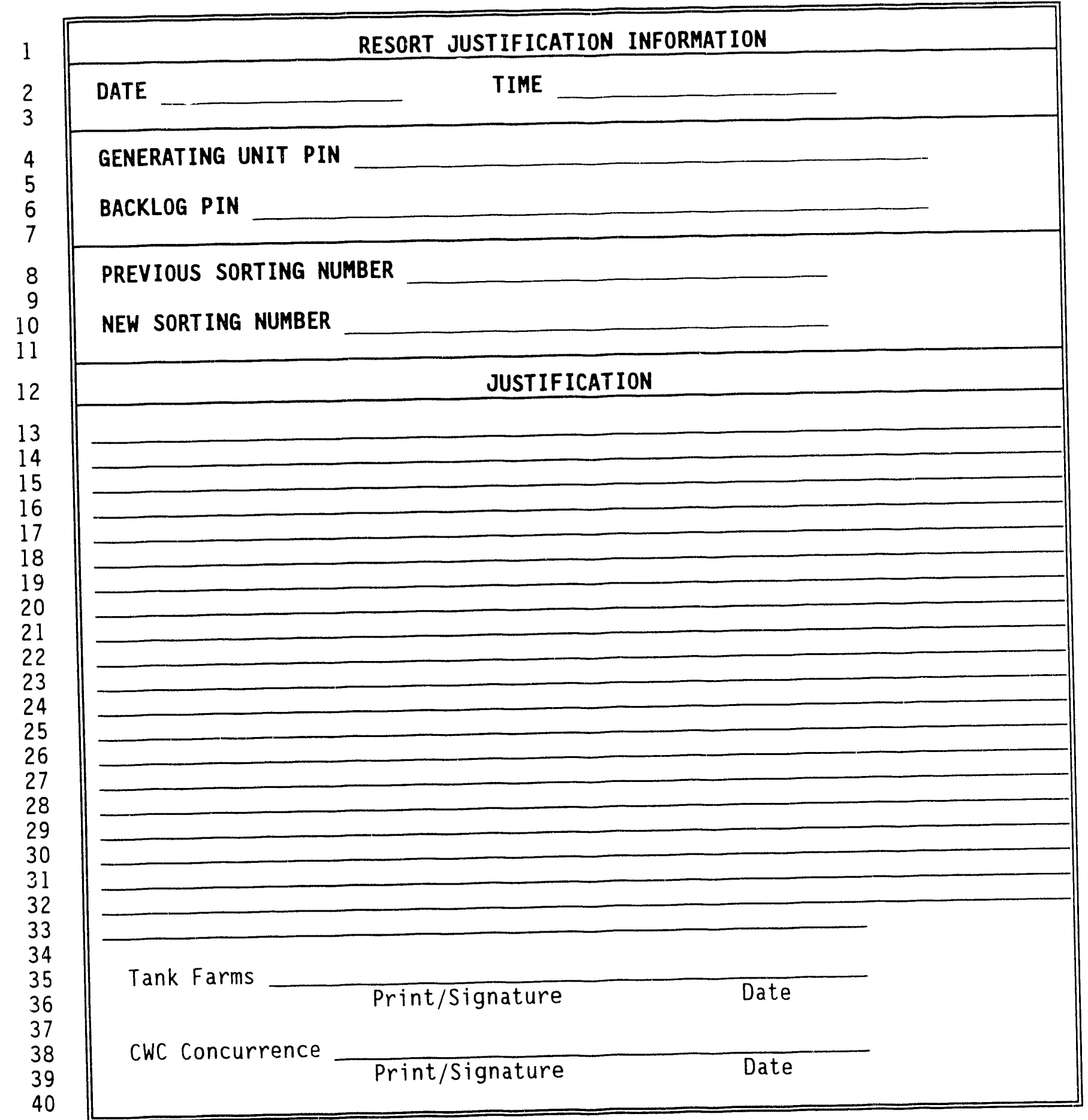

Figure Al. Typical Resort Justification Information. 
Table Al. Initial Backlog Waste Sort Description. (sheet 1 of 2)

\begin{tabular}{|c|c|}
\hline Sorting number & Waste description \\
\hline \multicolumn{2}{|r|}{ AEROSOLS } \\
\hline AOO-FLO-XX & Flammable aerosol cans \\
\hline AOO-NFO-XX & Nonflammable aerosol cans \\
\hline$A O 0-N I O-X X$ & Nonidentified aerosol cans \\
\hline \multicolumn{2}{|r|}{ PAINTS } \\
\hline$P Q 0-000-X X$ & Liquid non-1atex paint \\
\hline$P D 0-000-X X$ & Non-latex paint contaminated debris \\
\hline \multicolumn{2}{|r|}{ ACIDS } \\
\hline$A Q 0-000-X X$ & Liquid acid \\
\hline$A D 0-000-X X$ & Acid contaminated debris \\
\hline \multicolumn{2}{|r|}{ HAZARDOUS LIQUIDS } \\
\hline HOO-ORO-XX & $\begin{array}{l}\text { Hazardous } 1 \text { iquids regulated only for other regulated } \\
\text { material (ORM-E) (i.e., F-Listed, TCLP) }\end{array}$ \\
\hline HOO-FLO-XX & Flammable liquids \\
\hline HOO-CAO-XX & Caustic liquids \\
\hline HOO-REO-XX & Reactive liquids \\
\hline \multicolumn{2}{|r|}{ OILS } \\
\hline $0 Q 0-000-x x$ & Liquid oiT \\
\hline $000-000-x x$ & $0 i 1$ contaminated debris \\
\hline \multicolumn{2}{|r|}{ FREE LIQUIDS (condensates) } \\
\hline$F C O-000-X X$ & Free 1 iquids condensate \\
\hline \multicolumn{2}{|r|}{ MERCURY } \\
\hline MQO-000-XX & Liquid mercury in containers such as thermometers \\
\hline$M D O-000-X X$ & Mercury contaminated debris \\
\hline \multicolumn{2}{|r|}{ HEPA FILTERS } \\
\hline HFO-EXO-XX & Exhauster type HEPAs \\
\hline HFO-CCO-XX & Chemical cartridge HEPAs \\
\hline HFO-NSO-XX & Nonidentified HEPA cartridges \\
\hline
\end{tabular}


Table A1. Initial Backlog Waste Sort Description. (sheet 2 of 2)

\begin{tabular}{|c|c|}
\hline Sorting number & Waste description \\
\hline \multicolumn{2}{|r|}{ SOILS } \\
\hline SLO-TFC-XX & $\begin{array}{l}\text { Soils from tank farm enclosures. The tank farm } \\
\text { enclosures will be replaced by the enclosure code } \\
\text { to be identified. }\end{array}$ \\
\hline \multicolumn{2}{|r|}{ SOFT DEBRIS } \\
\hline SDO-TFC-XX & $\begin{array}{l}\text { Soft debris from tank farm enclosures. The tank farm } \\
\text { enclosures will be replaced by the enclosure code to } \\
\text { be identified. }\end{array}$ \\
\hline \multicolumn{2}{|r|}{ HARD DEBRIS } \\
\hline HDO-TFC-XX & $\begin{array}{l}\text { Hard debris from tank farm enclosures. The tank farm } \\
\text { enclosures will be replaced by the enclosure code to } \\
\text { be identified. }\end{array}$ \\
\hline \multicolumn{2}{|r|}{ ASBESTOS } \\
\hline ASO-TFC-XX & $\begin{array}{l}\text { Asbestos contaminated soft debris from tank farm } \\
\text { enclosures. The tank farm enclosures will be } \\
\text { replaced by the enclosure code to be identified. }\end{array}$ \\
\hline AHO-TFC-XX & $\begin{array}{l}\text { Asbestos contaminated hard debris from tank farm } \\
\text { enclosures. The tank farm enclosures will be } \\
\text { replaced by the enclosure code to be identified. }\end{array}$ \\
\hline \multicolumn{2}{|r|}{ LLW } \\
\hline LWO-000-XX & Low-level waste \\
\hline \multicolumn{2}{|r|}{ SPECIAL CASE } \\
\hline$s c 0-Z Z Z-X X$ & $\begin{array}{l}\text { Unique numbers will replace the } Z \text { 's as these containers } \\
\text { are identified. }\end{array}$ \\
\hline
\end{tabular}

HEPA = high-efficiency particulate air.

TCLP = toxicity characteristics leaching procedure. 
$\mathrm{DOE} / \mathrm{RL}-93-70$, Rev. 0 $08 / 31 / 93$

\section{APPENDIX B}

GUIDANCE ON CONFIRMING THE DESIGNATION 


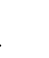

\section{FIGURES}

B1. Typical Lot/Batch Waste Documentation Checklist . . . . . APP B F-1 B2. Lot/Batch Waste Information Worksheet . . . . . . . . APP B F-2

\section{TABLE}

B1. Analytical Testing for Completion of Designation . . . . . APP B T-1 
DOE/RL-93-70, Rev. 0

$08 / 31 / 93$

\subsection{PURPOSE}

This appendix describes the procedure that will be used for confirming the designation of backlog waste. Each lot/batch will be evaluated to determine the completeness of the documentation on which the designation is based. The process used to evaluate the documentation is outlined; the results are used to establish the confirmation protocol for each lot/batch.

The confirmation protocol for each 1ot/batch will be based on the waste type and the level of confidence associated with the documentation for the batch. This appendix specifies the confirmation protocol for all confidence levels associated with a waste stream.

A worksheet documenting the confirmation for each lot/batch will be completed. The results of the confirmation also will be documented on this worksheet.

\subsection{REQUIREMENTS}

This appendix must be followed when completing the confirmation of the backlog waste in accordance with this waste analysis plan.

\subsection{DOCUMENTATION ASSESSMENT}

Each lot/batch of waste defined during the sorting process will be evaluated in accordance $:$ ith the 'Lot/Batch Waste Documentation Checklist' (Figure B1). The BWISs for each lot/batch will be reviewed and compared to information gathered from the Tank Farms container files. The checklist will be completed at the time of the review.

\subsection{TRACKING INFORMATION}

The signature of the evaluator and the date of the evaluation will be completed. A Sorting Number will be given.

\subsection{DOCUMENTED PROCESS KNOWLEDGE}

This section evaluates the quality and completeness of the data provided by Tank Farms. Each question in this section will be answered by assigning a number from 1 to 4 based on the completeness and the reliability of the data.

The overall completeness of the data for each question will be evaluated for the entire lot/batch. 
EXAMPLE: A lot of 20 is being assessed. Only 15 of the containers have certified inventory sheets. A "3" will be assigned because 75 percent of the questions concerning the containers have answers.

Only whole numbers will be assigned. If the overall completeness results in a fraction, the lower number will be assigned to ensure a conservative approach is being taken when assessing the data.

The assigned number is multiplied by the weighting factor to establish a Level of Completeness. This number will be entered in the column titled 'Level of Completeness'. A 'NO' answer recorded on the checklist will result in a zero being placed in the 'Level of Completeness' column. Comments specific to the decision should be noted on the Checklist.

Once each question has been answered, the levels of completeness will be summed and recorded next to the 'Totai Level of Completeness' at the bottom of the column. The 'Total Level of Completeness' will then be compared to the 'Ranking' ranges to establish an overall ranking for process knowledge of the containerized waste.

\subsection{TANK FARMS PERFORMANCE HISTORY}

Tank Farms shipping status, packaging procedures, training qualifications, container management, and container control programs are evaluated by the Solid Waste Disposal organization. No weighting takes place for Section B of the Lot/Batch Waste Documentation Checklist. If the answer is 'YES', all points available are placed in the 'Assigned Ranking' column; if the answer is 'NO', the question is assigned a zero ranking. Any comments pertinent to the decision should be noted.

The individual rankings for each question are summed to arrive at a total ranking for performance history. This number should be placed in the 'Total Ranking for this Section' row.

\subsection{RESORTING}

Information could be obtained by the evaluator during the Documentation Assessment that would cause some of the containers in the lot/batch to be resorted. The Resort Justification Information form (Appendix A) $: i 11$ be completed to document the resort.

\subsection{LOT/BATCH WASTE INFORMATION WORKSHEET}

The 'Lot/Batch Waste Information Worksheet' (Figure. B2) documents the confirmation to be performed on each lot/batch. First, a confidence level is established for each lot/batch. From this confidence level, a confirmation level for the lot/batch is defined. The confirmation protocol is defined for 
each lot/batch and the results of the confirmation are documented on the worksheet.

\subsection{TRACKING INFORMATION}

The signature of the evaluator and the date of the evaluation will be completed. A Sorting Number will be given.

\subsection{LOT/BATCH CONFIDENCE DECISION CHART}

The Rankings determined from the 'Lot/Batch Waste Documentation Checklist' (Figure B1) will be used to establish an overall confidence level in the lot/batch.

The Ranking Factor of 0 to 4 obtained from Documented Process Knowledge (Section A) will be transposed to the appropriate box. Similarly, the Ranking Factor from the Generating Unit Performance History (Section B) will be marked in the appropriate box.

The ranking factor will be multiplied by the weight to establish a confidence level for each criterion. The total confidence level will be obtained by summing the confidence levels for the Documented Process Knowledge and the Generating Unit Performance History.

\subsection{CONFIDENCE/CONF IRMATION LEVEL}

A confirmation level of I, II, or III will be established based on the number obtained for the Confidence Leve1. The appropriate box will be checked.

The lot/batch size will be written down; this number will provide the basis for selecting the appropriate sample size for both the physical and chemical confirmation measures.

\subsection{CONFIRMATION PROTOCOL}

The confirmation protocol will be based on the established protocol for $\varepsilon$ ach waste type. This protocol is given in Appendix C.

The exact sample size will be determined for each lot/batch using the appropriate waste stream table and confidence level. Using the sample size method specified, the sample size will be calculated for both physical and chemical confirmation.

The exact physical and chemical confirmation methods will be specified for the lot/batch. For chemical confirmation, the exact analysis will be specified. The analysis is specified in Table Bl "Analytical Testing for Completion of Designation". This determination will be made by SWAS as out1ined in the waste analysis plan, Section 4.6 . 


\subsection{CONFIRMATION RESULTS}

Confirmation results will be documented on the worksheet. The containers randomly chosen for confirmation will be listed by PIN. The type(s) of confirmation will be listed. If more than one container has the same type of confirmation, the containers should be listed in the same block.

The 'Comments' section will be used to document the PINs that failed and the reason for failure.

\subsection{CONTINGENCY ACTIONS}

For those lots/batches that fail confirmation, the actions that will be required are documented. If resorting is to be done, additional confirmation will be needed, or changes in designation will be performed and the justification will be stated in this section. 


\section{LOT/BATCH WASTE DOCUMENTATION CHECKLIST}

Date:

Evaluator:

Sorting No.:

\section{A. DOCUMENTED PROCESS KNOWLEDGE}

\begin{tabular}{|c|c|c|}
\hline $\begin{array}{c}(Y) \text { OR } \\
(N)\end{array}$ & WEIGHT & $\begin{array}{c}\text { LEVEL OF } \\
\text { COMPLETENESS } \\
\text { (Weight *(1-4)) }\end{array}$ \\
\hline 1 & & \\
\hline & 1 & \\
\hline & 1 & \\
\hline & & \\
\hline & & \\
\hline
\end{tabular}

1. Does an inventory sheet exist and does it accurately support the information and designation supplied on the BWIS?

2. Is the inventory sheet certified with a signature and date?

3. Is specific information related to the waste generating process inat supports the BWIS designation container/referenced in the file?

4. Are analytical results available and do the results support the BWIS designation?

5. Are specific dangerous constituents and percents listed or MSDSs provided in the field file?

6. Is documented process knowledge available for other containers from the same activity?

7. Are analytical results available from other containers from the same activity?

- Is historical designation information available for the general location?

RANKING FOR THIS SECTION $\circ(40-31)=4 ; \circ(30-21)=3$;

$0(21-11)=2 ; 0(11-1)=1 ;$

$00=0$

TOTAL LEVEL OF COMPLETENESS

\begin{tabular}{|c|c|c|c|c|}
\hline $\begin{array}{l}\text { B. GENERATING UNIT PERFORMANCE } \\
\text { HISTORY }\end{array}$ & $\begin{array}{l}(Y) O R \\
(N)\end{array}$ & $\begin{array}{l}\text { MAXIMUM } \\
\text { RANKING } \\
\#\end{array}$ & $\begin{array}{l}\text { ASSIGNED } \\
\text { RANKING \# }\end{array}$ & COMMENTS \\
\hline $\begin{array}{l}\text { 1. Was the generating unit approved by the } \\
\text { oversight and Certification panel? }\end{array}$ & & 1 & & \\
\hline $\begin{array}{l}\text { 2. Were administrative procedures and training } \\
\text { adequate? }\end{array}$ & & 1 & & \\
\hline $\begin{array}{l}\text { 3. Were physical controls in place to manage the } \\
\text { container as the waste was generated? }\end{array}$ & & 1 & & \\
\hline $\begin{array}{l}\text { 4. Were physicat controls in place to manage the } \\
\text { container after the waste was generated? }\end{array}$ & & 1 & & \\
\hline RANKING FOR THIS SECTION & & 4 & & \\
\hline
\end{tabular}

Figure B1. Typical Lot/Batch Waste Documentation Checklist. 


\section{LOT/BATCH WASTE INFORMATION WORKSHEET (Page 1 of 2 )}

DATE:

EVALUATOR:
SORTING \#:

LOT/BATCH CONFIDENCE DECISION CHART

\section{Criteria}

Weight $\begin{gathered}\text { Ranking Factor from } \\ \text { Documentation Checklist }\end{gathered}$

$\frac{1}{1}$

\section{Confidence} Level

Weight * Ranking Factor

DOCUMENTED PROCESS KNOWLEDGE

GENERATING UNIT PERFORMANCE HISTORY

TOTAL - CONFIOENCE LEVEL

\section{CONFIDENCE/CONFIRMATION LEVEL (check one)}
LOT SIZE
O I $(80-100)$
O II $(40-80)$
II I $(0-40)$

CONFIRMATION PROTOCOL

\begin{tabular}{l|l|l} 
Type of Confirmation & Sample Size & \\
\hline Physical $(P)$ & & \\
Chemical $(C)$ & & \\
\hline
\end{tabular}

PINS for SAMPLE LOT (randorily selected)

\begin{tabular}{|c|c|}
\hline $\begin{array}{c}\text { Confirmation } \\
\text { Type }(P-C)\end{array}$ & $\begin{array}{c}\text { Pass/ } \\
\text { Fail }\end{array}$ \\
\hline
\end{tabular}

\section{Measures}

\section{COMMENTS}

(Reason, if failed)

Figure B2. Typical Lot/Batch Waste Information Worksheet. (sheet 1 of 2; 


\section{LOT/BATCH WASTE INFORMATION WORKSHEET (Page 2 of 2 )}

DATE: EVALUATOR:

SORTING \# :

\begin{tabular}{|c|c|c|c|}
\hline $\begin{array}{l}\text { PINs for SAMPLE LOT } \\
\text { (randormly selected) }\end{array}$ & $\begin{array}{c}\text { CONFIRMATION } \\
\begin{array}{c}\text { Confirmation } \\
\text { Type }(P-C)\end{array}\end{array}$ & $\begin{array}{l}\text { RESULTS } \\
\text { PasS/ } \\
\text { Fail }\end{array}$ & $\begin{array}{c}\text { COMMENTS } \\
\text { (Reason, if failed) }\end{array}$ \\
\hline & & & \\
\hline & & & - \\
\hline & & & \\
\hline & & & \\
\hline & & & \\
\hline & & & \\
\hline & & & \\
\hline & & & \\
\hline & & & \\
\hline & & & \\
\hline & & & \\
\hline & & & \\
\hline & & & \\
\hline & & & \\
\hline & & & \\
\hline & 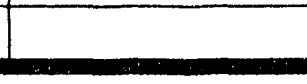 & & 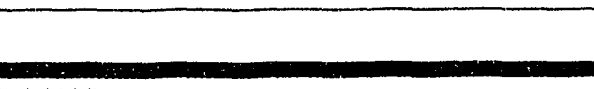 \\
\hline
\end{tabular}

Explain Required Contingency Actions, (If Failed).

Figure B2. Typical Lot/Batch Waste Information Worksheet. (sheet 2 of 2) 
1

2

3

4

5

6

7

9

10

11

12

13

14

15

Table B1. Analytical Testing for Completion of Designation.

\begin{tabular}{|c|c|}
\hline Designation criteria & Analysis and information required \\
\hline Discarded chemical products & Process knowledge \\
\hline Dangerous waste sources & SVOA, VOA and process knowledge \\
\hline Toxicity & $\begin{array}{l}\text { SVOA, VOA, ICP metals, anions, } \\
\text { process knowledge }\end{array}$ \\
\hline Carcinogenic & $\begin{array}{l}\text { SVOA, VOA, ICP metals, anions, } \\
\text { process knowledge }\end{array}$ \\
\hline Persistence & TOX \\
\hline Ignitability & $\begin{array}{l}\text { Flashpoint } \\
\text { Field flammability testing } \\
\text { Field oxidizer testing } \\
\end{array}$ \\
\hline Corrosivity & $\mathrm{pH}$ \\
\hline Reactivity & $\begin{array}{l}\text { Analytical cyanide/sulfide } \\
\text { field reactivity testing }\end{array}$ \\
\hline TCLP & ICP meta1s, SVOA, VOA \\
\hline PCB & PCB; process knowledge \\
\hline
\end{tabular}

NOTE: TCLP will not necessarily be used as a basis for designation. A TCLP analysis could be taken on a percentage of the samples with the primary use of the results being for future treatment and disposal of the waste [i.e., to meet the Land Disposal Restriction Requirements (40 CFR 268)].

SVOA = semivolatile organic analysis.

VOA = volatile organic analysis.

$I C P=$ inductively coupled plasma.

TOX = total organic halogens.

$P C B=$ polychlorinated biphenyls .

TCLP = toxicity characteristics leaching procedure. 
DOE/RL-93-70, Rev. 0 $08 / 31 / 93$

\section{APPENDIX C}

UASTE TYPE SPECIFIC CONFIRMATION PROTOCOL 


\section{APPENDIX C}

\section{CONTENTS}

\section{FIGURES}

C1. Typical Process for Physical Confirmation of Non-Soil Drums................ APP C F-1

C2. Typical Process for Physical Confirmation of Soil Drums and Boxes................. APP C F-2

\section{TABLES}

C1. Aerosols . . . . . . . . APP C T-1

C1. A . . . . . APP C T-2

C2. Paints and Associated Debris ...................... APP T T-3

C3. Acids.................... APP C T-4

C4. Hazardous Liquids................... . . APP C T-5

C5. 0ils . . . . . . . . . . . . . . . . . . . . APP C T-6

C6. Free Liquids . . . . . . . . . . . . . . . . . . APP C T-7

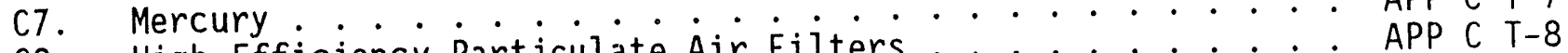

C8. High-Efficiency Particulate Air Filters . . . . . . . . APP C T-9

C9. Soils . . . . . . . . . . . . . . . . . . APP C T-10

C10. 'Soft' Debris.................... . . APP C T-11

C11. 'Hards' Debris . . . . . . . . . . . . . . . . APP C T-12

C12. Asbestos . . . . . . . . . . . . . . . . . . . APP C T-13

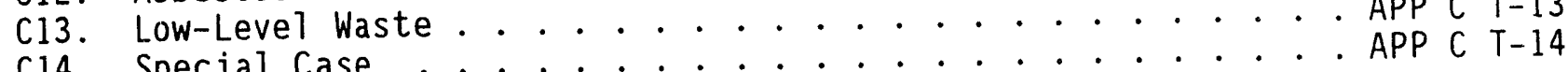

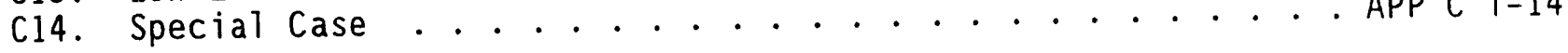


1

2

3

4

5

6

\section{APPENDIX C}

This appendix specifies the confirmation of designation measures, sample size, and error tolerances that will be used for each waste type. Each waste type specifies the measures for all possible confidence levels.

In some cases, exact analytes cannot be specified because the fingerprint of the waste type might vary (i.e., aerosols, paints, etc.). In these cases, a determination will be made in the field as to the most appropriate fingerprint based on process information (e.g., MSDS or container label). Also, 'hards' cannot be sampled because it is not possible to obtain a representative sample. In cases where a crust or film is on the surface of the 'hard', a sample will be taken based on waste characteristics.

The number of containers to be sampled will be based on a percentage of the containers or ASTM D140-70, "Cubed Root" Method [found in EPA Guidance; Waste Analysis Plans, A Guidance Manual, EPA-530-SW-84-012 (EPA 1984)].

Unless otherwise indicated, physical and/or chemical confirmations are based on SW-846 methods. 
DOE/RL-93-70, Rev. 0

$08 / 31 / 93$

This page intentionally left blank. 


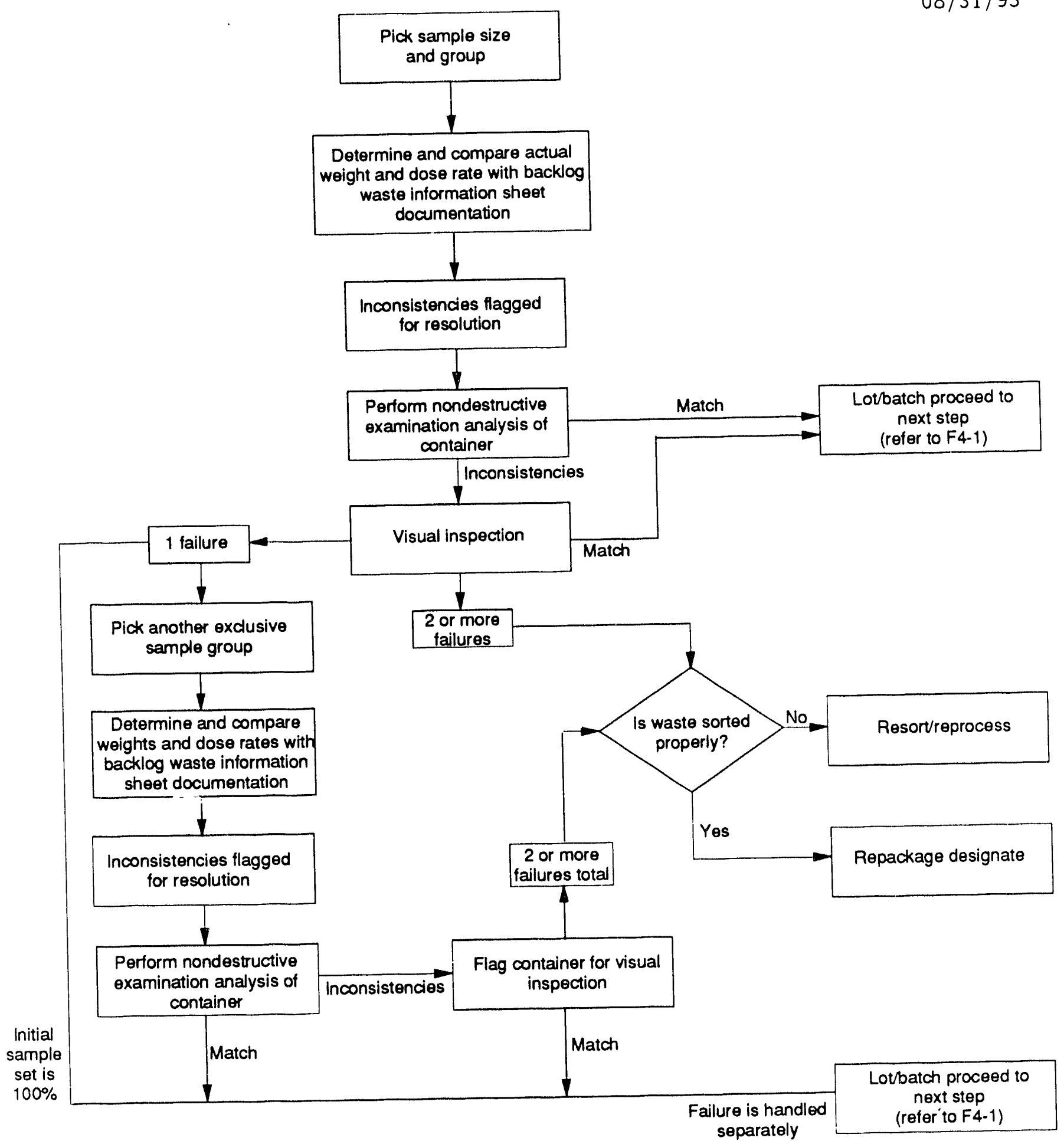

Figure C1. Typical Process for Physical Confirmation of Non-Soil Drums. 


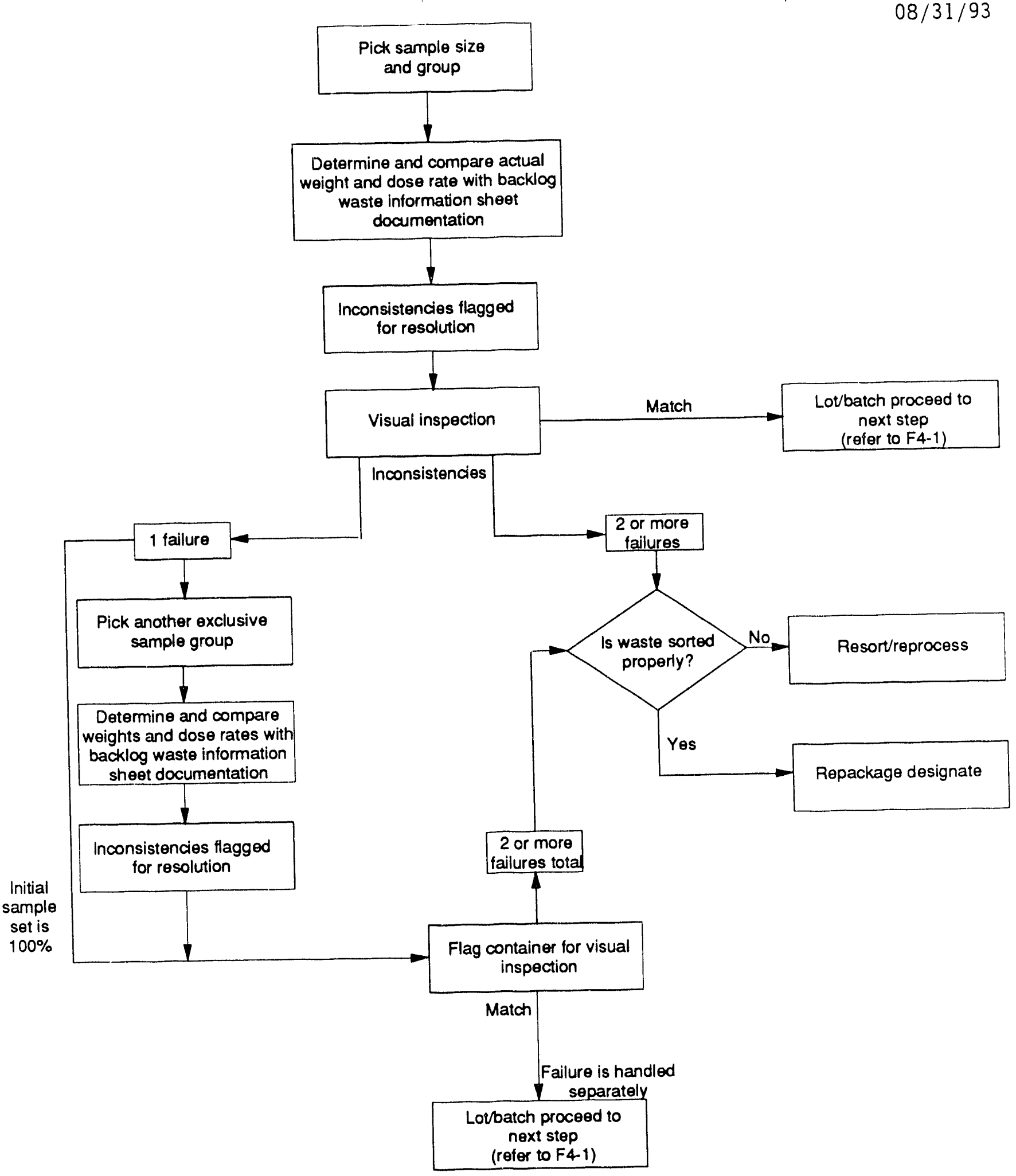

Figure C2. Typical Process for Physical Confirmation of Soil Drums and Boxes. 
Table C1. Aerosols.

\begin{tabular}{|c|c|c|}
\hline METHOD & SAMPLE SIZE & ERROR TOLERANCE \\
\hline \multicolumn{3}{|c|}{ CONF IRMATION LEVEL I } \\
\hline \multicolumn{3}{|c|}{ Physical Confirmation } \\
\hline $\begin{array}{l}\text { In accordance with } \\
\text { Figures } \mathrm{C} 1 \text { and } \mathrm{C} 2 \text {. }\end{array}$ & Cubed root method & 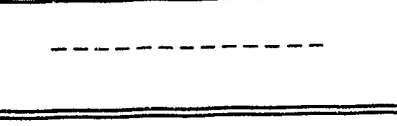 \\
\hline \multicolumn{3}{|c|}{ CONFIRMATION LEVEL II } \\
\hline \multicolumn{3}{|c|}{ Physical Confirmation } \\
\hline $\begin{array}{l}\text { In accordance with } \\
\text { Figures } \mathrm{C} 1 \text { and } \mathrm{C} 2 \text {. }\end{array}$ & Cubed root method & $\cdots-\cdots-\cdots$ \\
\hline \multicolumn{3}{|l|}{ Chemical Confirmation } \\
\hline Field fingerprint analysis & Cubed root method & $\begin{array}{l}\text { Qualitative } \\
\text { confirmation } \\
\text { testing; } 10 \% \text { of } \\
\text { field analysis } \\
\text { will be confirmed } \\
\text { by analytical } \\
\text { testing } \\
\end{array}$ \\
\hline $\begin{array}{l}\text { Analytical fingerprint } \\
\text { analysis }\end{array}$ & $\begin{array}{l}10 \% \text { of cubed root } \\
\text { method }\end{array}$ & $\pm 20 \%$ \\
\hline \multicolumn{3}{|c|}{ CONFIRMATION LEVEL III } \\
\hline \multicolumn{3}{|c|}{ Physical Confirmation } \\
\hline $\begin{array}{l}\text { In accordance with } \\
\text { Figures } \mathrm{C} 1 \text { and } \mathrm{C} 2 \text {. }\end{array}$ & $50 \%$ & - - - - - - - - - \\
\hline \multicolumn{3}{|l|}{ Chemical Confirmation } \\
\hline Field fingerprint analysis & Cubed root method & $\begin{array}{l}\text { Qualitative } \\
\text { confirmation } \\
\text { testing; 10\% of } \\
\text { field analysis } \\
\text { will be confirmed } \\
\text { by analytical } \\
\text { testing }\end{array}$ \\
\hline $\begin{array}{l}\text { Analytical fingerprint } \\
\text { analysis }\end{array}$ & $\begin{array}{l}10 \% \text { of cubed root } \\
\text { method }\end{array}$ & $\pm 20 \%$ \\
\hline
\end{tabular}


Table C2. Paints and Associated Debris.

\begin{tabular}{|c|c|c|}
\hline METHOD & SAMPLE SIZE & ERROR TOLERANCE \\
\hline \multicolumn{3}{|c|}{ CONF IRMATION LEVEL I } \\
\hline \multicolumn{3}{|c|}{ Physical Confirmation } \\
\hline $\begin{array}{l}\text { In accordance with } \\
\text { Figures } \mathrm{C} 1 \text { and } \mathrm{C} 2 \text {. } \\
\end{array}$ & Cubed root method & $-------\cdots$ \\
\hline \multicolumn{3}{|c|}{ CONFIRMATION LEVEL II } \\
\hline \multicolumn{3}{|l|}{ Physical Confirmation } \\
\hline $\begin{array}{l}\text { In accordance with } \\
\text { Figures } \mathrm{Cl} \text { and } \mathrm{C} 2 \text {. }\end{array}$ & Cubed root method & --------- \\
\hline \multicolumn{3}{|l|}{ Chemical Confirmation } \\
\hline Field fingerprint analysis & Cubed root method & $\begin{array}{l}\text { Qualitative } \\
\text { confirmation } \\
\text { tasting, } 10 \% \text { of } \\
\text { field analysis } \\
\text { will be confirmed } \\
\text { by analytical } \\
\text { testing }\end{array}$ \\
\hline $\begin{array}{l}\text { Analytical fingerprint } \\
\text { analysis } \\
\end{array}$ & $\begin{array}{l}10 \% \text { of rubed root } \\
\text { method }\end{array}$ & $\pm 20 \%$ \\
\hline \multicolumn{3}{|c|}{ CONFIRMATION LEVEL III } \\
\hline \multicolumn{3}{|c|}{ Physical Confirmation } \\
\hline $\begin{array}{l}\text { In accordance with } \\
\text { Figures } \mathrm{Cl} \text { and } \mathrm{C} 2 \text {. }\end{array}$ & $50 \%$ & - - \\
\hline \multicolumn{3}{|l|}{ Chemical Confirmation } \\
\hline Field fingerprint analysis & Cubed root method & $\begin{array}{l}\text { Qualitative } \\
\text { confirmation } \\
\text { testing; } 10 \% \text { of } \\
\text { field analysis } \\
\text { will be confirmed } \\
\text { by analytical } \\
\text { testing }\end{array}$ \\
\hline $\begin{array}{l}\text { Analytical fingerprint } \\
\text { analysis }\end{array}$ & $\begin{array}{l}10 \% \text { of Cubed Root } \\
\text { Method }\end{array}$ & $\pm 20 \%$ \\
\hline
\end{tabular}


Table C3. Acids.

CONFIRMATION LEVEL I

Physical Confirmation

Figures $\mathrm{Cl}$ and $\mathrm{C} 2$.
In accordance with

Cubed root method

CONFIRMATION LEVEL II

\section{Physical Confirmation}

In accordance with

Fiqures $\mathrm{C} 1$ and $\mathrm{C} 2$.

Cubed root method

Chemical Confirmation

Field pH (WAC 173-303)

Anions (field testing)

$10 \%$ laboratory inorganic anions

$10 \%$ of cubed root method $\pm 2$

Qualitative test;

$10 \%$ sent to the

laboratory for

analytical

analysis.

$\pm 20 \%$

CONFIRMATION LEVEL III

\section{Physical Confirmation}

In accordance with

Figures $\mathrm{C} 1$ and $\mathrm{C} 2$.

Chemical Confirmation

Field $\mathrm{pH}$ (WAC 173-303)

Anions (Field testing)

$10 \%$ laboratory inorganic anions
$50 \%$

Cubed root method

$10 \%$ of cubed root method $\pm 2$

Qualitative test.

$10 \%$ sent to the

laboratory for

analytical

analysis.

$\pm 20 \%$ 
Table C4. Hazardous Liquids.

\begin{tabular}{|c|c|c|}
\hline METHOD & SAMPLE SIZE & ERROR TOLERANCE \\
\hline \multicolumn{3}{|c|}{ CONFIRMATION LEVEL I } \\
\hline \multicolumn{3}{|c|}{ Physical Confirmation } \\
\hline $\begin{array}{l}\text { In accordance with } \\
\text { Figures } \mathrm{C} 1 \text { and } \mathrm{C} 2 \text {. }\end{array}$ & Cubed root method & $-\cdots------$ \\
\hline \multicolumn{3}{|c|}{ CONFIRMATION LEVEL II } \\
\hline \multicolumn{3}{|c|}{ Physical Confirmation } \\
\hline $\begin{array}{l}\text { In accordance with } \\
\text { Figures } \mathrm{C} 1 \text { and } \mathrm{C} 2 \text {. }\end{array}$ & Cubed root method & -...- \\
\hline \multicolumn{3}{|c|}{ Chemical Confirmation } \\
\hline Field $\mathrm{pH}$ (WAC 173-303) & \multirow[t]{2}{*}{ Cubed root method } & \pm 2 \\
\hline $\begin{array}{l}\text { Fingerprint analysis as } \\
\text { determined by field } \\
\text { screening }\end{array}$ & & $\begin{array}{l}\text { Qualitative test; } \\
10 \% \text { sent to the } \\
\text { iaboratory for } \\
\text { analytical } \\
\text { analysis. }\end{array}$ \\
\hline \multicolumn{3}{|c|}{ CONFIRMATION LEVEL III } \\
\hline \multicolumn{3}{|c|}{ Physical Confirmation } \\
\hline $\begin{array}{l}\text { In accordance with } \\
\text { Figures } \mathrm{Cl} \text { and } \mathrm{C} 2 \text {. }\end{array}$ & $50 \%$ & - - - - - - - - - \\
\hline \multicolumn{3}{|c|}{ Chemical Confirmation } \\
\hline Field pH (WAC 173-303) & \multirow[t]{2}{*}{ Cubed root method } & \pm 2 \\
\hline $\begin{array}{l}\text { Fingerprint analysis as } \\
\text { determined by field } \\
\text { screening. }\end{array}$ & & $\pm 20 \%$ \\
\hline
\end{tabular}


Table C5. 0ils.

\begin{tabular}{|c|c|c|}
\hline METHOD & SAMPLE SIZE & ERROR TOLERANCE \\
\hline \multicolumn{3}{|c|}{ CONFIRMATION LEVEL I } \\
\hline \multicolumn{3}{|c|}{ Physical Confirmation } \\
\hline $\begin{array}{l}\text { In accordance with } \\
\text { Figures } \mathrm{Cl} \text { and } \mathrm{C} 2 \text {. }\end{array}$ & Cubed root method & 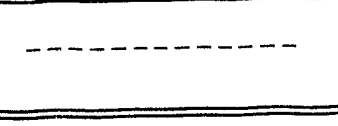 \\
\hline \multicolumn{3}{|c|}{ CONFIRMATION LEVEL II } \\
\hline \multicolumn{3}{|c|}{ Physical Confirmation } \\
\hline $\begin{array}{l}\text { In accordance with } \\
\text { Figures } \mathrm{C} 1 \text { and } \mathrm{C} 2 \text {. }\end{array}$ & $50 \%$ & - n-n- \\
\hline \multicolumn{3}{|c|}{ Chemical Confirmation } \\
\hline Total ICP metals $(6010)$ & \multirow[t]{3}{*}{ Cubed root method } & $\pm 20 \%$ \\
\hline TOX & & $\pm 20 \%$ \\
\hline PCB & & $\pm 20 \%$ \\
\hline \multicolumn{3}{|c|}{ CONFIRMATION LEVEL III } \\
\hline \multicolumn{3}{|c|}{ Physical Confirmation } \\
\hline $\begin{array}{l}\text { In accordance with } \\
\text { Figures } \mathrm{Cl} \text { and } \mathrm{C} 2 \text {. }\end{array}$ & $100 \%$ & ---------- \\
\hline \multicolumn{3}{|c|}{ Chemical Confirmation } \\
\hline Total ICP metals $(6010)$ & \multirow[t]{3}{*}{ Cubed root method } & $\pm 20 \%$ \\
\hline TOX & & $\pm 20 \%$ \\
\hline PCB & & $\pm 20 \%$ \\
\hline
\end{tabular}


Table C6. Free Liquids.

\begin{tabular}{|c|c|c|}
\hline METHOD & SAMPLE SIZE & ERROR TOLERANCE \\
\hline \multicolumn{3}{|c|}{ CONFIRMATION LEVEL I } \\
\hline \multicolumn{3}{|c|}{ Physical Confirmation } \\
\hline $\begin{array}{l}\text { In accordance with } \\
\text { Figures } \mathrm{Cl} \text { and } \mathrm{C} 2 \text {. }\end{array}$ & Cubed root method & $-\cdots---\cdots$ \\
\hline \multicolumn{3}{|c|}{ CONFIRMATION LEVEL II } \\
\hline \multicolumn{3}{|c|}{ Physical Confirmation } \\
\hline $\begin{array}{l}\text { In accordance with } \\
\text { Figures } \mathrm{C} 1 \text { and } \mathrm{C} 2 \text {. }\end{array}$ & Cubed root method & $-\cdots--\cdots-\cdots$ \\
\hline \multicolumn{3}{|c|}{ Chemical Confirmation } \\
\hline Field pH (WAC 173-303) & \multirow[t]{2}{*}{ Cubed root method } & \pm 2 \\
\hline $\begin{array}{l}\text { Fingerprint analysis as } \\
\text { determined by field } \\
\text { screening }\end{array}$ & & $\begin{array}{l}\text { Qualitative test; } \\
10 \% \text { sent to the } \\
\text { laboratory for } \\
\text { analytical } \\
\text { analysis. } \\
\end{array}$ \\
\hline \multicolumn{3}{|c|}{ CONFIRMATION LEVEL III } \\
\hline \multicolumn{3}{|c|}{ Physical Confirmation } \\
\hline $\begin{array}{l}\text { In accordance with } \\
\text { Figures } \mathrm{C} 1 \text { and } \mathrm{C} 2 \text {. }\end{array}$ & $50 \%$ & --------- \\
\hline \multicolumn{3}{|c|}{ Chemical Confirmation } \\
\hline Field $\mathrm{pH}$ (WAC 173-303) & \multirow[t]{2}{*}{ Cubed root method } & \pm 2 \\
\hline $\begin{array}{l}\text { Fingerprint analysis as } \\
\text { determined by field } \\
\text { screening. }\end{array}$ & & $\pm 20 \%$ \\
\hline
\end{tabular}


Table C7. Mercury.

\begin{tabular}{|c|c|c|}
\hline METHOD & SAMPLE SIZE & ERROR TOLERANCE \\
\hline \multicolumn{3}{|c|}{ CONFIRMATION LEVEL I } \\
\hline \multicolumn{3}{|l|}{ Physical Confirmation } \\
\hline $\begin{array}{l}\text { In accordance with } \\
\text { Figures } \mathrm{C} 1 \text { and } \mathrm{C} 2 \text {. }\end{array}$ & Cubed root method & - n- - - - - - \\
\hline \multicolumn{3}{|c|}{ CONFIRMATION LEVEL II } \\
\hline \multicolumn{3}{|c|}{ Physical Confirmation } \\
\hline $\begin{array}{l}\text { In accordance with } \\
\text { Figures } \mathrm{C} 1 \text { and } \mathrm{C} 2 \text {. }\end{array}$ & Cubed root method & 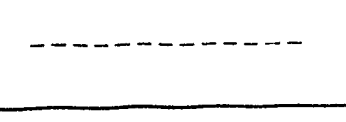 \\
\hline \multicolumn{3}{|c|}{ Chemical Confirmation } \\
\hline ICP metals testing $(6010)$ & \multirow[t]{3}{*}{ Cubed root method } & $\pm 20 \%$ \\
\hline Mercury $(7470,7471)$ & & $\pm 20 \%$ \\
\hline Cyanide/sulfide $(7.33 / 7.34)$ & & $\pm 20 \%$ \\
\hline \multicolumn{3}{|l|}{ CONFIRMATION LEVEL III } \\
\hline \multicolumn{3}{|l|}{ Physical Confirmation } \\
\hline $\begin{array}{l}\text { In accordance with } \\
\text { Figures } \mathrm{C} 1 \text { and } \mathrm{C} 2 \text {. }\end{array}$ & $50 \%$ & $-\cdots-$ \\
\hline \multicolumn{3}{|l|}{ Chemical Confirmation } \\
\hline ICP metals $(6010)$ & \multirow[t]{3}{*}{ Cubed root method } & $\pm 20 \%$ \\
\hline Mercury $(7470,7471)$ & & $\pm 20 \%$ \\
\hline Cyanide/sulfide $(7.33 / 7.34)$ & & $\pm 20 \%$ \\
\hline
\end{tabular}


Table C8. High-Efficiency Particulate Air Filters.

\begin{tabular}{|c|c|c|}
\hline METHOD & SAMPLE SIZE & ERROR TOLERANCE \\
\hline \multicolumn{3}{|c|}{ CONFIRMATION LEVEL I } \\
\hline \multicolumn{3}{|c|}{ Physical Confirmation } \\
\hline $\begin{array}{l}\text { In accordance with } \\
\text { Figures } \mathrm{C} 1 \text { and } \mathrm{C} 2 \text {. }\end{array}$ & Cubed root method & 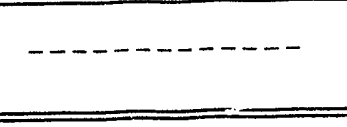 \\
\hline \multicolumn{3}{|c|}{ CONF IRMATION LEVEL II } \\
\hline \multicolumn{3}{|c|}{ Physical Confirmation } \\
\hline $\begin{array}{l}\text { In accordance with } \\
\text { Figures } \mathrm{C} 1 \text { and } \mathrm{C} 2 \text {. }\end{array}$ & $50 \%$ & -------- \\
\hline \multicolumn{3}{|l|}{ Chemical Confirmation } \\
\hline Total ICP metals $(6010)$ & \multirow[t]{3}{*}{ Cubed root method } & $\pm 20 \%$ \\
\hline SVOA $(8250$ or 8270$)$ & & $\pm 20 \%$ \\
\hline VOA $(8240)$ & & $\pm 20 \%$ \\
\hline \multicolumn{3}{|c|}{ CONFIRMATIIN LEVEL III } \\
\hline \multicolumn{3}{|c|}{ Physical Confirmation } \\
\hline $\begin{array}{l}\text { In accordance with } \\
\text { Figures } \mathrm{Cl} \text { and } \mathrm{C2} \text {. }\end{array}$ & $100 \%$ & $-\ldots \ldots-n-\cdots$ \\
\hline \multicolumn{3}{|c|}{ Chemical Confirmation } \\
\hline Total ICP metals $(6010)$ & \multirow[t]{3}{*}{ Cubed root method } & $\pm 20 \%$ \\
\hline SVOA $(8250$ or 8270$)$ & & $\pm 20 \%$ \\
\hline VOA $(8240)$ & & $\pm 20 \%$ \\
\hline
\end{tabular}




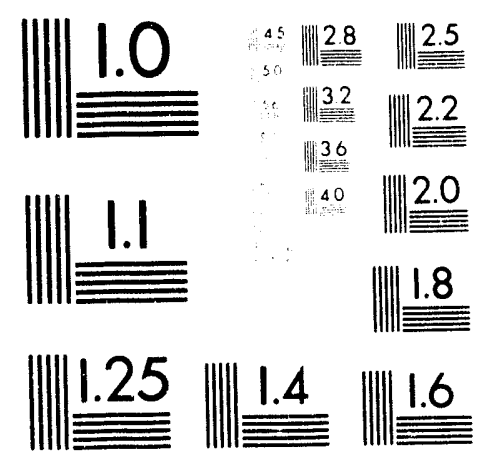



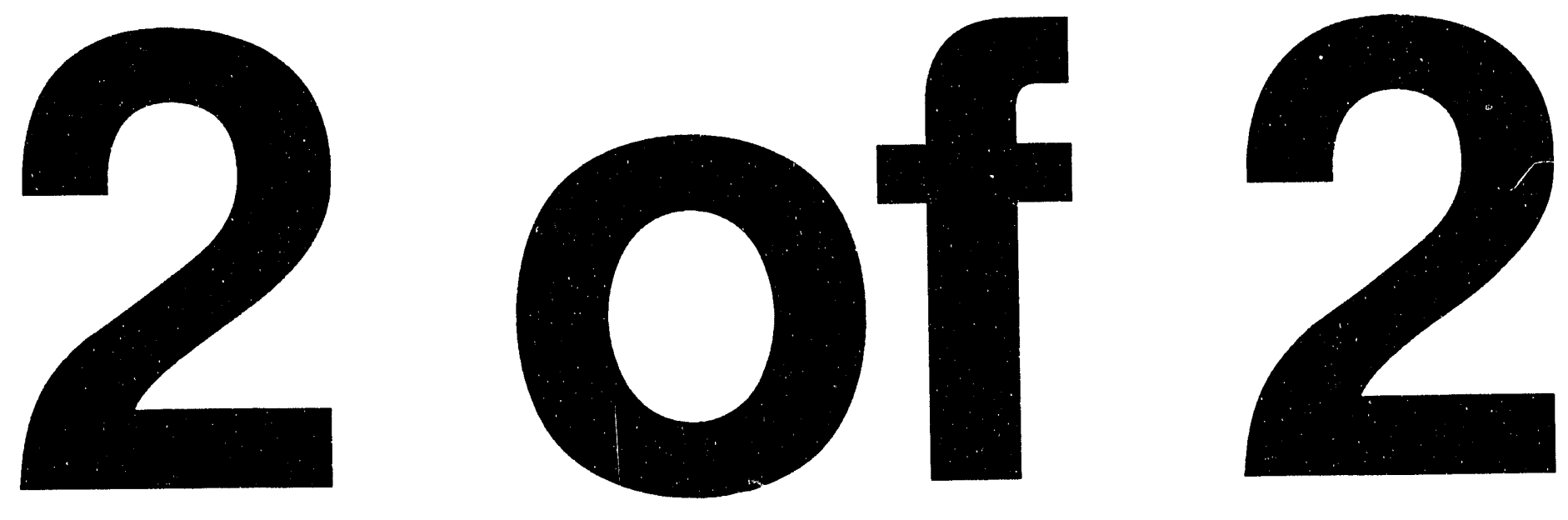
Table C9. Soils.

\begin{tabular}{|c|c|c|}
\hline METHOD & SAMPLE SIZE & ERROR TOLERANCE \\
\hline \multicolumn{3}{|c|}{ CONFIRMATION LEVEL I } \\
\hline \multicolumn{3}{|l|}{ Physical Confirmation } \\
\hline $\begin{array}{l}\text { In accordance with } \\
\text { Figures C1 and } \mathrm{C} 2 \text {. }\end{array}$ & Cubed root method & ---------- \\
\hline \multicolumn{3}{|c|}{ CONFIRMATION LEVEL II } \\
\hline \multicolumn{3}{|c|}{ Physical Confirmation } \\
\hline $\begin{array}{l}\text { In accordance with } \\
\text { Figures } \mathrm{C} 1 \text { and } \mathrm{C} 2 \text {. }\end{array}$ & Cubed root method & $\ldots \ldots-\ldots$ \\
\hline \multicolumn{3}{|l|}{ Chemical Confirmation } \\
\hline Field pH (WAC 173-303) & \multirow[t]{4}{*}{ Cubed root method } & \pm 2 \\
\hline SVOA $(8250$ or 8270$)$ & & $\pm 20 \%$ \\
\hline VOA $(8240)$ & & $\pm 20 \%$ \\
\hline Cyanide/sulfide $(7.33 / 7.34)$ & & $\pm 20 \%$ \\
\hline \multicolumn{3}{|c|}{ CONFIRMATION LEVEL III } \\
\hline \multicolumn{3}{|c|}{ Physical Confirmation } \\
\hline $\begin{array}{l}\text { In accordance with } \\
\text { Figures C.l and C2. }\end{array}$ & $50 \%$ & --- - - - - - - - \\
\hline \multicolumn{3}{|l|}{ Chemical Confirmation } \\
\hline Field $\mathrm{pH}$ (WAC 173-303) & \multirow[t]{4}{*}{ Cubed root method } & \pm 2 \\
\hline SVOA $(8250$ or 8270$)$ & & $\pm 20 \%$ \\
\hline VOA $(8240)$ & & $\pm 20 \%$ \\
\hline Cyanide/sulfide $(7.33 / 7.34)$ & & $\pm 20 \%$ \\
\hline
\end{tabular}


Table C10. 'Soft' Debris.

METHOD

SAMPLE SIZE

ERROR TOLERANCE

CONFIRMATION LEVEL I

Physical Confirmation

In accordance with

Figures $\mathrm{Cl}$ and $\mathrm{C} 2$.

Cubed root method

CONFIRMATION LEVEL II

Physical Confirmation

In accordance with

Figures $\mathrm{Cl}$ and $\mathrm{C} 2$.

$50 \%$

Chemical Confirmation

Field pH (WAC 173-303)

Cubed root method

$\pm 2$

SVOA (8250 or 8270$)$

VOA (8240)

Cyanide/sulfide $(7.33 / 7.34)$

CONFIRMATION LEVEL III

Physical Confirmation

In accordance with

Figures $\mathrm{C} 1$ and $\mathrm{C} 2$.

$100 \%$

Chemical Confirmation

Field pH (WAC 173-303)

Cubed root method

$\pm 2$

Cyanide/sulfide $(7.33 / 7.34)$

SVOA (8250 or 8270$)$

VOA (8240)

.

$\pm 20 \%$

$\pm 20 \%$

$\pm 20 \%$ 
Table C11. 'Hards' Debris.

\begin{tabular}{|c|c|c|}
\hline METHOD & SAMPLE SIZE & ERROR TOLERANCE \\
\hline \multicolumn{3}{|c|}{ CONFIRMATION LEVEL I } \\
\hline \multicolumn{3}{|c|}{ Physical Confirmation } \\
\hline $\begin{array}{l}\text { In accordance with } \\
\text { Figures } \mathrm{Cl} \text { and } \mathrm{C} 2 \text {. }\end{array}$ & Cubed root method & - - - - - - - - - \\
\hline \multicolumn{3}{|c|}{ CONFIRMATION LEVEL II } \\
\hline \multicolumn{3}{|c|}{ Physical Confirmation } \\
\hline $\begin{array}{l}\text { In accordance with } \\
\text { Figures } \mathrm{Cl} \text { and } \mathrm{C} 2 \text {. }\end{array}$ & $50 \%$ & ---------- \\
\hline \multicolumn{3}{|c|}{ CONFIRMATION LEVEL III } \\
\hline \multicolumn{3}{|c|}{ Physical Confirmation } \\
\hline $\begin{array}{l}\text { In accordance with } \\
\text { Figures } \mathrm{Cl} \text { and } \mathrm{C} 2 \text {. }\end{array}$ & $100 \%$ & $-\cdots---\cdots-\cdots$ \\
\hline
\end{tabular}


Table C12. Asbestos.

\begin{tabular}{|c|c|c|}
\hline METHOD & SAMPLE SIZE & ERROR TOLERANCE \\
\hline \multicolumn{3}{|c|}{ CONFIRMATION LEVEL I } \\
\hline \multicolumn{3}{|c|}{ Physical Confirmation } \\
\hline $\begin{array}{l}\text { In accordance with } \\
\text { Figures } \mathrm{Cl} \text { and } \mathrm{C} 2 \text {. }\end{array}$ & Cubed root method & $\ldots \ldots \ldots \ldots$ \\
\hline \multicolumn{3}{|c|}{ CONFIRMATION LEVEL II } \\
\hline \multicolumn{3}{|c|}{ Physical Confirmation } \\
\hline $\begin{array}{l}\text { In accordance with } \\
\text { Figures } \mathrm{Cl} \text { and } \mathrm{C} 2 \text {. }\end{array}$ & $50 \%$ & $-\ldots-1--1--$ \\
\hline \multicolumn{3}{|c|}{ CONFIRMATION LEVEL III } \\
\hline \multicolumn{3}{|c|}{ Physical Confirmation } \\
\hline $\begin{array}{l}\text { In accordance with } \\
\text { Figures } \mathrm{Cl} \text { and } \mathrm{C} 2 \text {. }\end{array}$ & $100 \%$ & - - - - - \\
\hline
\end{tabular}


Table C13. Low-Level Waste.

\begin{tabular}{|c|c|c|}
\hline METHOD & SAMPLE SIZE & ERROR TOLERANCE \\
\hline \multicolumn{3}{|c|}{ CONFIRMATION LEVEL I } \\
\hline \multicolumn{3}{|c|}{ Physical Confirmation } \\
\hline $\begin{array}{l}\text { In accordance with } \\
\text { Figures } \mathrm{Cl} \text { and } \mathrm{C2} \text {. }\end{array}$ & Cubed ruot method & -- \\
\hline \multicolumn{3}{|c|}{ CONF IRMATION LEVEL II } \\
\hline \multicolumn{3}{|c|}{ Physical Confirmation } \\
\hline $\begin{array}{l}\text { In accordance with } \\
\text { Figures } \mathrm{Cl} \text { and } \mathrm{C} 2 \text {. }\end{array}$ & $50 \%$ & $\ldots-$ \\
\hline \multicolumn{3}{|c|}{ CONFIRMATION LEVEL III } \\
\hline \multicolumn{3}{|c|}{ Physical Confirmation } \\
\hline $\begin{array}{l}\text { In accordance with } \\
\text { Figures } \mathrm{Cl} \text { and } \mathrm{C} 2 \text {. }\end{array}$ & $100 \%$ & $\cdots$ \\
\hline
\end{tabular}


Table·C14. Special Case.

\begin{tabular}{|c|c|c|}
\hline METHOD & SAMPLE SIZE & ERROR TOLERANCE \\
\hline \multicolumn{3}{|c|}{ CONFIRMATION LEVEL I } \\
\hline \multicolumn{3}{|c|}{ Physical Confirmation } \\
\hline $\begin{array}{l}\text { In accordance with } \\
\text { Figures } \mathrm{C} 1 \text { and } \mathrm{C} 2 \text {. }\end{array}$ & Cubed root method & $\cdots-\cdots-\cdots$ \\
\hline \multicolumn{3}{|c|}{ CONFIRMATION LEVEL II } \\
\hline \multicolumn{3}{|c|}{ Physical Confirmation } \\
\hline $\begin{array}{l}\text { In accordance with } \\
\text { Figures } \mathrm{C} 1 \text { and } \mathrm{C} 2 \text {. }\end{array}$ & Cubed root method & - - - - - - - - - - \\
\hline \multicolumn{3}{|c|}{ Chemical Confirmation } \\
\hline Field pH (WAC 173-303) & \multirow[t]{2}{*}{ Cubed root method } & \pm 2 \\
\hline $\begin{array}{l}\text { Fingerprint analysis as } \\
\text { determined by field } \\
\text { screening }\end{array}$ & & $\begin{array}{l}\text { Qualitative test; } \\
10 \% \text { sent to the } \\
\text { laboratory for } \\
\text { analytical } \\
\text { analysis. }\end{array}$ \\
\hline \multicolumn{3}{|c|}{ CONFIRMATION LEVEL III } \\
\hline \multicolumn{3}{|c|}{ Physical Confirmation } \\
\hline $\begin{array}{l}\text { In accordance with } \\
\text { Figures C1 and C2. }\end{array}$ & $50 \%$ & $-\cdots-\cdots-\cdots$ \\
\hline \multicolumn{3}{|c|}{ Chemical Confirmation } \\
\hline Field $\mathrm{pH}$ (WAC 173-303) & \multirow[t]{2}{*}{ Cubed root method } & \pm 2 \\
\hline $\begin{array}{l}\text { Fingerprint analysis as } \\
\text { determined by field } \\
\text { screening }\end{array}$ & & $\pm 20 \%$ \\
\hline
\end{tabular}


DOE/RL-93-70, Rev. 0 $08 / 31 / 93$

APPENDIX D

BACKLOG WASTE DESIGNATION GUIDANCE 


\section{CONTENTS}

1.0 PURPOSE $\ldots \ldots \ldots \ldots$ APP D-1

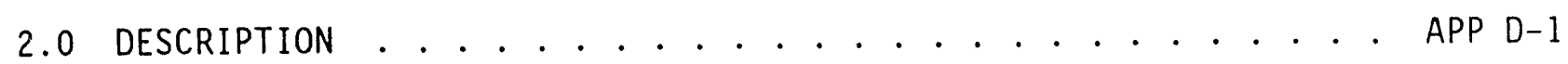

3.0 DEFINITION . . . . . . . . . . . . . . . . . . . APP D-1

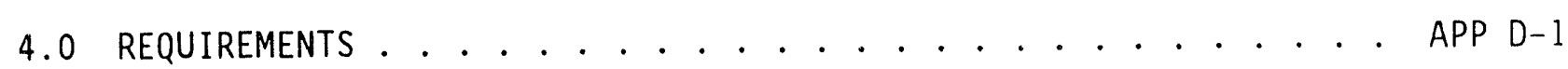

5.0 PROCEDURE . . . . . . . . . . . . . . . . . . . APP D-1

5.1 CHEMICAL COMPOSITION ........................ APP D-1

5.2 DISCARDED CHEMICAL PRODUCTS . . . . . . . . . . APP D-2

5.3 DANGEROUS WASTE SOURCES ....................... APP D-3

5.4 INFECTIOUS DANGEROUS WASTES $\ldots \ldots \ldots$. . . . . . . . . . . . . .

5.5 DANGEROUS WASTE MIXTURES . . . . . . . . . . . . . APP D-3

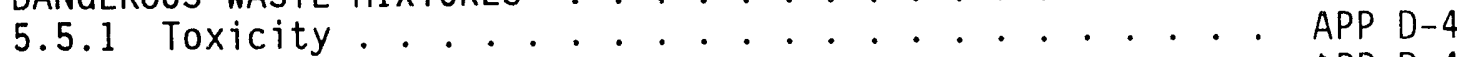

5.5 .2 Persistence ............ . . APP D-4

5.5.3 Carcinogens . . . . . . . . . . . APP D-5

5.6 DANGEROUS WASTE CHARACTERISTICS . . . . . . . . . . APP D-6

5.6 .1 Ignitability. . . . . . . . . . . . APP D-6

5.6 .2 Corrosivity .............. . . APP D-7

5.6 .3 Reactivity............. APP D-7

5.6.4 Toxicity Characteristic . . . . . . . . . . . APP D-8

5.7 POLYCHLORINATED BIPHENYLS . . . . . . . . . . . . . APP D-8

5.8 SUMMARY OF WASTE DESIGNATION PROCEDURE . . . . . . . APP D-9

5.9 SPECIAL CASE WASTES . . . . . . . . . . . . . APP D-9

5.9.1 Alkali Metals . . . . . . . . . APP D-10

5.9 .2 Aerosol Cans. . . . . . . . APP D-10

5.9.3 Fluorescent Light Ballasts . . . . . . . . . APP D-10

5.9.4 Nonregulated Empty Containers . . . . . . APP D-10

35

36

37

38

39

40

41

42

43

D1. Toxicity Characteristic List for Liquids and

Soluble Solids ......................... APP D T-1

\section{TABLE}

46

47 
21

26 27

\subsection{PURPOSE}

This appendix provides basic instructions on how to designate dangerous waste per WAC 173-303-070. This appendix does not contain all of the information necessary to perform designations. To be qualified, a designator must attend and pass a hazardous waste designation class.

\subsection{DESCRIPTION}

This appendix covers the steps necessary to determine confirmation or completion of designation.

\subsection{DEFINITION}

All acronyms and appendix-specific terms are defined in the glossary at the end of this appendix.

\subsection{REQUIREMENTS}

In accordance with this waste analysis plan, this guidance must be followed when designating backlog waste.

Personnel responsible for waste designation will be trained in Waste

Designation, Course No. 035012.

\subsection{PROCEDURE}

The following sections provide instructions on how to determine confirmation or completion of designation on backlog waste.

\subsection{CHEMICAL COMPOSITION}

It will be the responsibility of Tank Farms to provide SWAS with chemical cnaracterization information. This characterization can be as simple as including the MSDS(s) for the chemical(s) that make up the waste matrix or as complicated as performing laboratory analysis on the waste matrix. 
1 The MSDS does not always give adequate information on the chemical composition of the waste. In these cases, the manufacturer of the product should be contacted for more information. The designator should make a reasonable attempt to get a full chemical characterization from the manufacturer or at least, obtain the assurance that the product contains no halogenated hydrocarbons (HH) and polycyclic aromatic hydrocarbons (PAH), IARC carcinogens, or constituents from the EPA TC list (Table D1).

\subsection{DISCARDED CHEMICAL PRODUCTS}

A Discarded Chemical Product is an unused chemical product that is listed in the Discarded Chemical Product List (WAC 173-303-9903) and must be a commercial product or a manufacturing chemical intermediate. The Discarded Chemical Product List is separated into two sections: Moderately Dangerous and Acutely Dangerous Chemical Products. Both sections must be consulted when determining whether or not the chemical is a Discarded Chemical Product.

Each of the listed chemicals has a dangerous waste number in accordance with WAC 173-303-070. These numbers are located on the Discarded Chemical Products List. Designate 'Acutely Hazardous Waste' as AHW. Designate 'Acutely Dangerous Chemical Products' as EHW. Designate 'Moderately Dangerous Chemical Products' as DW.

NOTE: Refer to Glossary. The terms 'Acutely Dangerous' and 'Acutely Hazardous' do not share the same definition.

Discarded Chemical Products include the following.

- Original 'unused' products as received from the manufacturer that contain a listed product as the sole active ingredient. (Trace additives, inert constituents, and water are not considered active ingredients.)

- Any of these products that are of off-specification composition.

- Any container or inner liner that has been used to hold any of these products or off-specification products. If the chemical is an AHW, the container or inner liner will receive a waste number from the list. If the container has been triple-rinsed, this designation roes not apply.

- Any residue, contaminated soil, water, or other debris resulting from the cleanup of a spill of any off-specification product or listed product will receive a waste number from the list.

The designator must consider all mentioned criteria and determine if the waste falls under the criteria. 
2

3

4

5

6

7

8

9

10

11

12

13

14

15

16

17

18

19

20

21

22

23

24

25

26

27

28

29

30

31

32

33

34

35

36

37

38

39

40

41

42

43

44

45

46

\subsection{DANGEROUS WASTE SOURCES}

Dangerous Waste Sources are designated based on the list provided in WAC 173-303-9904. These 'Non-Specific Sources' and 'Specific Sources' describe waste with certain chemical components and/or waste from specific operations.

Dangerous Waste Sources include:

- Wastes 1isted in the WAC 173-303-9904 Tables

- Any mixture of a 'Dangerous Waste Source' with another waste

- Only wastes that are designated as 'Used' by Tank Farms.

If a waste contains one or more of the chemical components in a given source entry, or is produced by a listed process ${ }^{1}$, the waste will be designated Dangerous Waste Source. Dangerous waste numbers provided in WAC 173-303-9904 will be assigned. In general, Dangerous Waste Sources are designated DW. In some cases, however, footnotes on the tables in WAC 173-303-9904 describe special circumstances where these wastes are designated EHW.

The designator must examine the waste components and determine if the waste matrix meets the above criteria.

\subsection{INFECTIOUS DANGEROUS WASTES}

There are no infectious dangerous waste regulations at this time (WAC 173-303-083).

\subsection{DANGEROUS WASTE MIXTURES}

To designate Dangerous Waste Mixtures, the designator will determine if the waste is toxic, persistent, and/or carcinogenic as defined by WAC 173-303-101, 102, and 103. This designation applies to pure chemicals as wel1 as to waste mixtures. Note that additional codes are not required if a designation has been made under Discarded Chemical Products Lists (WAC 173-303-9903).

NOTE: The designator must designate the waste for any further special knowledge that is known concerning the waste and provide CWC with the appropriate information to allow for the proper storage of the waste (i.e., flammable, corrosive, reactive). The designator also must ensure that the waste has been appropriately designated DW or EHW.

${ }^{1}$ A "1isted source" is one that appears in the WAC 173-303-9904 Tables. 


\subsubsection{Toxicity}

To designate for Toxicity, the designator will assign 'Toxic Categories' to the constituents and will calculate the 'Equivalent Concentration' (EC). The designator will compare the EC to the ranges given.

The designator will determine Toxic Categories of $X, A, B, C$, or $D$ ( 1 isted in their order of severity) directly from the 'Registry of Toxic Effects of Chemical Substances' (RTECS), published by the National Institute for Occupational Safety and Health referenced in WAC 173-303-084. To determine the Toxic Cateyory from data, the designator will check each constituent against the Toxic Category Table.

Four toxicity criteria are given in WAC 173-303-084: oral, aquatic, inhalation, and dermal. The designator should be aware that these four criteria are not the only published toxicity parameters. However, these are the only criterid that Ecology uses to regulate for toxicity.

If data are available from more than one source, use orily RTECS to determine the Toxicity Category. If toxicity data are not found in the RTECS, do not assign a Toxic Category to that constituent (e.g., if the MSDS gives the toxicity for the product that is a mixture of several chemicals, use the toxicity noted on the MSDS).

Once the designator establishes toxic categories for all constituents, the designator will calculate the EC using the formula in WAC 173-303-084(5)(b).

For example, a waste of $10 \%$ Category A material, $5 \%$ Category B material.

$15 \%$ Category $D$ material, and $70 \%$ waste (non-toxic) will have the following EC:

$$
E C=10 \% / 10+5 \% / 100+15 \% / 10,000=1.0515
$$

The designator will assign the DW or EHW classifications based only on the EC, as follows:

- If a waste is DW, assign the waste code WT02

- If a waste is EHW assign the waste code WTOl

- If the EC\% $\mathrm{i}$ : below $.001 \%$, the waste is not regulated for toxicity.

$\begin{array}{cl}\text { Equivalent Concentration } & \frac{\text { Designation }}{\text { Not regulated }} \\ <0.001 & \text { DW } \\ 0.001 \text { to } 0.01 & \text { EHW } \\ >0.01 & \end{array}$

\subsubsection{Persistence}

If the waste contains $H H$, or PAH, the designator will evaluate for persistence.

Halogenated hydrocarbons are organic compounds composed of carbon, hydrogen. and any one or more of the halogens: fluorine, chlorine, astatine, bromine, 

2 3

or iodine. Halogenated hydrocarbons may also contain other elements. Other criteria also apply per WAC 173-303-084 (6).

The designator will evaluate the designation of $\mathrm{HH}$ by adding the weight percents of all HH in the waste mixture. The sum will be the 'Total HH Concentration'.

The designator will assign the waste category using the following:

$$
\begin{aligned}
& \frac{W t \% H}{>0.01} \\
& 0.01 \text { to } 1.0 \\
& <1.0
\end{aligned}
$$

\author{
Designation \\ Not Regulated \\ DW \\ EHW
}

The designator will assign EHW HH waste mixtures the dangerous waste number WPOl.

The designator wi11 assign DW HH waste mixtures the dangerous waste number WPO2.

Polycyclic aromatic hydrocarbons are hydrocarbon molecules composed of two or more fused benzene ring structures. Conjugated ('daisy-chain') ring structures are not regulated structures. Only molecules containing four, five, and six fused rings are regulated (WAC 173 303-084).

To evaluate PAH, the designator will add the weight percents of all of the four-, five-, and six-ring PAH in the waste mixture. The sum is the 'Total PAH Concentration' [WAC 173-303-084(4)(b)].

If the waste has a PAH concentration greater than $1.0 \mathrm{wt} \%$, the designator will designate the waste as EHW and use the waste code WP03. For example, a mixture of 5 wt\% pyrene and 95\% acetone is EHW, WPO3. Wastes with 1 ess than $1 \%$ PAH are not regulated for persistence.

\subsubsection{Carcinogens}

The third element of the Dangerous Waste Mixtures evaluation will involve checking the waste for carcinogens [WAC 173-303-084(7)].

The designator will check each constituent of the waste mixture to determine whether the waste is a human or animal sufficient or a limited carcinogen. This information is published by the IARC and available in the RTECS.

The designator will designate waste mixtures as carcinogens as follows.

- When the concentration of any one IARC sufficient carcinogen (human or animal) exceeds $1.0 \mathrm{wc} \%$ of the waste mixture, the mixture will be designated as EHW and assign the dangerous waste code WCOl. 
- When the concentration of any one IARC sufficient carcinogen (human or animal) is $>.01 \mathrm{wt} \%$ of the waste mixture, but $<1.0 \mathrm{wt} \%$, the mixture wi11 be designated as DW and assigned the dangerous waste code WCO2.

- When the total concentration summed for all IARC sufficient and limited carcinogens (human or animal) exceeds $1.0 \mathrm{wt} \%$ of the waste mixture, the mixture will be designated as DW and assigned the dangerous waste code WCO2.

The IARC carcinogenic wastes, labeled carcinogenic solely because of tests involving implantation into test animals, are not regulated as carcinogens. This information can be found in the IARC Monographs on the Evaluation of the Carcinogenic Risk of Chemicals to Humans [WAC 173-303-084(7)(c)]. Some respiratory carcinogens, such as asbestos, are exempt from the dangerous waste regulations as long as these are managed in compliance with the requirements of 10 CFR 61.

\subsection{DANGEROUS WASTE CHARACTERISTICS}

If the waste has not been designated previously as DW or EHW, analysis may be required to determine characteristics. The approved sampling methods are given in WAC 173-303-110. Instructions for checking wastes for the dangerous waste characteristics are provided in the following sections.

\subsubsection{Ignitability}

A waste is ignitable [WAC 173-303-090(5)] if the waste has any of the following properties:

- Liquid (other than an aqueous solution containing less than $24 \%$ alcohol by volume) with a flash point less than $60{ }^{\circ} \mathrm{C}$ according to published or experimental closed cup test data.

- Solid or sludge, under standard conditions of temperature and pressure, capable of causing fire through friction, absorption of moisture or spontaneous chemical changes, and when ignited, burns so vigorously and persistently that it creates a hazard.

NOTE: WAC 173-303-110 specifies the 'Chemical Testing Methods for Complying with the Dangerous Waste Regulations' as the appropriate procedure for ignitability determinations. This document states that the test for ignitable solids is a 'prose test'.

- Ignitable compressed gas as defined in 49 CFR 173.300.

- Oxidizer as defined in 49 CFR 173.151. Oxidizers include nitrates and nitrites in solid form or in solutions of $40 \%$ or greater. 
1 The designator will designate wastes determined to be ignitable as DW and will 2 assign the dangerous waste code D001. Aerosol cans, which have a MSDS that 3 states that the aerosol product is not flammable, will not be designated as a 4 D001. A MSDS that states that the product is flammable or combustible will be 5 regulated as a 0001 with a flash point $<100^{\circ} \mathrm{F}$ for flammable or flash point of $6100^{\circ} \mathrm{F}-140^{\circ} \mathrm{F}$ for combustible.

\subsubsection{Corrosivity}

A waste is corrosive [WAC $173 \div 303-090(6)$ ] if the waste has any of the following properties.

- Aqueous with a pH less than or equal to $2(\leq 2)$, or a $\mathrm{pH}$ greater than or equal to 12.5 ( $\geq 12.5)$ according to accepted Ecology test methods.

- Liquid that corrodes Society of Automotive Engineers (SAE) 1020 steel faster than 0.250 inch per year at a temperature of $130^{\circ} \mathrm{F}$. Rate is determined by an Ecology-approved method.

- Solid or Semi-Solid that has an aqueous phase $\mathrm{pH}$ of $\leq 2$, or a $\mathrm{pH} \geq 12.5$ when it is made into a 50 wt\% mixture with water. Ecology will provide approved test methods.

The designator will designate wastes determined to be Corrosive as DW and will assign the dangerous waste code D002.

\subsubsection{Reactivity}

A waste is Reactive [WAC 173-303-090(7)] if the waste has any of the following properties:

- Is normally unstable and readily undergoes violent change without detonating

- Reacts violently with water or forms potentially explosive mixtures with water

- When mixed with water, generates toxic gasses, vapors or fumes in quantities that present a danger to human health or the environment

- It is a cyanide $(-C N)$ or sulfide $(-S)$ bearing waste that, when exposed to $\mathrm{pH}$ conditions between 2 and 12.5 , can generate toxic gasses, vapors or fumes in amounts sufficient to present a danger to human health or the environment. Numbers provided in $\mathrm{SW}-846$ for evaluating reactivity are 250 milligrams hydrogen cyanide per kilogram of waste and 500 milligrams hydrogen sulfide per kilogram of waste

- Is capable of detonation or explosive reaction if subjected to a strong initiating source or heated under confinement 
- Is readily capable of detonation or explosive decomposition, or reaction at standard temperature and pressure.

- It is a U.S. Department of Transportation Forbidden Explosive, a Class A or Class B Explosive as defined in 49 CFR 173.51, .53 and .88. Examples are as follows:

Nitroglycerin, liquid: $\quad$ Forbidden Explosive (not desensitized)

Black powder (gunpowder): Class A Explosive

Exhibition display fireworks: Class B Explosive

The designator will designate the waste as DW and assign the dangerous waste code D003.

\subsubsection{Toxicity Characteristic}

The TC relates to the concentration of 40 specific chemicals [WAC 173-303-090(8)] that could leach from a solid or 1 iquid waste matrix. These chemicals include heavy metals (lead, chromium, etc.), and certain pesticides and herbicides. Wastes may be DW or EHW depending on the concentration of these chemicals in the leachate.

The TCLP is used to test the solubility and mobility of hazardous components in a buffered aqueous solution. In a 'worst-case' calculation, a solid waste could be assumed to dissolve completely in the buffered extractant, which is always 20 times the mass of the waste sample. For liquids, concentration limits are imposed directly on the waste. Table Dl specifies limiting concentrations that could cause the extract to be designated TC.

The designator will designate the waste and will assign the dangerous waste codes (Table D1). Select dangerous waste numbers from the table, select the waste class (EHW or DW).

\subsection{POLYCHLORINATED BIPHENYLS}

The designator will designate PCBs as follows.

- Not regulated

- Waste contains less than 50 parts per million PCBs

- Waste did not originate from a transformer, capacitor, or source of greater than 50 parts per million PCBs

- Waste is not mixed with a dangerous waste. 
2

- Regulated in Washington State only (W001)

- Waste contains PCBs in a concentration of 2 to 50 parts per million

NOTE: The lower regulatory limit for PCBs may be 2 parts per million. Reference WAC-173-303-071(3)(k)( $i$ i) for more information.

- Waste originated from a transformer or capacitor containing less than 50 parts per million PCBs.

- Regulated under Toxic Substances Control Act (TSCA) of 1976 (PCB2)

- Waste contains greater than 50 parts per million PCBs.

- PCB waste must be managed at it's source concentration. For example, a transformer containing oil with 1,000 parts per million PCBs is drained and flushed with a solvent. Even though the actual $P C B$ concentration in the solvent is 200 parts per million, it must be designated and disposed of as waste containing 1,000 parts per million.

- Waste is not mixed with a dangerous waste.

\subsection{SUMMARY OF WASTE DESIGNATION PROCEDURE}

After the waste designation has been completed, the designator will determine the Waste Class of the waste by reviewing all categories (WAC 173-303). If any of the categories have been designated an AHW, the waste is classed as an AHW. If any of the categories have been designated EHW, the waste is classed EHW. Otherwise, the waste is classed as a DW or not regulated.

\subsection{SPECIAL CASE WASTES}

Some wastes require special management. The following directions will aid in disposing of these wastes. Not all special cases are covered in this section. Whenever there are questions concerning management of an unusual waste, the designator will consult SWAS. The following special case wastes are not discussed in this appendix.

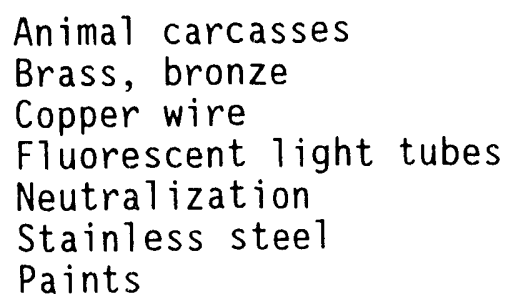

The following sections discuss sampling the most common special case wastes. 


\subsubsection{Alkali Metals}

Solid and semi-solid wastes that contain alkali metals will be designated as D001, D002, and D003 (WAC 173-303-090). Under no circumstances should alkali metals be mixed with water.

\subsubsection{Aerosol Cans}

Empty aerosol cans normally not regulated could be discarded to trash. Any empty aerosol can that held an AHW as the sole ingredient is regulated as if the container were full unless the container was triple-rinsed. Trace ingredients, water, and inert materials will be considered as ingredients.

Aerosol cans that have lost propellent but still contain material (shake the can) will be designated as if the product is there, but the designator will subtract the propellant and adjust the concentrations of remaining constituents. Aerosol cans that are punctured before disposal will be treated in the same manner.

\subsubsection{Fluorescent Light Ballasts}

This section applies to fluorescent light ballasts (or small capacitors) taken out-of-service. Items for collection are ballasts containing PCBS. All unmarked ballasts must be assumed to contain PCBs.

NOTE: PCB ballasts are regulated by TSCA 30-day storage requirements. The disposal of $P C B$-free ballasts will be determined by WAC 173-303 regulations.

\subsubsection{Nonregulated Empty Containers}

For designation, empty containers fall into two categories: Ecology regulated and nonregulated. Certain empty containers that previously held dangerous waste are not regulated by Ecology. These containers contained wastes that are not acutely hazardous, and that are not pesticide containers bearing a danger or warning label. 'Acutely Hazardous' wastes are defined in WAC 173-303-040 and in the Glossary. The following describes the designation of empty containers.

5.9.4.1 Ecology Regulated Containers. Ecology-regulated empty containers are those that contained an 'acutely hazardous' substance when full, and/or pesticide containers that bear a danger or warning label. The containers must have been designated and waste codes assigned, must have an EPA Hazardous Waste sticker, have a unique number when manifested, and be shipped exactly as if the containers were full.

5.9.4.2 Nonregulated Empty Containers. An empty container will not be regulated as follows: 
- It contained a U.S. Department of Transportation-regulated material and has been rinsed and cleaned. These containers must be marked 'Non-regulated, MT, cleaned'. All hazard or warning labels must be removed or obliterated.

- It contained an AHW and has been triple-rinsed per WAC 173-303-160. These containers must not have an EPA Hazardous Waste sticker and must be marked 'Non-regulated, MT, triple rinsed'. Hazard and warning labels must be removed or obliterated.

- It contained materials that were not regulated by U.S. Department of Transportation or Ecology when full. These containers must be labeled 'Non-regul ated, MT.'

- Containers of 5 gallons or less, are empty (MT), did not contain an AHW, are not regulated, and can be disposed of in a landfill.

\subsection{GLOSSARY}

Acutely dangerous waste--Any dangerous waste specifically identified on the WAC 173-303-9903 Discarded Chemical Products List as EHW by the Ecology.

Acutely hazardous waste (AHW)--Some items identified on the Discarded Chemical Products List and some pesticide containers and pesticide waste. Acutely Hazardous Wastes are those with dangerous waste numbers beginning with a ' $P$ ' or those that show an ' $X$ ' or an ' $A$ ' in the Reason for Designation column. Also pesticide containers that bear a 'Danger' or 'harning' 1 abel.

Combustible liquid--Term used in 49 CFR 173.115 for liquids with closed cup flash points at or above $100^{\circ} \mathrm{F}$ and below $200^{\circ} \mathrm{F}$. In WAC 173-303, this term includes material with a flash point $\geq 100^{\circ} \mathrm{F}$ and below $140{ }^{\circ} \mathrm{F}$.

Container--Any portable device in which a material is stored, transported, treated, disposed of, or otherwise handled.

Dangerous waste--The words 'dangerous waste' refer to the full universe of regulated solid wastes designated as either dangerous or extremely hazardous in WAC 173-303-070 through WAC 173-303-103. (Refer to 'DW' and 'EHW.' )

DW (dangerous waste)--The abbreviation 'DW' refers to that part of the solid waste universe that is dangerous waste only, and not EHW.

EHW (extremely hazardous waste)--The abbreviation 'EHW' refers to those dangerous wastes that are extremely hazardous. 
Empty (MT)--Containers that contain no more than $1 \%$ of its capacity if the container can hold under 110 gallons or no more than $0.3 \%$ of its capacity if the container can hold more than 110 gallons. A compressed gas container (aerosol can) is 'empty' when the pressure inside the container equals, or nearly equals, atmospheric pressure.

Equivalent concentration (EC)--Equivalent concentration is a value determined by dividing the concentration of a constituent by it's toxicity value. This value is used to determine the relative toxicity of a waste matrix.

Flammable liquid--Term used in 49 CFR 173.115 for liquids having closed cup flash points below $100^{\circ} \mathrm{F}$.

Generator--Any person, by site, whose act or process produces dangerous waste or whose act first causes a dangerous waste to become subject to regulation. For the purposes of this waste analysis plan, the generator is DOE-RL.

Halogenated hydrocarbon (HH)--An organic chemical compound composed of carbon, hydrogen, and any one or more of the halogens: fluorine, chlorine, bromine, or iodine. Halogenated hydrocarbons also might contain other elements. Other criteria are defined in WAC 173-303-084(6). The compound also might be referred to as halogenated organic compounds (HOC).

Halogenated organic compound (HOC)--Refer to halogenated hydrocarbon.

Hazardous substance--A chemical substance that is 1 isted in the hazardous materials table in 49 CFR 172.101 and exceeds its reportable quantity when packaged in a single container (refer to Reportable Quantity).

Ignitable--Term used in WAC 173-303-090 for a waste that can cause a fire through friction, absorption of moisture, or spontaneous chemical reaction, etc. This term generally applies to oxidizers as defined in 49 CFR 173.151. It also applies to liquids with flash points below $140{ }^{\circ} \mathrm{F}$.

Incompatible waste--A dangerous waste that is unsuitable for placement in a particular device or structure because the waste might corrode or decay the containment materials, or is unsuitable for mixing with another waste or material because the mixture might produce heat or pressure, fire or explosion, violent reaction, toxic dusts, fumes, mists or gases, or flammable fumes or gasses.

Listed product--A chemical product that meets the definition of a Discarded Chemical Product and appears in the Discarded Chemical Product List (WAC 173-303-9903).

Listed source--A waste source that has resulted from a process 1 isted in the Dangerous Waste Source List (WAC 173-303-9904). 
Material safety data sheet (MSDS)--A document that conveys product safety information from the manufacturer to the user.

Persistence--The quality of a material that retains more than half of its initial activity after 1 year (365 days) in either a dark anaerobic or dark aerobic environment of ambient conditions.

Polycyclic aromatic hydrocarbon (PAH)--Hydrocarbon molecules composed of two or more fused benzene ring structures.

Registry of Toxic Effects of Chemical Substances (RTECS)--This document is published by the National Institute for Occupational Safety and Health and provides the toxicity and IARC data used during the designation process.

Reportable quantity (RQ)--This is the quantity of material or waste that if released into the environment must be reported immediately to the National Response Center. Reportable quantities are listed in the hazardous materials table in 49 CFR 172.101 and in 40 CFR 302.4 (refer to Hazardous substance).

Solid waste--Any solid, semi-solid, liquid or contained gaseous material, garbage, refuse, sludge or discarded commodity resulting from industrial, commercial, mining, agricultural, or community operations or activities that is not a primary product of such operations or activities.

Some solid wastes, which are dangerous wastes, are identified in WAC 173-303-016. The reuse, use for energy recovery, reclamation, and speculative accumulation, as well as disposal of some of these wastes, are regulated by Ecology as described in WAC 173-303-016.

Waste generator--Any person, by site, whose act or process produces dangerous waste and whose act first causes a dangerous waste to become subject to regulation (WAC 173-303-040). For purposes of RCRA and WAC 173-303, the Hanford Site is considered to be a single generator comprised of a number of generating units.

Washington Administrative Code (WAC)--Specifically, WAC 173-303 contains all the solid waste regulations for the state of Washington. 
DOE/RL-93-70, Rev. 0

$08 / 31 / 93$

This page intentionally left blank. 
Table D1. Toxicity Characteristic List for Liquids and Soluble Solids. (sheet 1 of 2)

\begin{tabular}{|c|c|c|c|c|c|c|}
\hline \multirow[t]{2}{*}{$\begin{array}{l}\text { Waste } \\
\text { code }\end{array}$} & \multirow[t]{2}{*}{ Constituent } & \multirow[t]{2}{*}{$\begin{array}{l}\text { CAS } \\
\text { no. }\end{array}$} & \multicolumn{2}{|c|}{$\begin{array}{c}\text { Liquid waste } \\
\text { concentration } \\
(\mathrm{mg} / 1)\end{array}$} & \multicolumn{2}{|c|}{$\begin{array}{c}\text { Solid waste } \\
\text { concentration (wt } \%)\end{array}$} \\
\hline & & & DW & EHW & DW & EHW \\
\hline D004 & Arsenic & $7440-38-2$ & $5-500$ & $>500$ & $0.01-1$ & $>1$ \\
\hline 0005 & Barium & $7440-39-3$ & $100-10,000$ & $>10,000$ & $0.2 \cdot 20$ & $>20$ \\
\hline$D 006$ & Cadmium & $7440-43-9$ & $1-100$ & $>100$ & $0.002-0.2$ & $>0.2$ \\
\hline 0007 & Chromium & $7440-47-3$ & $5-500$ & $>500$ & $0.01-1$ & $>1$ \\
\hline D008 & Lead & $7439-92-1$ & $5-500$ & $\geq 500$ & $0.01-1$ & $>1$ \\
\hline 0009 & Mercury & $7439-97-6$ & $0.2-20$ & $>20$ & $0.0004-0.04$ & $>0.04$ \\
\hline 0010 & Selenium & $7782-49-2$ & $1-100$ & $>100$ & $0.002-0.2$ & $>0.2$ \\
\hline D011 & silver & $7440-22-4$ & $5-500$ & $>500$ & $0.01-1$ & $>1$ \\
\hline 0012 & Endrin & $72-20-8$ & $0.02-2$ & $>2$ & $0.00004-0.004$ & $>0.004$ \\
\hline D013 & Lindane & $58-89-9$ & $0.4-40$ & $>40$ & $0.0008-0.08$ & $>0.08$ \\
\hline D014 & Methoxychlor & $72-43-5$ & $10-1,000$ & $>1,000$ & $0.02-2$ & $>2$ \\
\hline D015 & Toxaphene & $8001-35-2$ & $0.5-50$ & $>50$ & $0.001-1$ & $>1$ \\
\hline 0016 & $2,4-0$ & $94-75-7$ & $10-1,000$ & $>1,000$ & $0.02-2$ & $>2$ \\
\hline 0017 & $2,4,5$-TP silvex & $93-72-1$ & $1-100$ & $>100$ & $0.002-0.2$ & $>0.2$ \\
\hline D018 & Benzene & $71-43-2$ & $0.5 \cdot 50$ & $>50$ & $0.001-0.1$ & $>0.1$ \\
\hline 0019 & Carbon Tetrachluride & $56-23-5$ & $0.5-50$ & $>50$ & $0.001-0.1$ & $>0.1$ \\
\hline D020 & Chlordane & $57-74-9$ & $0.03=3$ & $>3$ & $0.00006-0.006$ & $>0.006$ \\
\hline D021 & Chlorobenzene & $108-90-7$ & $100-10,000$ & $>10,000$ & $0.2-20$ & $>20$ \\
\hline 0022 & Chloroform & $67-66-3$ & $6.0-600$ & $>600$ & $0.012-1.2$ & $>1.2$ \\
\hline 0023 & 0-Cresol* & $95-48-7$ & $200-20,000$ & $>20,000$ & $0.4-40$ & $>40$ \\
\hline 0024 & $m$-Cresol* & $108 \cdot 39 \cdot 4$ & $200-20,000$ & $>20,000$ & $0.4-40$ & $>40$ \\
\hline 0025 & p-Cresol* & $106-44-5$ & $200-20,000$ & $>20,000$ & $0.4-40$ & $>40$ \\
\hline$D 026$ & Cresol & $\ldots \ldots \ldots$ & $200-20,000$ & $>20,000$ & $0.4-40$ & $>40$ \\
\hline D027 & 1,4-Dichlorobenzene & $106-46-7$ & $7.5 \cdot 750$ & $>750$ & $0.015-1.5$ & $>1.5$ \\
\hline D028 & 1,2-Dichlorobenzene & $107-06-2$ & $0.5-50$ & $>50$ & $0.001-0.1$ & $>0.1$ \\
\hline
\end{tabular}

31

* If $0-, m-$, and $p$-cresol concentrations cannot be differentiated, the total cresol (D026) is used. 
Table D1. Toxicity Characteristic List for Liquids and Soluble Solids. (sheet 2 of 2)

6

\begin{tabular}{|c|c|c|c|c|c|c|}
\hline \multirow[t]{2}{*}{$\begin{array}{l}\text { Waste } \\
\text { code }\end{array}$} & \multirow[t]{2}{*}{ Constituent } & \multirow[t]{2}{*}{ CAS no. } & \multicolumn{2}{|c|}{$\begin{array}{c}\text { Liquid waste } \\
\text { concentration } \\
(\mathrm{mg} / 1)\end{array}$} & \multicolumn{2}{|c|}{$\begin{array}{c}\text { Solid waste } \\
\text { concentration (wt\%) }\end{array}$} \\
\hline & & & DW & EHW & DW & EHW \\
\hline D029 & $\begin{array}{l}1,1- \\
\text { Dichloroethylene }\end{array}$ & $75-35-4$ & $0.7-70$ & $>70$ & $0.0014-0.14$ & $>0.14$ \\
\hline D030 & 2,4-Dinitrotoluene & $12.1-14-2$ & $0.13-13$ & $>13$ & $0.00026-0.026$ & $>0.026$ \\
\hline D031 & $\begin{array}{l}\text { Heptachlor ( \& its } \\
\text { OH) }\end{array}$ & $76-44-8$ & $0.008-0.8$ & $>0.8$ & $0.000016-0.0016$ & $>0.0016$ \\
\hline D032 & Hexach Lorobenzene & $118-74-1$ & $0.13-13$ & $>13$ & $0.00026-0.026$ & $>0.026$ \\
\hline 0033 & Hexachlorobutadiene & $87-68-3$ & $0.5-50$ & $>50$ & $0.001-0.1$ & $>0.1$ \\
\hline D034 & Hexachloroe thane & $67-72-1$ & $3-300$ & $>300$ & $0.006-0.6$ & $>0.6$ \\
\hline D035 & Methyl ethyl ketone & $78-93-3$ & $200-20,000$ & $>20,000$ & $0.4-40$ & $>40$ \\
\hline D036 & Nitrobenzene & $98-95-3$ & $2-200$ & $>200$ & $0.004-0.4$ & $>0.4$ \\
\hline D037 & Pentachlorophenol & $87-86-5$ & $100-10,000$ & $>10,000$ & $0.2-20$ & $>20$ \\
\hline D038 & Pyridine & $110-86-1$ & $50-500$ & $>500$ & $0.01-1$ & $>1$ \\
\hline D039 & Tetrachloroethylene & $127 \cdot 18-4$ & $0.7-70$ & $>70$ & $0.0014-0.14$ & $>0.14$ \\
\hline D040 & Trichloroethylene & $79-01-6$ & $0.5-50$ & $>50$ & $0.001-0.1$ & $>0.1$ \\
\hline D041 & $\begin{array}{l}2,4,5- \\
\text { Trichlorophenol }\end{array}$ & $95-95-4$ & $400-40,000$ & $>40,000$ & $0.8-80$ & $>80$ \\
\hline D042 & $\begin{array}{l}2,4,6- \\
\text { Trichlorophenol }\end{array}$ & $88-06-2$ & $2-200$ & $>200$ & $0.004-0.4$ & $>0.4$ \\
\hline D043 & Vinyl Chloride & $75-01-4$ & $0.2-20$ & $>20$ & $0.0004-0.04$ & $>0.04$ \\
\hline
\end{tabular}

Conversion:

$1 \mathrm{ppm}=0.0001 \%$

$1,000 \mathrm{ppm}=0.1 \%$

$10 \mathrm{ppm}=0.001 \%$

$100 \mathrm{ppm}=0.01 \%$

$10,000 \mathrm{ppm}=1.0 \%$

$100,000 \mathrm{ppm}=10.0 \%$

CAS no. = Chemical Abstract Service number.

$\mathrm{mg} / 1=$ milligrams per 1iter .

$w t \%=$ weight percent.

DW = dangerous waste.

$\mathrm{EHW}=$ extremely hazardous waste.

ppm = parts per million. 
DOE/RL-93-70, Rev. 0

$08 / 31 / 93$

\section{APPENDIX E}

BACKLOG WASTE REAL-TIME RADIOGRAPHY GUIDANCE 
DOE /RL $-93-70$, Rev. 0

$08 / 31 / 93$

1

2

3

4

5

APPENDIX E

This appendix provides a NDE Confirmation Checklist to be used in RTR of the backlog waste. 


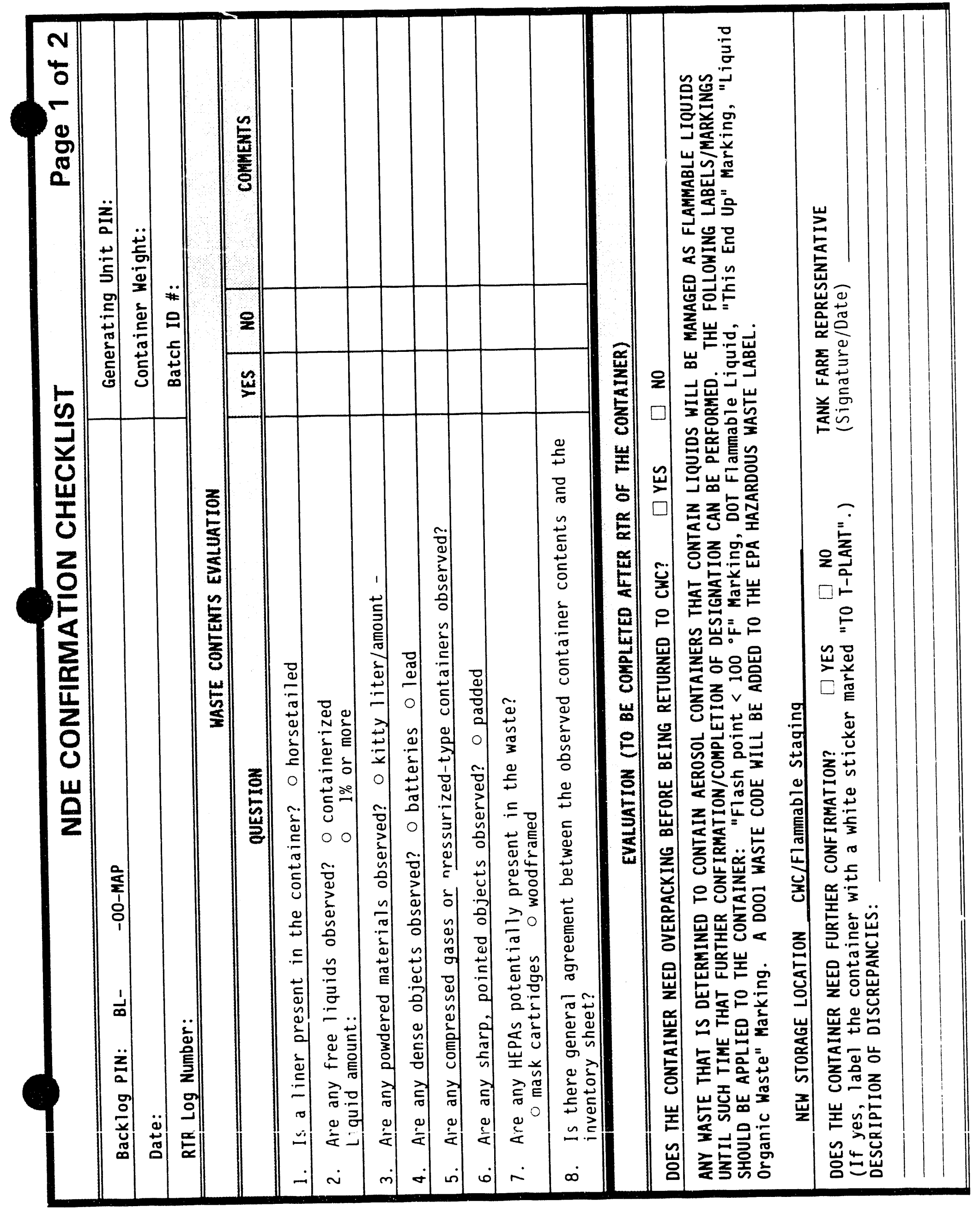




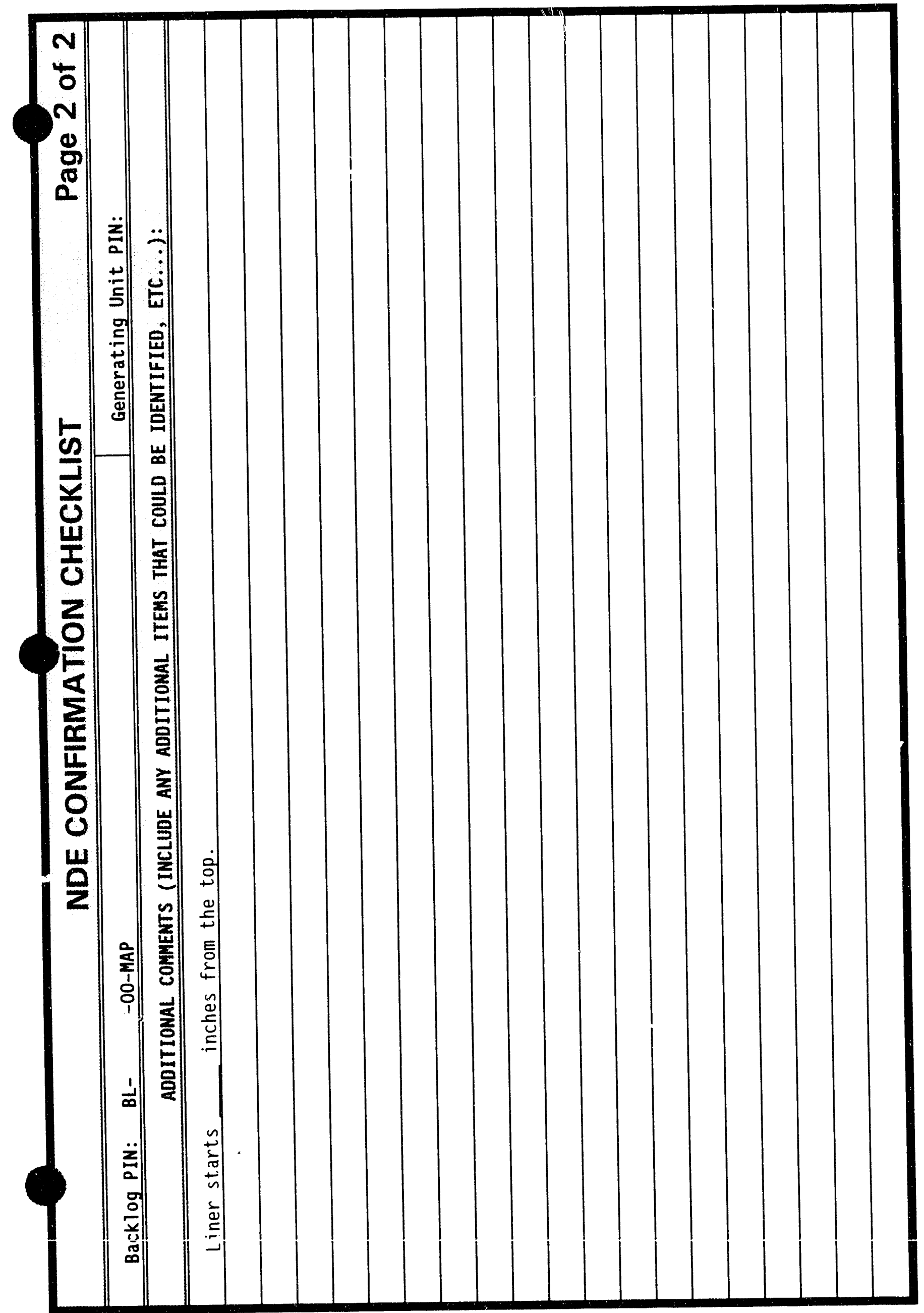



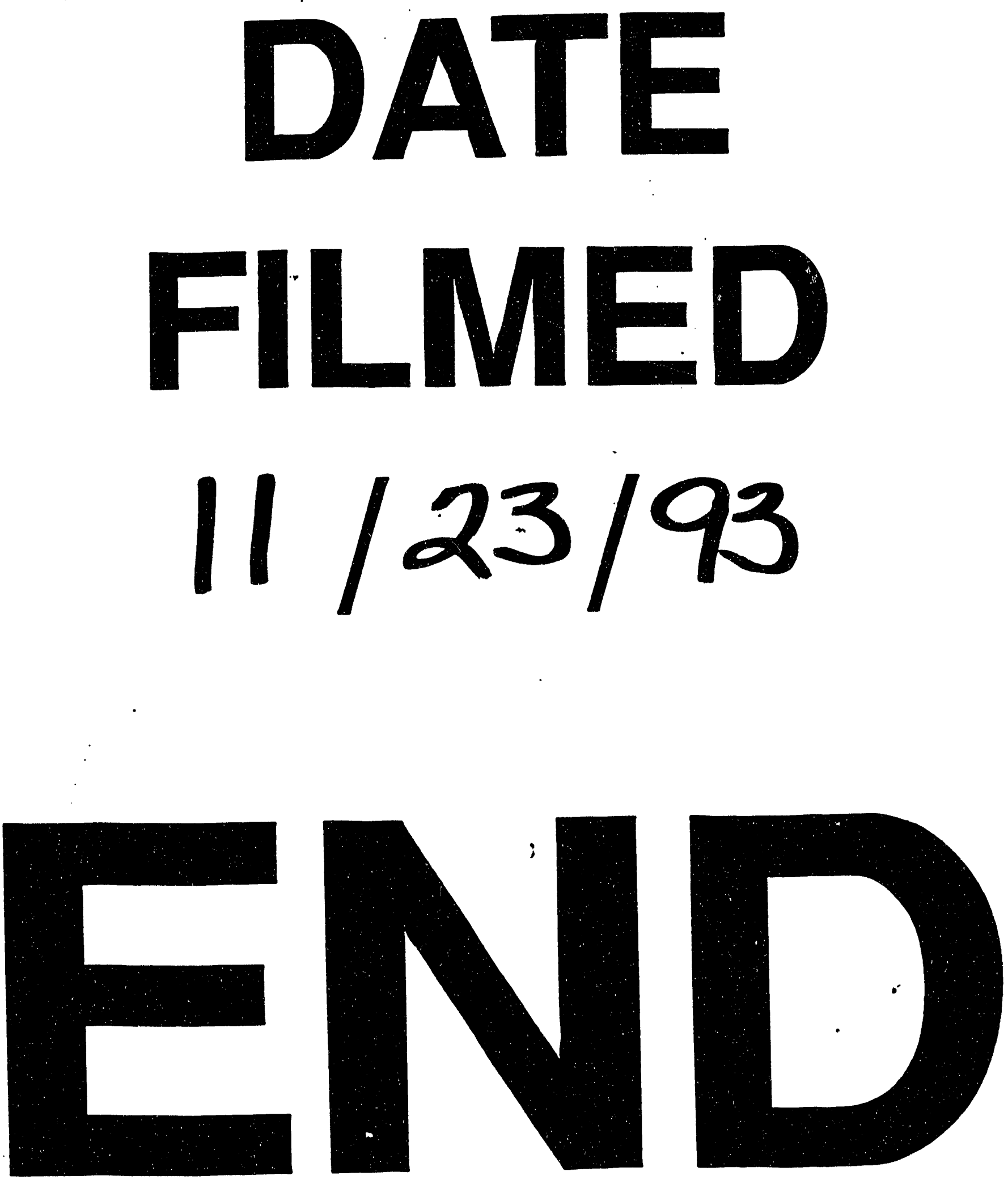
